Construção do livro de ofertas a partir de dados de alta frequência e um algoritmo de predição de valores baseado em técnicas de agrupamento e regressão linear

Rodrigo Bossini Tavares Moreira

DISSERTAÇÃO APRESENTADA $\mathrm{AO}$ INSTITUTO DE MATEMÁTICA E ESTATÍSTICA DA UNIVERSIDADE DE SÃO PAULO PARA OBTENÇÃO DO TÍTULO $\mathrm{DE}$ MESTRE EM CIENCIAS Universidade de São Paulo Instituto de Matemática e Estatística Departamento de Ciência da Computação

Programa: Ciência da Computação Orientador: Prof. Dr. Anatoli Iambartsev 
São Paulo, Junho de 2013 


\title{
Construção do livro de ofertas a partir de dados de alta frequência e um algoritmo de predição de valores baseado em técnicas de agrupamento e regressão linear
}

\author{
Esta dissertação contém as correções e alterações \\ sugeridas pela Comissão Julgadora durante a defesa \\ realizada por Rodrigo Bossini Tavares Moreira em 24/06/2013. \\ O original encontra-se disponível no Instituto de \\ Matemática e Estatística da Universidade de São Paulo.
}

Comissão Julgadora:

- Prof. Dr. Anatoli Iambartsev (orientador) - IME-USP

- Prof. Dr. Iouri Soukhov - University of Cambridge

- Prof. Dr. Vladimir Belitsky - IME-USP 


\section{Agradecimentos}

Quando ingressei na pós-graduação do IME, o fiz pelo gosto pelos estudos, embora desconhecesse do que se tratava exatamente realizar uma pós-graduação com foco acadêmico. Após algum susto inicial, me adaptei e aprendi as regras do jogo. Descobri que estava exatamente onde gostaria de estar. Isto foi uma conquista que não poderia alcançar sem a ajuda de algumas pessoas. Alguns professores do IME se mostraram especialmente dispostos a ajudar, provavelmente por já terem sentido na pele tais dificuldades. Agradeço ao Anatoli, meu orientador, pelo apoio incondicional que ofereceu durante todo o tempo em que trabalhamos juntos. Pelas reuniões produtivas, pelos conselhos, por ter-me dado liberdade de realizar meu trabalho, mostrando-me sempre que necessário um caminho que poderia resultar em bons frutos, mesmo que nem sempre (na verdade, na maioria das vezes) este fosse o mais fácil de se percorrer. Obrigado, Anatoli.

Agradeço ao Alair pelas boas aulas e forma dedicada de lidar com seus alunos. Também pelos assuntos polêmicos que fez questão de introduzir nas aulas e por compartilhar sua opinião a respeito destes, embora às vezes se mostre tão polêmica quanto. Agradeço ao Zé Augusto pela forma eficaz com que ministrou a disciplina de Autômatos. Fico muito feliz em poder dizer que minha visão sobre a computação mudou seriamente após ter cursado esta disciplina. Agradeço ao Paulo Feofiloff por compartilhar seu conhecimento de maneira irrestrita. Pela séria dedicação que teve ministrando a especial disciplina "grafinhos". Pelas suas anotações, com as quais aprendi muito.

Além dos professores do IME, existem também algumas pessoas especiais às quais gostaria de dedicar este trabalho. Uma delas, muito querida, teve participação especial neste trabalho. Um dos tópicos centrais do trabalho surgiu de uma daquelas boas conversas durante o café. $\mathrm{O}$ amadurecimento de outras ideias também aconteceu nos muitos agradabilíssimos momentos em que conversamos durante o trabalho, almoço etc. Pelo apoio durante a realização deste trabalho e principalmente pela amizade, te agradeço, Andreia Machion.

Agradeço também a Luciene Rinaldi por estar sempre presente e me lembrar da minha competência mesmo quando minhas sérias crises existenciais tentavam tomar espaço. 


\section{Resumo}

A negociação algorítmica[Joh10] oferece algoritmos que tomam decisões de compra e/ou venda com base em parâmetros pré-determinados, oscilações de preços no mercado, dados históricos etc. Uma vantagem oferecida por ela é a possibilidade de atuação rápida no mercado, possivelmente aproveitando as melhores ofertas disponíveis.

A Bovespa disponibiliza dados referentes à troca de mensagens entre as partes que constituem o mercado financeiro. A partir dessas mensagens, geralmente é possível fazer a construção do livro de ofertas, que contém informações referentes às ofertas de compra e venda disponíveis em dado instante e também sobre negociações que foram concretizadas. Esses dados são disponibilizados em diferentes formatos. Os dados de futuros utilizados neste trabalho, por exemplo, seguem o formato padrão do protocolo FIX, que define cada mensagem como uma coleção de pares de chave/valor. Um outro formato de dados próprio da Bovespa é utilizado para a disponibilização de dados de ações. Neste trabalho faz-se a construção do livro de ofertas a partir dos dados de futuros, com a proposta de uma estrutura de dados eficiente para a manipulação de mensagens no formato do protocolo FIX. Também discute-se sobre a possibilidade de construção do livro de ofertas a partir dos dados de ações. Finalmente, um algoritmo de predição de valores baseado em técnicas de mineração de dados como agrupamento é proposto e analisado quanto à sua aplicabilidade.

Palavras-chave: livro de ofertas, protocolo FIX, mercado de alta frequência, predição de valores, agrupamento 


\title{
Abstract
}

\begin{abstract}
Algorithmic trading[Joh10] offers algorithms that make buy/sell decisions based on predetermined parameters, market price fluctuations, historical data and so on. One advantage it offers is the possibility of quickly operating on the market, possibly taking advantage of the best buy/sell offers currently available. Bovespa provides data regarding message exchange between the constituent parts of the financial market. From these messages, it is usually possible to extract the offerbook, which contains information regarding buy/sell offers available at a given moment in time. This data is provided in different formats. The future data used in this work, for example, is according to the Fix protocol format, which defines each message as a collection of key/value pairs. Another data format proprietary from Bovespa is used to provide stock data. In this work the construction of the offerbook is made from the future data and the proposal of an eficient data structure for dealing with messages in Fix format is made. It is also discussed the possibility of constructing the offerbook from the stock data. Finally, a predicting values algorithm based on data mining techniques such as clustering is proposed and its applicability is analysed.
\end{abstract}

Keywords: offerbook, Fix protocol, high-frequency market, values prediction, clustering 


\section{Sumário}

1 Introdução $\quad 1$

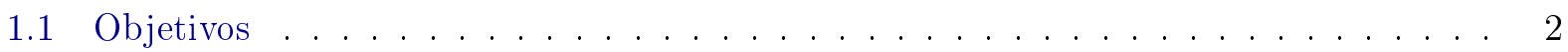

1.2 Organização do Trabalho . . . . . . . . . . . . . . . . . . . 2

2 Base teórica para a resolução do problema $\quad 3$

2.1 Agrupamento (clustering) e o algoritmo K-means . . . . . . . . . . . . . . . 3

2.2 Correlação e Regressão Linear . . . . . . . . . . . . . . . . . . . . . . . . . . . 4

3 Descrição dos Dados $\quad 6$

3.1 Troca de mensagens e o livro de ofertas . . . . . . . . . . . . . . 6

3.2 Dados de Futuros . . . . . . . . . . . . . . . . . . . . . . . . . . 8

3.3 Dados de Ações . . . . . . . . . . . . . . . . . . . . . . . . . . . 8

4 Tratamento de dados $\quad 11$

4.1 Tratamento de dados de futuros . . . . . . . . . . . . . . . . . . . 11

4.2 Tratamento de dados de ações . . . . . . . . . . . . . . . . . . . . . . . . 14

5 Um algoritmo para predição de valores baseado em agrupamento e regressão $\begin{array}{ll}\text { linear } & 17\end{array}$

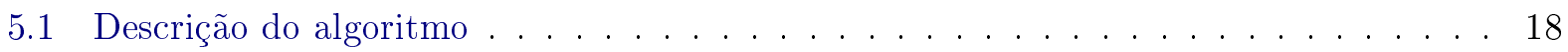

5.2 Considerações sobre o algoritmo . . . . . . . . . . . . . . . . . . . 22

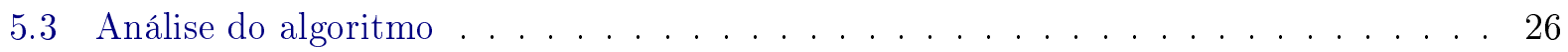

6 Análise dos resultados e trabalhos futuros $\quad 30$

6.1 Sobre a construção do livro de ofertas . . . . . . . . . . . . . . 30

6.2 Sobre o algoritmo de predição de valores . . . . . . . . . . . . . . . 31

6.2.1 Uma proposta de alteração para o algoritmo de predição . . . . . . . . . . . . 32

6.3 Trabalhos futuros . . . . . . . . . . . . . . . . . . . 33

$\begin{array}{ll}\text { A Gráficos } & 35\end{array}$

B Tecnologia empregada $\quad 85$

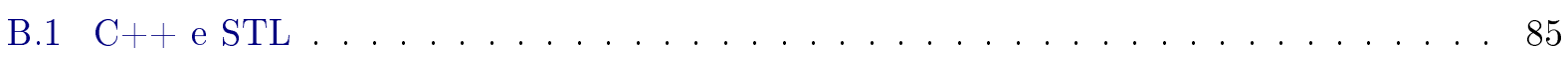

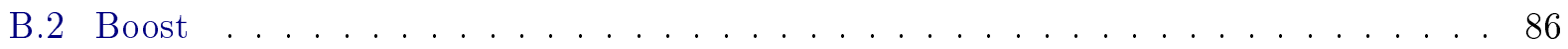

B.2.1 Processamento paralelo - fila bloqueante . . . . . . . . . . . 86 
Referências Bibliográficas 


\section{Capítulo 1}

\section{Introdução}

Suponha que em um dado instante um usuário deseja comprar 1000 unidades de um dado ativo. Dependendo das condições atuais do mercado, talvez seja interessante efetuar a compra imediatamente. Ou pode ser que seja interessante aguardar alguns minutos até que exista uma oferta de venda mais interessante. Dada a natureza incerta do mercado financeiro, nunca se pode dizer ao certo quando (ou se) uma oferta de compra ou venda terá melhores preços. Assim, talvez seja interessante realizar a compra das 1000 unidades em partes. Uma possibilidade seria adotar a estratégia de a cada meia hora comprar 100 unidades até que as 1000 unidades tenham sido compradas. Dessa forma poder-se-ia evitar a possibilidade de realizar a compra em um momento em que o preço de venda estivesse muito alto. Por outro lado, cada intervenção no mercado financeiro é taxada pela corretora, que necessariamente intermedeia o acesso ao mercado, e assim, deve-se levar em conta as taxas aplicadas pelas corretoras e eventuais impostos. Ao informar uma oferta de compra, o comprador pode também informar que a compra somente deve ser realizada se o preço de venda não for maior do que certo valor. Esses são alguns exemplos de parâmetros que geralmente são levados em conta ao negociar ativos em geral no mercado financeiro. Obviamente, quando há ofertas de venda interessantes, compradores desejam que suas ofertas de compra sejam processadas rapidamente. $\mathrm{O}$ mesmo vale para vendedores quando no mercado há ofertas de compra interessantes. A negociação algorítmica [Joh10] oferece algoritmos que tomam decisões de compra e/ou venda com base em parâmetros pré-determinados, oscilações de preços no mercado, dados históricos etc. Uma vantagem oferecida por ela é a possibilidade de atuação rápida no mercado, possivelmente aproveitando as melhores ofertas disponíveis. Segundo [Joh10], um importante aspecto da negociação eletrônica tem sido a maior disponibilidade do livro de ofertas, conforme os mercados passaram a adotar a negociação eletrônica. Muitos dos algoritmos que [Joh10] classifica como sendo da primeira geração utilizam como parâmetros para a tomada de decisão somente os preços de ofertas de compra e venda. Conforme dados referentes as negociações realizadas se tornam mais acessíveis, mais algoritmos são desenvolvidos de modo a tomar decisões mais aprimoradas de acordo com esses dados. A Bovespa ${ }^{1}$ disponibiliza dados referentes à troca de mensagens entre as partes que constituem o mercado financeiro. A partir dessas mensagens, geralmente é possível fazer a extração do livro de ofertas, que contém informações referentes às ofertas de compra e venda disponíveis em dado instante e também sobre negociações que foram concretizadas. Esses dados são disponibilizados em diferentes formatos. Os dados de futuros utilizados neste trabalho, por exemplo, seguem o formato padrão do protocolo FIX $^{2}$, que define cada mensagem como uma coleção de pares de chave/valor. Um outro formato de dados próprio da Bovespa é utilizado para a disponibilização de dados de ações. Neste trabalho faz-se a construção do livro de ofertas a partir dos dados de futuros, com a proposta de uma estrutura de dados eficiente para a manipulação de mensagens no formato do protocolo FIX. Também discute-se sobre a possibilidade de construção do livro de ofertas a partir dos dados de ações. Finalmente, um algoritmo de predição de valores baseado em técnicas de mineração de dados como agrupamento é proposto e analisado quanto à sua aplicabilidade.

\footnotetext{
${ }^{1}$ http://www.bovespa.com.br

${ }^{2}$ http://www.fixprotocol.org/
} 


\subsection{Objetivos}

Os objetivos deste trabalho são:

- Desenvolver um algoritmo para construção do livro de ofertas a partir de dados de alta frequência de futuros que estão em conformidade com o protocolo FIX

- Verificar a possibilidade de construção do livro de ofertas a partir de dados de alta frequência de ações que estão de acordo com um formato próprio da Bovespa

- Propor um algoritmo para predição de valores e verificar sua aplicabilidade

\subsection{Organização do Trabalho}

O Capítulo 2 faz uma sucinta introdução sobre os principais aspectos utilizados durante a realização deste trabalho. O Capítulo 3 descreve o formato dos dados de ações e futuros disponibilizados pela Bovespa. A construção do livro de ofertas a partir dos dados de futuros é detalhada no Capítulo 4, no qual são propostas estruturas de dados eficientes para a manipulação de mensagens de acordo com o protocolo FIX, bem como apresentados os principais campos utilizados para essa construção. O Capítulo 4 também fornece um trabalho inicial para a construção do livro de ofertas a partir de dados de ações. Embora esta construção ainda não tenha sido concluída, acredita-se que os detalhes oferecidos fornecem um caminho que pode ser seguido para que se conclua a construção do livro de ofertas a partir destes dados. O Capítulo 5 exibe o algoritmo proposto para predição de valores, bem como considerações sobre este e uma análise sobre sua aplicabilidade. O Capítulo 6 inclui discussões sobre os resultados obtidos e uma proposta de alteração ao algoritmo de predição de valores que pode resultar em melhores predições. Também são inclusas sugestões para possíveis trabalhos futuros. 


\section{Capítulo 2}

\section{Base teórica para a resolução do problema}

Os trabalhos desenvolvidos fazem uso de diversas técnicas de áreas como mineração de dados e estatística. Estas possuem alguns tópicos em intersecção, como a regressão linear discutida na seção 2.2. Neste Capítulo apresentam-se sucintamente os tópicos necessários ao pleno entendimento do trabalho realizado. A seção 2.1 apresenta o problema de agrupamento ou clustering e um algoritmo para este conhecido como k-means. Aspectos essenciais sobre o funcionamento do algoritmo kmeans são discutidos. A Seção 2.2 também mostra uma medida de correlação linear entre variáveis. Uma vez identificada uma correlação linear entre variáveis, a seção mostra como o método de regressão linear pode ser utilizado para capturá-la. O Capítulo obviamente não pretende oferecer uma completa cobertura sobre os tópicos. Trata-se apenas de uma introdução sucinta e focada na forma como os métodos foram aplicados neste trabalho. Para um tratamento mais aprofundado sugere-se a consulta das obras presentes na bibliografia deste trabalho.

\subsection{Agrupamento (clustering) e o algoritmo K-means}

A técnica de agrupamento (clustering) consiste em dividir-se os dados em estudo em grupos que contém itens considerados semelhantes entre si, de acordo com um critério de comparação estabelecido previamente. Pode-se utilizar como critério, por exemplo, a distância Euclidiana. Trata-se de uma técnica muito conhecida e utilizada, geralmente descrita em obras sobre mineração de dados, como em [WFH11].

Formalmente, tem-se um conjunto de $n$ pontos $p_{1}, p_{2}, \ldots, p_{n}$ com $p_{i} \in \mathbb{R}^{d}$ para $i \in\{1,2, \ldots, n\}$ e um número inteiro $k$ que representa o número de grupos desejado. Escolhe-se $k$ centros arbitrários e associa-se cada ponto ao centro que estiver mais próximo. Assim, deseja-se minimizar a soma das distâncias entre cada ponto e o centro ao qual cada um foi associado.

Como descrito em [AV07], encontrar uma solução exata para este problema é NP-difícil. Apesar disso, um algoritmo conhecido como k-means propõe uma técnica que, embora não garanta a solução exata, encontra um ótimo local, o que em muitas situações pode ser suficiente, especialmente por se tratar de um método simples e rápido.

O algoritmo k-means consiste nos seguintes passos:

- escolha k pontos arbitrários como centros iniciais

- associe cada ponto restante ao centro mais próximo

- recalcule os centros iniciais como o ponto médio entre aqueles associados a cada centro 
- termine quando os centros se mantiverem os mesmos

Embora os resultados obtidos pelo algoritmo k-means possam ser razoáveis em geral, há diversos exemplos que mostram que a técnica empregada pode dar origem a resultados muito ruins. Em particular, se $\phi$ é a soma das distâncias obtidas pelo k-means e $\phi_{O P T}$ é a soma das distâncias melhor possível, é possível que $\frac{\phi}{\phi_{O P T}}$ cresça arbitrariamente, mesmo com $n$ e $k$ fixos [AV07].

[AV07] sugere uma escolha inteligente dos pontos iniciais. A ideia proposta consiste em escolherse o primeiro ponto arbitrariamente e então fazer a escolha dos $k-1$ pontos restantes dando maior probabilidade de escolha aos pontos que estiverem mais distantes daqueles que já foram escolhidos. Embora essa técnica, no pior caso, não seja melhor que aquela empregada pelo k-means, [AV07] demonstra que no caso médio, o algoritmo que emprega esta técnica proposta, batizado de $k$-means ++ é $O(l g k)$-competitivo. Em outras palavras, no caso médio, o resultado obtido pelo k-means ++ somente pode ser pior do que o resultado ótimo por um fator da ordem de $O(l g k)$.

Enquanto [AV07] preocupa-se com a qualidade dos resultados obtidos, [AV09], demonstra um limite superior para o número de iterações realizadas pelo algoritmo k-means. No caso médio, [AV09] demonstra que o algoritmo k-means tem complexidade de $O\left(n^{k}\right)$. Ou seja, o limite superior demonstrado independe do número de dimensões tratado e cresce exponencialmente em função do número de grupos desejado.

\subsection{Correlação e Regressão Linear}

Regressão linear é um tópico importante que aparece descrito em obras reconhecidas de estatística [MdL07] e mineração de dados [WFH11]. Trata-se de um método com o qual é possível estabelecer uma relação entre duas ou mais variáveis. Quando aplicado a dados brutos como feito neste trabalho, a relação encontrada pode ser útil para calcular-se os valores de uma dada variável $v$, caso se saibam os valores das demais variáveis, com as quais $v$ mantém uma relação, que, como o nome do método sugere, deve ser linear. Não se espera que os valores calculados sejam exatos, mas que sejam próximos dos reais, caso a relação de fato exista. Assim, antes de aplicar-se o método de regressão linear, pode ser interessante verificar se de fato uma relação linear existe. Para tal, pode-se utilizar o coeficiente de correlação linear entre variáveis.

Se $X$ e $Y$ são duas variáveis com n valores cada, representados por $\left(x_{i}, y_{i}\right)$ para $i=1,2, \ldots n$, o coeficiente de correlação linear entre $X$ e $Y$ é dado em 2.1 .

$$
\rho_{X, Y}=\frac{\sum_{i=1}^{n}\left(x_{i}-\operatorname{avg}(X)\right)\left(y_{i}-\operatorname{avg}(Y)\right)}{\sqrt{\left(\sum_{j=1}^{n}\left(x_{j}-\operatorname{avg}(X)\right)^{2}\right)\left(\sum_{j=1}^{n}\left(y_{j}-\operatorname{avg}(Y)\right)^{2}\right)}}
$$

Em 2.1, $\operatorname{avg}(\mathrm{Z})$ denota a média artimética da variável $Z$. Verifica-se que $-1 \leq \rho_{X, Y} \leq 1$. Se $\rho_{X, Y}=0$ então não há correlação linear entre $X$ e $Y$, embora possa existir algum outro tipo de correlação que não linear.

Uma vez identificada a correlação linear entre duas variáveis, pode-se desejar estabelecê-la por meio de uma equação. O método de regressão linear permite que se calcule uma equação que descreve como o comportamento de uma variável pode ser "explicado" em função de uma mais variáveis. Em nosso trabalho, o método de regressão linear foi utilizado para obter-se uma equação utilizando-se dados conhecidos. Uma vez obtida a equação, esta foi utilizada para a tentativa de predição de 
valores, realizada pelo algoritmo 5.4.

Se $x$ é a variável cujos valores desejam-se definir em função de outras variáveis e $a_{1}, a_{2}, \ldots, a_{k}$ são as demais variáveis, deseja-se obter uma expressão como 2.2 .

$$
x=w_{0}+w_{1} a_{1}+w_{2} a_{2}+\ldots+w_{k} a_{k}
$$

Em 2.2 os valores $w_{0}, w_{1}, \ldots, w_{k}$ são calculados pelo método de regressão linear. Estes são calculados de modo a minimizar-se a diferença entre o valor obtido pela regressão e os valores reais, para cada item dos dados conhecidos, como em 2.3.

$$
\sum_{i=1}^{n}\left(x^{(i)}-\sum_{j=0}^{k} w_{j} a_{j}{ }^{(i)}\right)^{2}
$$

Em 2.3, $z^{(i)}$ denota o valor real da variável z para o $i$-ésimo item dos dados utilizados. Assim, deseja-se minimizar a soma das diferença entre valor real e valor calculado pela equação obtida. 


\section{Capítulo 3}

\section{Descrição dos Dados}

Os dados de alta frequência utilizados neste trabalho estão de acordo com diferentes formatos. Enquanto os dados de futuros seguem o padrão proposto pelo protocolo FIX, os dados de ações estão de acordo com um formato proprietário da Bovespa. Os dados representam mensagens trocadas entre as partes do mercado financeiro interessadas em negociar ativos e seu formato têm influência nos algoritmos utilizados para a construção do livro de ofertas a partir destes. Inicialmente, descrevemse conceitos a respeito da troca de mensagens e sobre o livro de ofertas. A seguir, os formatos de dados utilizados no trabalho são também descritos.

\subsection{Troca de mensagens e o livro de ofertas}

O livro de ofertas trata-se de um resumo dos fatos importantes acontecidos no mercado. Nele são registradas ofertas de compra e venda ocorridas e negócios concluídos. As ofertas são ordenadas de acordo com sua competitividade. A competitividade de uma oferta é baseada exclusivamente em seu preço. Quanto mais alto for o preço de uma oferta de compra, mais competitiva será essa oferta. É claro que quanto maior for a oferta de compra, maior será a probabilidade de fechamento de negócio, aumentando a liquidez do mercado. Similarmente, quanto menor for o preço de uma oferta de venda, mais competitiva ela será. Obviamente, uma oferta de venda com preço baixo também aumenta a probabilidade de concretização de negócio.

No livro de ofertas, as ofertas são separadas entre ofertas de compra e venda, e mostradas em ordem, de acordo com sua competitividade. Em geral, para um dado instante e para um dado instrumento financeiro, as ofertas de compra mais competitivas têm sempre seu preço menor do que as ofertas de venda mais competitivas. Isso ocorre pelo simples fato de que quando a oferta de compra é maior ou igual à oferta de venda, então um negócio é concretizado.

A Figura 3.1 mostra um livro de ofertas simplificado. A primeira linha mostra as ofertas disponíveis para um dado papel em um dado instante.

\begin{tabular}{|c|c|c|c|}
\hline \multicolumn{2}{|c|}{ Compra } & \multicolumn{2}{c|}{ Venda } \\
\hline 80 & 70 & 105 & 110 \\
\hline 100 & 80 & 105 & 110 \\
\hline 100 & 80 & 102 & 105 \\
\hline
\end{tabular}

Figura 3.1: Um livro de ofertas simplificado. Cada linha mostra os preços das duas ofertas de compra e das duas ofertas de venda mais competitivas em um dado instante. Na segunda linha, uma oferta de compra mais competitiva foi realizada, e o livro de ofertas foi atualizado. Na terceira linha, uma oferta de venda mais competitiva foi realizada, causando uma nova alteração no livro de ofertas.

A Figura 3.1 mostra somente os preços das ofertas de compra e venda. Em um livro de ofertas típico, pode ser interessante também incluir a quantidade de cada oferta, embora a quantidade não tenha influência sobre a competitividade de uma dada oferta. 
Na negociação eletrônica, as partes que compõem o mercado trocam mensagens a fim de realizar negócios. Como discutido nas Seções 3.2 e 3.3, uma dada mensagem pode incluir diversas informações. Preço e quantidade de uma dada oferta são exemplos de informações inclusas em uma dada mensagem. Dependendo do formato em que a mensagem é enviada, ela pode conter informações referentes a mais de uma oferta. Como se menciona, neste trabalho foram utilizados dois formatos de dados distintos. O formato proposto pelo protocolo FIX, utilizado pelos dados de futuros, permite que uma mensagem contenha mais de uma oferta, conforme seção 3.2, ao passo que o formato proprietário descrito pela seção 3.3 e utilizado pelos dados de ações não permite.

O livro de ofertas utilizado neste trabalho é composto por itens chamados de "ticks". Um tick é composto pelas ofertas de compra e venda mais interessantes e também pela data e hora em que essas ofertas eram as mais interessantes. Neste trabalho, também consideraram-se o valor e volume de um negócio concretizado com itens que compõem um tick, quando em um dado instante um negócio tiver sido de fato concretizado. Assim, o livro de ofertas neste trabalho é composto por ticks, os quais são compostos pelas seguintes variáveis. Cada variável tem um nome que será utilizado em partes subsequentes deste trabalho.

- date A data em que ocorreu aquele tick

- time O horário em que ocorreu aquele tick. Neste trabalho o tempo é medido com precisão de milissegundos.

- os5 O volume da quinta oferta de venda mais interessante

- os4 O volume da quarta oferta de venda mais interessante

- os3 O volume da terceira oferta de venda mais interessante

- os2 O volume da segunda oferta de venda mais interessante

- os1 O volume da primeira oferta de venda mais interessante

- op5 O preço da quinta oferta de venda mais interessante

- op4 O preço da quarta oferta de venda mais interessante

- op3 O preço da terceira oferta de venda mais interessante

- op2 O preço da segunda oferta de venda mais interessante

- op1 O preço da primeira oferta de venda mais interessante

- bs5 O volume da quinta oferta de compra mais interessante

- bs4 O volume da quarta oferta de compra mais interessante

- bs3 O volume da terceira oferta de compra mais interessante

- bs2 O volume da segunda oferta de compra mais interessante

- bs1 O volume da primeira oferta de compra mais interessante

- bp5 O preço da quinta oferta de compra mais interessante

- bp4 O preço da quarta oferta de compra mais interessante

- bp3 O preço da terceira oferta de compra mais interessante

- bp2 O preço da segunda oferta de compra mais interessante 
- bp1 O preço da primeira oferta de compra mais interessante

- tp O preço de um negócio concretizado

- ts $\mathrm{O}$ volume de um negócio concretizado

Nos itens mencionados, as siglas "op", "os", "bp" e "bs" vêm do inglês e significam respectivamente "offer price", "offer size", "bid price" e "bid size". No inglês, a palavra offer é utilizada como sinônimo de oferta de venda e a palavra bid é utilizada como sinônimo de oferta de compra. As siglas "tp" e "ts" também vêm do inglês e significam "trade price" e "trade size". Essas variáveis são usadas quando um negócio ocorre, representando o valor e volume negociados respectivamente.

\subsection{Dados de Futuros}

Os dados de futuros estão de acordo com o padrão do protocolo FIX. O protocolo FIX define cada mensagem como uma coleção de pares chave/valor. Uma chave é um número inteiro com um significado específico. Um par chave/valor tem a forma chave=valor. Os pares de uma dada mensagem são separados pelo símbolo cujo nome ASCII é "SOH" - um acrônimo para start of heading. Em uma dada mensagem, algumas chaves são obrigatórias e outras não. Por exemplo, a chave que define a versão do protocolo utilizada é obrigatória. Obviamente, uma mensagem não contém chaves cujo significado está relacionado com negócios concretizados se seu intuito for somente indicar a inserção de uma nova oferta de compra, por exemplo. Uma mensagem FIX típica com $n$ pares chave/valor tem o seguinte formato, sendo cada $k_{i}$ uma chave válida definida pela protocolo FIX e $v_{i}$ seu respectivo valor, para $i=1,2, \ldots, n$ :

$$
k_{1}=v_{1} S O H k_{2}=v_{2} S O H \ldots S O H k_{n}=v_{n} S O H
$$

Uma mesma chave pode aparecer mais de uma vez em uma dada mensagem. Essa possibilidade existe por conta do conceito de grupos de repetição do protocolo FIX. Um grupo de repetição é uma sequência de $p$ pares chave/valor repetida $n$ vezes. Seu formato é o seguinte:

$$
\begin{gathered}
k_{1}=v_{1}^{1} S O H k_{2}=v_{2}^{1} S O H \ldots S O H k_{p}=v_{p}^{1} S O H k_{1}=v_{1}^{2} S O H k_{2}=v_{2}^{2} S O H \ldots S O H k_{p}^{2}= \\
v_{p}^{2} S O H \ldots S O H k_{1}=v_{1}^{n} S O H k_{2}=v_{2}^{n} S O H \ldots S O H k_{p}^{n}=v_{p}^{n} S O H
\end{gathered}
$$

Dentro de um grupo de repetição, cada sequência de $p$ pares refere-se a uma mesma ordem enviada. Uma sequência pode se referir à inserção de uma nova oferta de compra. Uma outra sequência pode se referir à uma negociação concretizada. Assim, utilizando o conceito de grupos de repetição, uma única mensagem pode permiter que ofertas de compra/venda sejam inseridas ou atualizadas, negócios concretizados sejam informados etc. Dentro de um grupo de repetição, cada chave tem múltiplos valores e a ordem dos valores importa. Para cada $k_{i}(i=1,2, \ldots, n)$, cada $v_{i}^{j}$ $(j=1,2, \ldots, n)$ se refere à uma mesma ordem enviada.

Os dados de futuros são oferecidos pela Bovespa em um único arquivo. Mensagens referentes a ofertas de compra, ofertas de venda e negócios concretizados pertencem a um único arquivo, eventualmente até a uma mesma linha, utilizando o conceito de grupos de repetição do protocolo FIX. Como descrito na Seção 3.3, o mesmo não ocorre com os dados de ações.

\subsection{Dados de Ações}

Diferentemente dos dados de futuros, os dados de ações não estão de acordo com o formato do protocolo FIX. Cada mensagem é constituída por uma sequência de campos separados por ponto e 
vírgula. O significado de cada campo é implícito, de acordo com sua posição na mensagem. Assim, não é necessário o uso de pares de chaves/valor, como ocorre com mensagens que seguem o padrão do protocolo FIX. Mensagens de ofertas de compra e venda têm a mesma quantidade de campos, e cada campo tem o mesmo significado, independentemente de pertencer a uma mensagem de compra ou venda. Mensagens que representam negócios concretizados têm uma quantidade diferente de campos com significados eventualmente diferentes. Diferentemente dos dados de futuros, cada mensagem contém apenas uma oferta de compra ou venda.

Descrevemos ambos os tipos de mensagens a seguir.Uma mensagem de oferta de compra ou venda é constituída de 12 campos.

- Data Sessão - ocupa 10 caracteres na mensagem. Indica a data da sessão em que a mensagem foi enviada.

- Papel - ocupa 12 caracteres na mensagem. Indica o código do instrumento financeiro a que a mensagem se refere.

- Sequência - ocupa 10 caracteres na mensagem. É um número sequencial que identifica a transação a que a mensagem se refere.

- Preço Of.Compra/Venda - ocupa 19 caracteres na mensagem. Indica o preço da oferta.

- Qtd.Total Of.Compra/Venda - ocupa 18 caracteres na mensagem. Indica a quantidade da oferta.

- Qtd.Negociada Of.Compra/Venda - ocupa 18 caracteres na mensagem. Caso parte da oferta seja negociada, indica a quantidade negociada.

- Hora Prioridade - ocupa 15 caracteres na mensagem. Indica a hora em que a oferta foi inserida no sistema com precisão de microssegundo.

- Data de Entrada Of.Compra/Venda - ocupa 19 caracteres na mensagem. Indica data/hora em que a oferta foi inserida no sistema, sem a mesma precisão do campo "Hora Prioridade".

- Estado Of.Compra/Venda - ocupa 1 caracter na mensagem. Indica o tipo de transação desejado, como inserir uma nova oferta, alterar, cancelar, congelar etc.

- Data Modif. Of.Compra/Venda - ocupa 10 caracteres na mensagem. Caso uma oferta seja modificada, indica a data em que a modificação ocorreu.

- Nr.Of.Compra/Venda Modif. - ocupa 10 caracteres na mensagem. Indica o número da oferta a que a modificação se refere.

- Hora Fim Tratam. Of.Compra/Venda - ocupa 19 caracteres na mensagem. Indica a hora em que ocorreu o fim do tratamento de uma dada oferta.

Para a extração do livro de ofertas, nem todos os campos descritos acima são utilizados. Na seção 4.2 discute-se sobre quais campos são utilizados e são fornecidos detalhes sobre sua importância para a extração do livro de ofertas.

O formato de uma mensagem que representa uma negociação concretizada é descrito a seguir. Uma mensagem de concretização de negócio é constituída por 11 campos.

- Data Sessão - ocupa 10 caracteres na mensagem. Indica a data da sessão em que a mensagem foi enviada.

- Papel - ocupa 12 caracteres na mensagem. Indica o código do instrumento financeiro a que a mensagem se refere. 
- Nr.Negócio - ocupa 7 caracteres na mensagem. É um número sequencial que identifica a transação a que a mensagem se refere.

- Preço Negócio - ocupa 19 caracteres na mensagem. Indica o valor do negócio concretizado.

- Quantidade - ocupa 18 caracteres na mensagem. Identifica a quantidade negociada.

- Hora - ocupa 15 caracteres na mensagem. Indica a hora em que a negociação ocorreu, com precisão de microssegundo.

- Ind.Anulação - ocupa 1 caracter na mensagem. Indica o tipo da mensagem. É aqui que se define se a negociação está sendo concretizada ou anulada.

- Data Oferta Compra - ocupa 10 caracteres na mensagem. Para ser concretizada, uma negociação precisa ter uma oferta de compra. Esse campo indica a data da oferta de compra a que essa negociação se refere.

- Seq.Oferta Compra - ocupa 10 caracteres na mensagem. Para ser concretizada, uma negociação precisa ter uma oferta de compra. Esse campo indica o número da oferta de compra a que essa negociação se refere.

- Data Oferta Venda - ocupa 10 caracteres na mensagem. Para ser concretizada, uma negociação precisa ter uma oferta de venda. Esse campo indica a data da oferta de venda a que essa negociação se refere.

- Seq.Oferta Venda - ocupa 10 caracteres na mensagem. Para ser concretizada, uma negociação precisa ter uma oferta de venda. Esse campo indica o número da oferta de venda a que essa negociação se refere.

Assim como acontece com as mensagens de oferta de compra e venda, nem todos os campos de uma mensagem de negociação concretizada são utilizados para compor o livro de ofertas. Vide seção 4.2 para detalhes.

A Bovespa disponibiliza os dados de ações em arquivos separados por tipo de transação. São três os arquivos: um arquivo contendo mensagens referentes a ofertas de compra; um arquivo contendo mensagens referentes a ofertas de venda; e finalmente um arquivo contendo mensagens referentes a negócios concretizados. 


\section{Capítulo 4}

\section{Tratamento de dados}

Neste Capítulo são detalhados os trabalhos referentes à construção do livro de ofertas a partir de dados de futuros e de ações. Uma estrutura de dados para manipulação de mensagens de acordo com o protocolo FIX é proposta e é feita uma discussão sobre a possibilidade de construção do livro de ofertas a partir de dados de ações, que estão de acordo com um formato proprietário da Bovespa. Diversos detalhes são mencionados considerando-se a implementação de estruturas de dados, as quais são descritas no apêncice B.

\subsection{Tratamento de dados de futuros}

Para a extração do livro de ofertas, utiliza-se apenas um subconjunto de chaves existentes em cada mensagem. Como descrito na Seção 3.2, uma chave é simplesmente um número inteiro. O protocolo FIX define também um nome para cada chave. O nome de cada chave é apenas uma descrição e não aparece no arquivo de mensagens (também não aparece no livro de ofertas). A seguir descrevem-se as chaves utilizadas para a extração do livro de ofertas, bem como o nome que o protocolo FIX define para cada uma:

- chave:55 nome:Symbol descrição:Nome do instrumento financeiro a que a mensagem se refere.

- chave:52 nome:SendingTime descrição: Data/hora de envio no padrão UTC.

- chave:279 nome:MDUpdateAction descrição:Tipo de ação realizada. Valores podem indicar a inserção de uma nova oferta, que uma oferta foi removida ou que uma oferta foi atualizada.

- chave:269 nome:MDEntryType descrição:Serve para indicar se a mensagem se trata de uma oferta de compra/venda ou negociação concretizada, entre outros.

- chave:270 nome:MDEntryPx descrição: Indica o preço da oferta/negociação.

- chave:271 nome:MDEntrySize descrição: Indica a quantidade da oferta/negociação.

- chave:290 chave:MDEntryPositionNo descrição:Indica a posição de uma oferta de compra ou venda, de acordo com sua competitividade.

Os valores cujas chaves são MDEntryPx e MDEntrySize são importantes para a composição do livro de ofertas pois, como discutido na Seção 3.1, cada linha do livro de ofertas é composta principalmente pelos preços e quantidades das ofertas mais interessantes. O valor cuja chave é Symbol permite selecionar as mensagens de um dado instrumento financeiro, ignorando as demais. $\mathrm{O}$ valor cuja chave é MDUpdateAction permite identificar a que tipo de transação se refere uma dada mensagem. Assim, as informações podem ser adicionadas às colunas corretas do livro de ofertas. Como deseja-se que cada linha do livro de ofertas possua uma data, o valor cuja chave é SendingTime também é necessário. Finalmente, o valor cuja chave é MDEntryPositionNo é fundamental pois ele 
indica a competitividade de uma dada oferta. Na Seção 3.1 menciona-se que o livro de ofertas de interesse para esse trabalho contém as 5 ofertas mais interessantes de compra e venda, bem como seus volumes associados. O valor da chave MDEntryPositionNo permite identificar o quão competitiva é uma oferta de compra/venda.

Uma mensagem pode ser arbritrariamente grande, já que o conceito de grupos de repetição permite que chaves se repitam em uma mesma mensagem. Para fazer o tratamento de cada mensagem, extraindo as partes relevantes para o livro de ofertas, pode ser interessante construir uma estrutura de dados que permita que as partes relevantes sejam extraídas e posteriormente acessadas de forma eficiente. A forma como as mensagens são definidas (sequências de pares chave/valor) sugere a ideia inicial de se utilizar um std::map <int,std::string> (Seção B.1). Um std::map permite que operações de inserção e de recuperação de valores sejam executadas com complexidade $O(l g n)$, sendo $n$ o número de elementos existentes. A complexidade $O(\lg n)$ se dá pelo fato de um std::map armazenar seus elementos ordenados pela chave. Apesar de parecer interessante a princípio, um std::map não é apropriado, pois ele não permite chaves duplicadas e, portanto, não captura o conceito de grupos de repetição do protocolo FIX. Uma chave estaria limitada a ter um único valor associado a ela. Esse problema poderia ser resolvido utilizando-se um std::multimap <int,std::string> (Seção B.1), um container associativo similar a std::map que permite que chaves duplicadas sejam armazenadas e que tem complexidade de $O(\lg n)$ para operações de inserção, remoção, atualização e recuperação. Embora um std::multimap permita chaves duplicadas, a ordem em que os valores associados a uma chave são recuperados não é garantida. Assim, um std::multimap pode não ser suficiente para representar um grupo de repetição do protocolo FIX.

Neste trabalho, propõe-se a utilização de um std::map <int,std::vector < std::string > > Dessa forma, uma chave pode ter associado a ela um único valor. Porém esse valor é um std::vector, que por sua vez pode armazenar múltiplos valores. Pode-se acessar cada elemento de um std::vector em tempo constante. Considere o seguinte grupo de repetição dentro de uma mensagem:

$$
\begin{gathered}
k_{1}=v_{1}^{1} S O H k_{2}=v_{2}^{1} S O H \ldots S O H k_{p}=v_{p}^{1} S O H k_{1}=v_{1}^{2} S O H k_{2}=v_{2}^{2} S O H \ldots S O H k_{p}^{2}= \\
v_{p}^{2} S O H \ldots S O H k_{1}=v_{1}^{n} S O H k_{2}=v_{2}^{n} S O H \ldots S O H k_{p}^{n}=v_{p}^{n} S O H
\end{gathered}
$$

A Figura 4.1 mostra a estrutura de dados resultante para esse grupo de repetição, utilizando um std::map <int,std::vector < std::string $>>$.

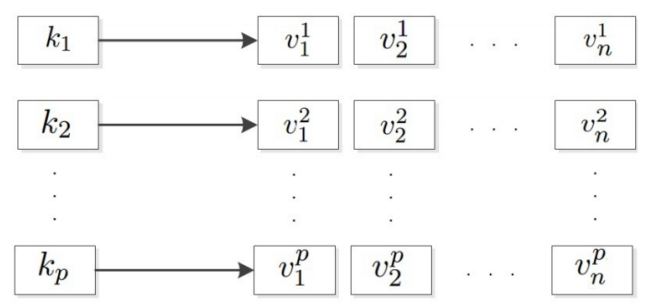

Figura 4.1: Um std::map $<$ int, std::vector $<$ std::string $>>$. A primeira coluna da esquerda para a direita representa as chaves do mapa. Cada chave tem um std::vector associado. As setas representam essa associação. Uma chave pode ser recuperada em tempo $O(\lg n)$. Um elemento $v_{i}^{j}$ pode ser acessado em tempo constante.

No trabalho desenvolvido, as chaves que aparecem em grupos de repetição são 279, 269, 270, 271 e 290. Portanto, o número de chaves $p$ é igual a 5 . O algoritmo 4.1 percorre a estrutura de dados 
descrita.

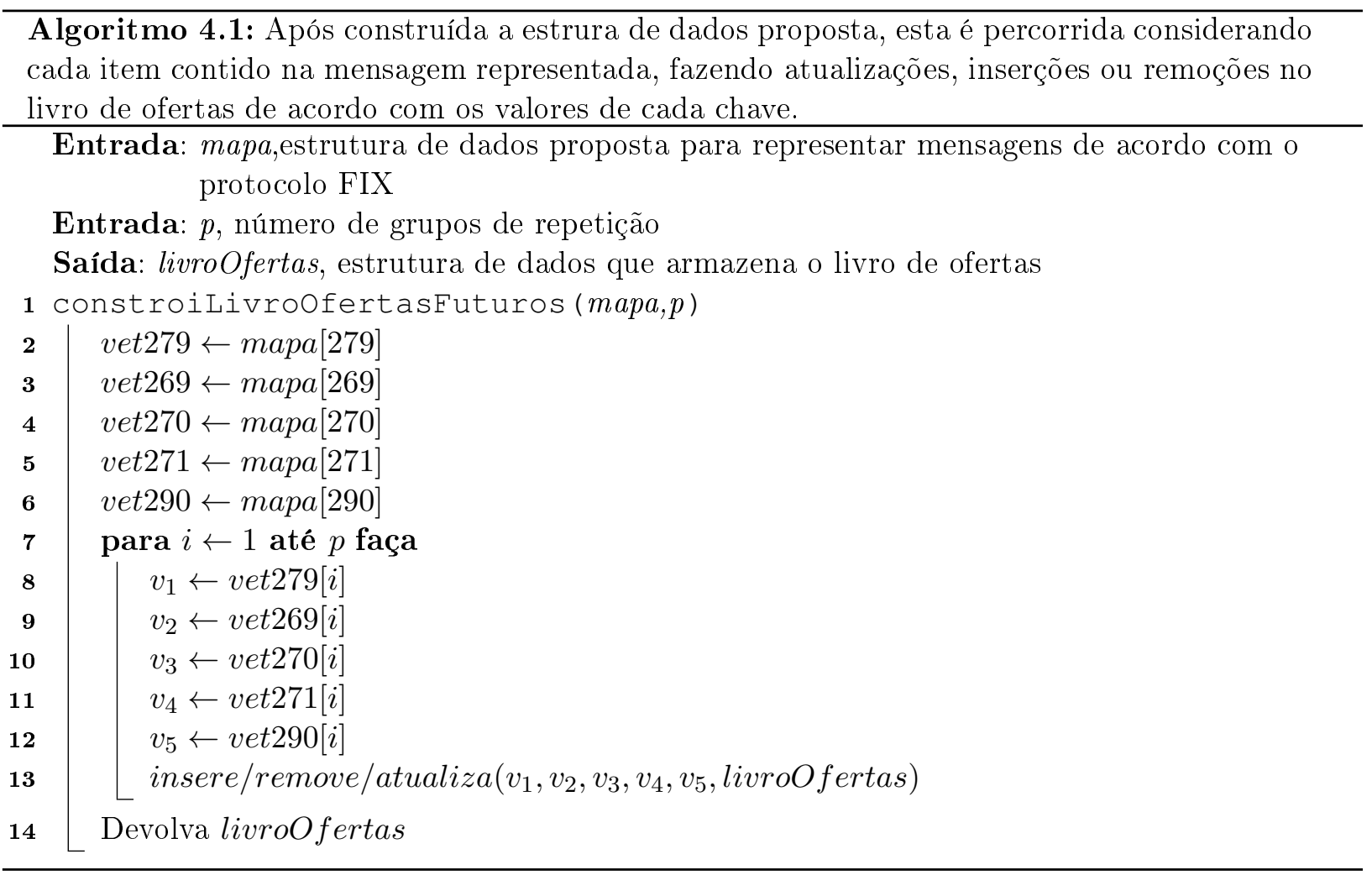

As linhas de 2 a 6 executam em tempo $O(\lg p)$ sendo $p$ o número de chaves do mapa. Neste caso $p=5$, então o tempo de execução das linhas de 2 a 6 é $O(1)$. As linhas 8 a 12 executam em tempo constante, garantido pela forma como um std::vector é implementado. A linha 13 mostra uma chamada de função. Esta chamada representa o tratamento realizado com os valores de cada chave, de modo a decidir como deve ser feita a inserção no livro de ofertas. A cada iteração, armazena-se os valores adequados em uma estrutura de dados, que representa o livro de ofertas. Cada oferta de compra/venda deve ser armazenada durante toda a construção do livro de ofertas, pois posteriormente pode haver uma nova mensagem que altera seu valor ou até mesmo a remove, possivelmente alterando quais ofertas são adicionadas ao livro de ofertas.

Para representar o livro de ofertas, poderia ser utilizada uma estrutura linear sequencial simples, encapsulada por um template de classe do $\mathrm{c}++$, como std::vector. Assim, a chave MDEntryPositionNo representaria a posição em que uma nova oferta deve ser inserida (ou a posição de uma oferta de deve ser alterada ou removida). Fazer isto seria problemático, pois o tempo de inserção/remoção de uma oferta seria proporcional ao número de ofertas já inseridas, o que pode ser proibitivamente caro.

Propõe-se a utilização de um std::map <int, Offer >. Cada chave representa a posição (de acordo com sua competitividade) de uma oferta e seu valor associado é a própria oferta. Dada uma chave, o tempo de acesso a seu valor associado em um std::map é $O(\lg n)$, e assim a chamada à função trata no algoritmo acima tem tempo de execução proporcional ao número de ofertas existentes no arquivo.

Para analisar o custo computacional associado à construção do livro de ofertas utilizando a abordagem proposta, é preciso considerar os seguintes itens:

- Número de linhas no arquivo fonte.

- Número de pares percententes a grupos de repetição em cada linha. 
- Custo associado à construção da estrutura proposta para cada linha.

- Custo associado à inserção de ofertas na estrutura que representa o livro de ofertas.

Seja $l$ o número de linhas no arquivo fonte. Dada uma sequência de chaves, o número de vezes que essa sequência se repete em um grupo de repetição em cada linha é variável. Assim, seja $p$ o número máximo de vezes que uma dada sequência se repete em uma dada linha. Seja $g(z)^{1}$ uma função que representa o custo computacional associado à construção da estrutura de dados proposta para uma dada linha com comprimento $z$. Seja $o$ o número total de ofertas existentes no arquivo. Para cada linha, constrói-se a estrutura de dados proposta, com complexidade $O(l \times g(z))$. Além disso, a cada linha são processadas $O(p)$ ofertas, e para cada oferta, é feita a inserção/alteração na estrutura de dados que representa o livro de ofertas, resultando na complexidade de

$$
O(l \times(O(g(z))+O(p) \times O(\lg o)) .
$$

Observa-se a seguinte relação:

$$
\sum_{\text {linha } \in \text { linhas }} \operatorname{linh} a_{p} \leq o
$$

Na relação 4.2, "linhas" representa o conjunto de linhas do arquivo. linha $a_{p}$ representa o número de vezes que uma dada sequência de chaves se repete na linha linha, formando um grupo de repetição em linha. A igualdade ocorre quando cada elemento da repetição se refere a uma oferta de compra ou venda. Existem no máximo o ofertas, independentemente de elas aparecerem todas em uma única linha ou separadas em múltiplas linhas. A possibilidade de desigualdade existe pelo fato de nem todos os elementos da repetição representarem ofertas de compra e venda; alguns representam negócios concretizados. Negócios concretizados não são armazenados na estrutura de dados que representa o livro de ofertas. Eles simplesmente são transcritos para o arquivo final. Este fato tem impacto no limite superior dado acima. Tratar um grupo de chaves que representa um negócio concretizado leva tempo constante. Assim, o limite superior 4.1 mostra somente o pior caso de execução do algoritmo. No melhor caso, tem-se somente itens que representam negócios concretizados e assim a complexidade do algoritmo é $O(p)$, pois a linha 13 executa em tempo constante neste caso.

\subsection{Tratamento de dados de ações}

Os dados de ações estão de acordo com o padrão descrito na seção 3.3. Este padrão difere fundamentalmente daquele proposto pelo protocolo FIX. A construção do livro de ofertas a partir destes dados não pôde ser concluída, porém acredita-se que os detalhes descritos nesta seção sejam de grande valia para concluir-se esta tarefa. Em particular, acredita-se que o livro de ofertas a partir destes dados pode ser construído caso seja possível obter informações precisas referentes ao campo que descreve o status de cada oferta.

Para a construção do livro de ofertas, utiliza-se somente um subconjunto dos campos descritos na seção 3.3. Conforme descreve a seção 3.1, cada linha de um livro de ofertas típico é composta por data e hora, ofertas de compra e venda mais interessantes naquele instante e quantidade e valor de negócios concretizados. Assim, para fazer a extração do livro de ofertas, utiliza-se os campos que representam cada um desses conceitos. Além disso, existem outros campos que, apesar de não terem seus valores incluídos no livro de ofertas, têm fundamental importância para a correta construção do livro de ofertas.

Para cada mensagem de oferta de compra/venda, os campos utilizados são os seguintes:

\footnotetext{
${ }^{1} \mathrm{~A}$ ordem desta função depende dos algoritmos de processamento de cadeia empregados. É possível empregar algoritmos que garantem complexidade $O(z)$
} 
- Papel

- Sequência

- Preço Of.Compra

- Qtd.Total Of.Compra

- Hora Prioridade

- Data de Entrada Of.Compra - somente a data, pois a hora já existe no campo "Hora Prioridade" com maior precisão.

- Estado Of.Compra

A importância dos campos Preço Of.Compra, Qtd.Total Of.Compra, Hora Prioridade e Data de Entrada Of.Compra é evidente para a composição do livro de ofertas. Seus valores estarão presentes em cada linha do livro de ofertas. Os campos Papel, Sequência, a princípio, podem parecer irrelevantes. O campo Papel é importante pois pode-se desejar construir o livro de ofertas referente a um único ativo. O campo Sequência é importante pois ele identifica uma dada oferta. Se no futuro uma oferta for alterada, utiliza-se esse campo para encontrar a mensagem sobre a qual a alteração deve ser realizada. O campo Estado Of.Compra é importante pois seu valor indica se deve-se considerar que uma nova oferta está sendo realizada ou se uma oferta existente deve ser alterada, entre outras possibilidades. Este é o campo cujo significado deve-se verificar com maior profundidade para que o algoritmo 4.2 possa ser completado e para que se possa fazer a construção do livro de ofertas corretamente.

Para cada mensagem de negócio concretizado, utilizam-se os seguintes campos:

- Data Sessão

- Papel

- Preço Negócio

- Quantidade

- Hora

- Ind.Anulação

Os campos Data Sessão, Preço Negócio, Quantidade e Hora são relevantes para a extração do livro de ofertas pois seus valores é que aparecem em cada linha do livro de ofertas. O campo Papel é importante pois pode-se desejar extrair o livro de ofertas referente a um único ativo. $\mathrm{O}$ campo Ind.Anulação é importante pois ele indica se um negócio foi concretizado ou está sendo cancelado. Somente adiciona-se ao livro de ofertas negócios que estão sendo concretizados.

Como descrito na Seção 3.1, um livro de ofertas típico é composto pelas ofertas de compra e venda mais interessantes e pelos negócios concretizados. Para fazer a construção do livro de ofertas dos dados de ações, precisa-se tratar os três arquivos disponibilizados pela Bovespa simultaneamente. O algoritmo 4.2 sugere que se faça o tratamento dos três arquivos mesclando os dados destes em um único arquivo final, que representa o livro de ofertas. Faz-se a leitura da primeira linha de cada arquivo e verifica-se qual delas é a menos recente, ou seja, aconteceu primeiro. Adiciona-se as informações relevantes dessa linha ao livro de ofertas, e faz-se a leitura da próxima linha do arquivo que contém a linha utilizada. Novamente, verifica-se qual das três linhas tem a data de ocorrência menos recente, e utiliza-se suas informações para compor a próxima entrada no livro de ofertas. Ao 
final do processamento, obtém-se o livro de ofertas contendo ofertas de compra e venda e negócios concretizados com suas entradas ordenadas pela data em que cada transação ocorreu.

Uma observação importante é que os dados de ações fornecidos não estão ordenados pela data. Assim, antes de fazer a extração do livro de ofertas, é necessária a ordenação das entradas de cada arquivo (ofertas de compra, venda e negociações) de acordo com a data em que ocorreram. Como o volume de dados com o qual é preciso lidar é grande, neste trabalho optou-se por utilizar um algoritmo de ordenação externa. O projeto external sorting in java ${ }^{2}$ foi utilizado. Esse projeto funciona da seguinte forma. O arquivo a ser ordenado é dividido em arquivos menores. Cada arquivo menor é ordenado na memória principal utilizando o algoritmo de ordenação MergeSort. Uma vez que todos os arquivos menores estejam ordenados, eles são mesclados em um único arquivo. O projeto external sorting in java está disponível gratuitamente no domínio público.

O algoritmo 4.2 mostra a forma como sugere-se que se faça a construção do livro de ofertas a partir dos dados disponibilizados pela Bovespa. A linha TAL deve ser completada após uma análise detalhada sobre o significado de cada possível status de oferta. Após isso, acredita-se que seja possível obter-se o livro de ofertas apropriadamente.

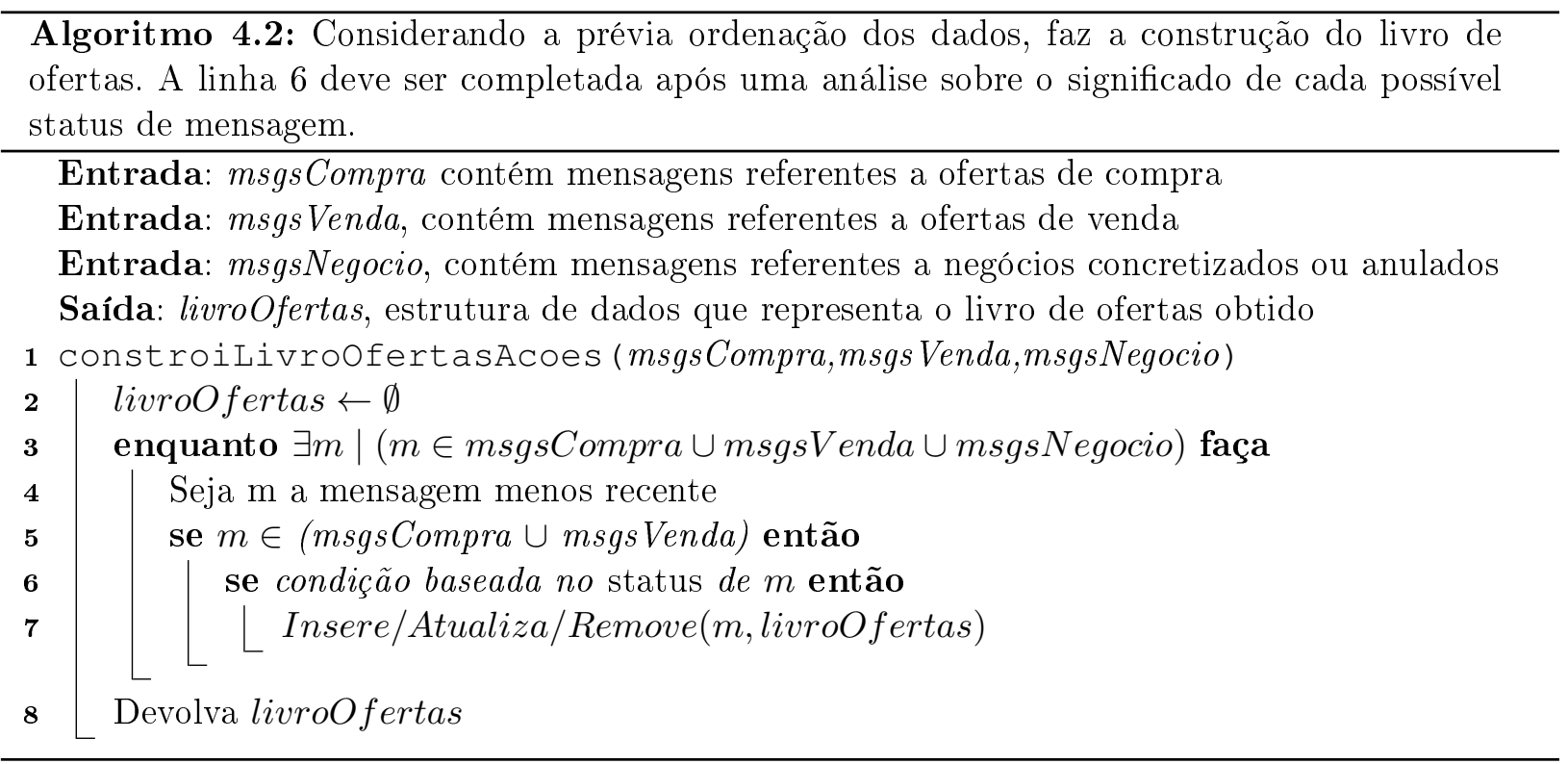

O algoritmo 4.2 supõe que os dados já estão ordenados. A estrutura de dados que representa o livro de ofertas deve, de alguma forma, manter as ofertas ordenadas por competividade.

Como descrito na seção 4.1, os dados de futuros estão de acordo com o protocolo FIX, que oferece a chave MDEntryPositionNo, que permite identificar o quão competitiva é uma dada oferta. Infelizmente, os dados de ações não têm um conceito semelhante. Não obstante, pode-se utilizar uma estrutura de dados que garanta que as ofertas estejam sempre ordenadas de acordo com o critério que desejar-se. A estrutura de dados sugerida é um std::set. Essa estrutura mantém seus dados ordenados de acordo com um critério que pode-se especificar. Ofertas de compra mais interessantes são aquelas cujo valor é maior. Ofertas de venda mais interessantes são aquelas cujo valor é menor. Um std::set é geralmente implementado utilizando-se uma árvore balanceada, como uma árvore rubro-negra[CLRS09]. Uma árvore rubro-negra é um tipo específico de árvore binária que, a cada inserção, se mantem "razoavelmente" balanceada. Uma árvore rubro-negra garante que as operações básicas sejam executadas com complexidade $O(\lg n)$, sendo n o número de elementos existentes na árvore.

\footnotetext{
${ }^{2}$ http://code.google.com/p/externalsortinginjava/
} 


\section{Capítulo 5}

\section{Um algoritmo para predição de valores baseado em agrupamento e regressão linear}

Ao se negociar ativos em uma bolsa de valores, é natural o desejo de se fazer as melhores compras/vendas possíveis. Em geral, deseja-se comprar quando o preço estiver o mais baixo possível e, analogamente, deseja-se vender quando o preço estiver o mais alto possível. O livro de ofertas mostra as ofertas de compra e venda mais interessantes e com base neste, pode ser interessante decidir o momento certo de comprar ou vender. Diversos fatores têm impacto nos valores mostrados no livro de ofertas, como notícias, catástrofes etc. Assim, nunca se sabe ao certo o momento em que o preço de um determinado instrumento financeiro vai subir ou descer. Apesar disso, uma análise detalhada das variações contidas em um livro de ofertas pode revelar relações interessantes entre as variáveis que o compõem. Por exemplo, pode ser razoável supor que quando o volume de venda sobe o preço tende a cair. Também discute-se no meio financeiro a influência que os preços do dia anterior podem ter sobre os preços do dia atual Utilizando técnicas de mineração de dados e estatística pode-se identificar relações entre as variáveis do livro de ofertas bem como relações entre dias diferentes.

Se fosse possível prever a variação dos preços, seria possível saber o momento mais interessante para se realizar uma compra ou venda. Neste Capítulo apresenta-se um algoritmo para predição de valores baseado em agrupamento (clustering) e regressão linear. Com base em dados de dias anteriores e no estado atual do livro de ofertas, o algoritmo tenta prever qual será o próximo valor de uma dada variável do livro de ofertas. Por exemplo, pode-se aplicar este algoritmo para fazer a predição do próximo valor de venda mais interessante. Caso o valor previsto seja baixo o suficiente, esta predição pode indicar que o momento é bom para se realizar uma compra.

Este Capítulo inclui uma descrição do algoritmo juntamente com pseudocódigo. Em seguida, mostra-se uma discussão sobre a ideia que deu origem ao algoritmo e uma análise sobre resultados obtidos pelo algoritmo quando executado sobre livros de ofertas de diferentes instrumentos financeiros. 


\subsection{Descrição do algoritmo}

O algoritmo proposto pode ser utilizado para fazer a previsão de um próximo valor de uma dada variável baseando-se em valores de outras variáveis, supondo-se que exista uma correlação linear entre a variável cujos valores devem ser previstos e as demais variáveis. Utiliza-se o algoritmo k-Means descrito na Seção 2.1 para fazer o agrupamento de dados históricos. Após isso, indicando qual variável deve ter seu valor previsto, calculam-se coeficientes para cada uma das demais variáveis, de modo a se obter o valor previsto com o menor erro possível. Considerando-se variações em dados históricos, calcula-se a frequência de ocorrência de um dado grupo, dado o passado. Com esta informação, utilizam-se os coeficientes associados ao grupo com maior probabilidade de ocorrência para obter o valor previsto.

A primeira etapa, ou seja, o agrupamento de dados históricos, é realizada pelo algoritmo 5.1. O algoritmo inicia selecionando $\mathrm{k}$ itens arbitrários de Told. Cada item selecionado tem a ele associado um grupo e é considerado o "centro" do grupo. Cada grupo tem um número inteiro associado a ele, de 1 até $\mathrm{k}$. Em seguida, cada um dos itens restantes é adicionado ao grupo cujo centro é o mais próximo de si. Em geral, utiliza-se a distância de Euclides. Neste caso, utiliza-se a distância de Euclides ignorando o atributo identificado por "ignore". Caso haja empate, utiliza-se como critério de desempate o número associado ao grupo: o menor deles é escolhido. Por conveniência, cada item tem um atributo ou dimensão que armazena o número do grupo ao qual pertence:clusterItBelongsTo. No pseudocódigo, utiliza-se o operador "." para acessar os atributos de cada item, prática comum em linguagens com suporte à orientação a objetos. Os centros de cada grupo são recalculados e os seus ponto médios são considerados os novos centros .Os pontos médios são calculados pela chamada à função "centroide". Os itens são novamente processados um a um e atribuídos ao grupo cujo centro é o mais próximo, utilizando o mesmo critério de desempate. O algoritmo para quando o cálculo de pontos médios não revela nenhum centro novo, momento em que não há mais qualquer alteração nos grupos, devolvendo uma estrutura de dados que armazena o centro de cada grupo. 


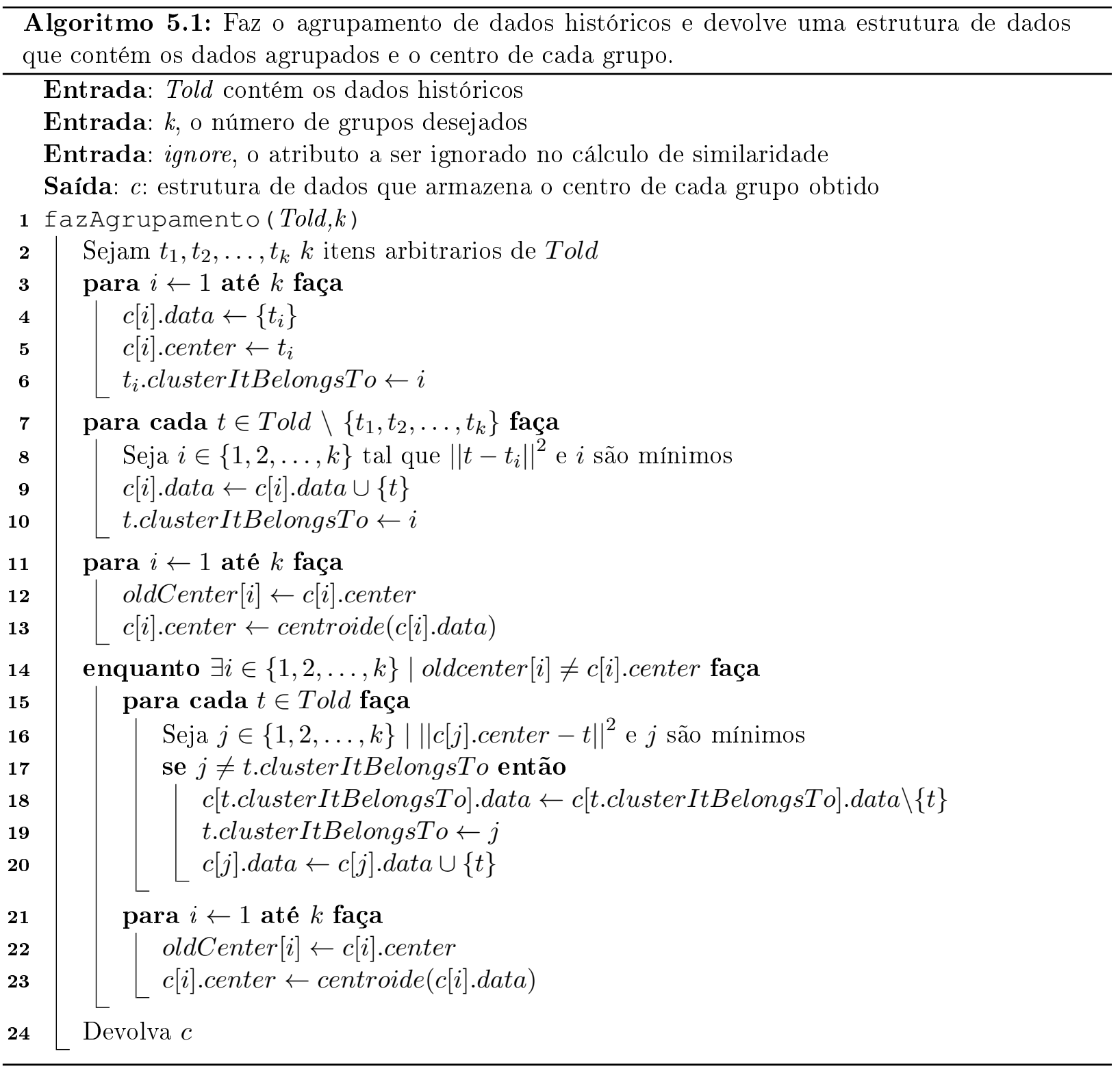

A segunda etapa do algoritmo de predição de valores, realizada pelo algoritmo 5.2, consiste em verificar a frequência com que cada grupo aparece, dado um passado finito. Fixa-se um número inteiro $p$, considera-se cada possível cadeia $s=s_{1} s_{2} \ldots s_{p} \mid s_{i} \in\{1,2, \ldots, k\}$ e constrói-se uma estrutura de dados que armazena, para cada possível $s$, a frequência com que cada um dos grupos aparece no conjunto de dados históricos logo após uma ocorrência de $s$. 


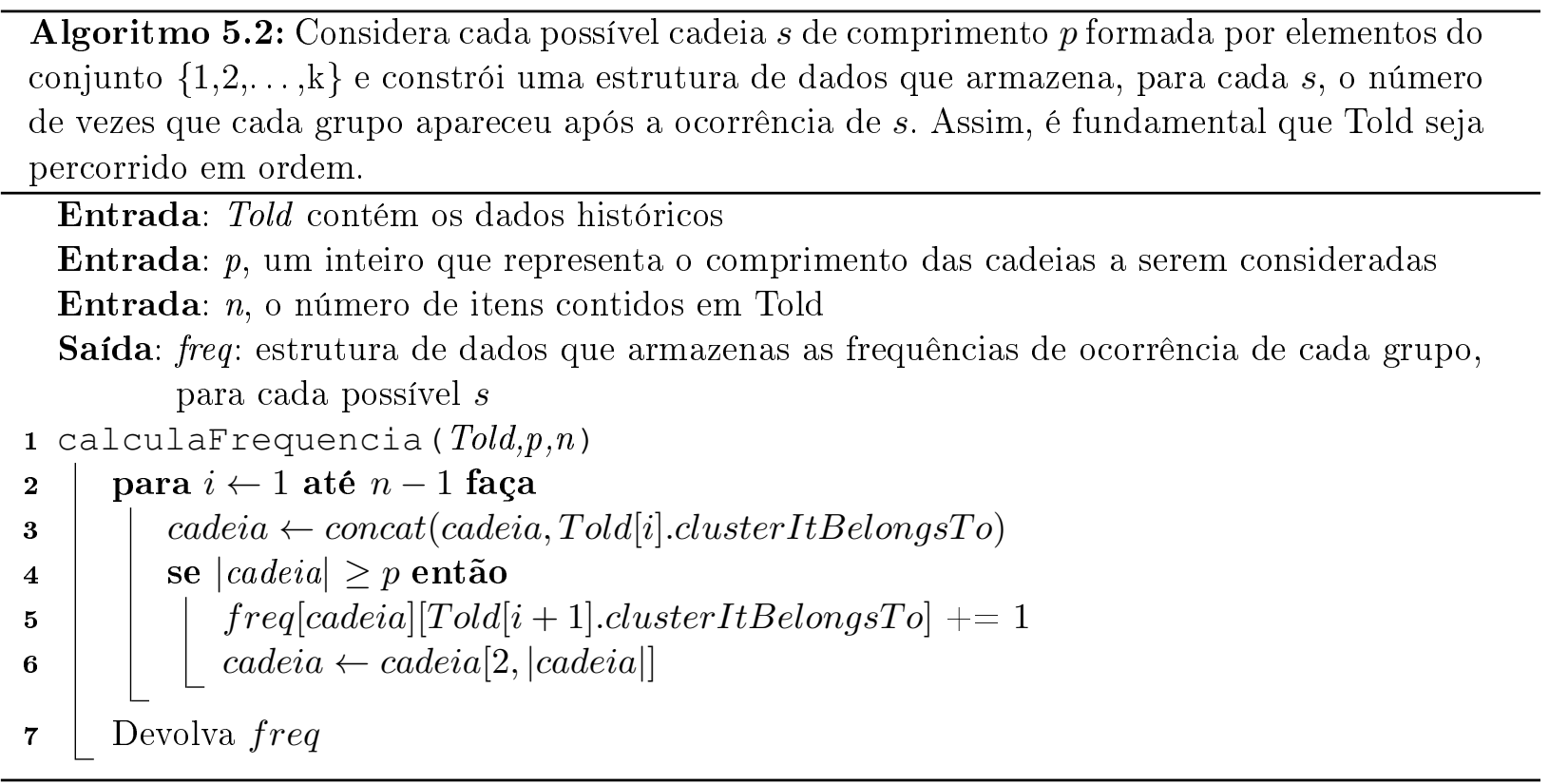

O último passo a ser realizado antes que se possa fazer a predição de valores é realizado pelo algoritmo 5.3. É executada uma regressão linear para cada um dos grupos obtidos pelo algoritmo 5.1. Uma estrutura de dados que armazena os coeficientes calculados para cada grupo é devolvida pelo algoritmo 5.3.

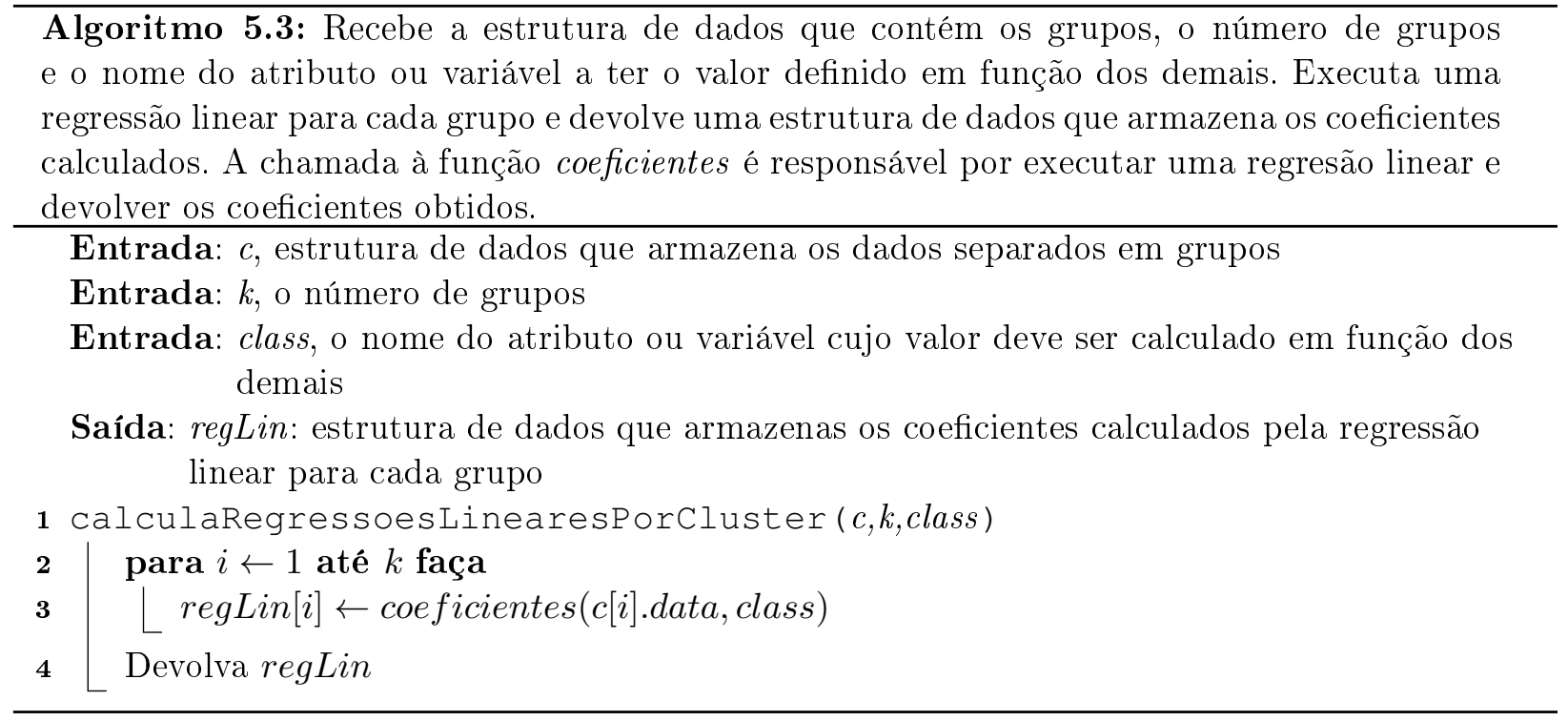

Com os dados agrupados, frequências e coeficientes calculados, pode-se fazer a predição de valores. O algoritmo 5.4 utiliza as estruturas de dados contruídas previamente para prever valores de uma variável escolhida. 


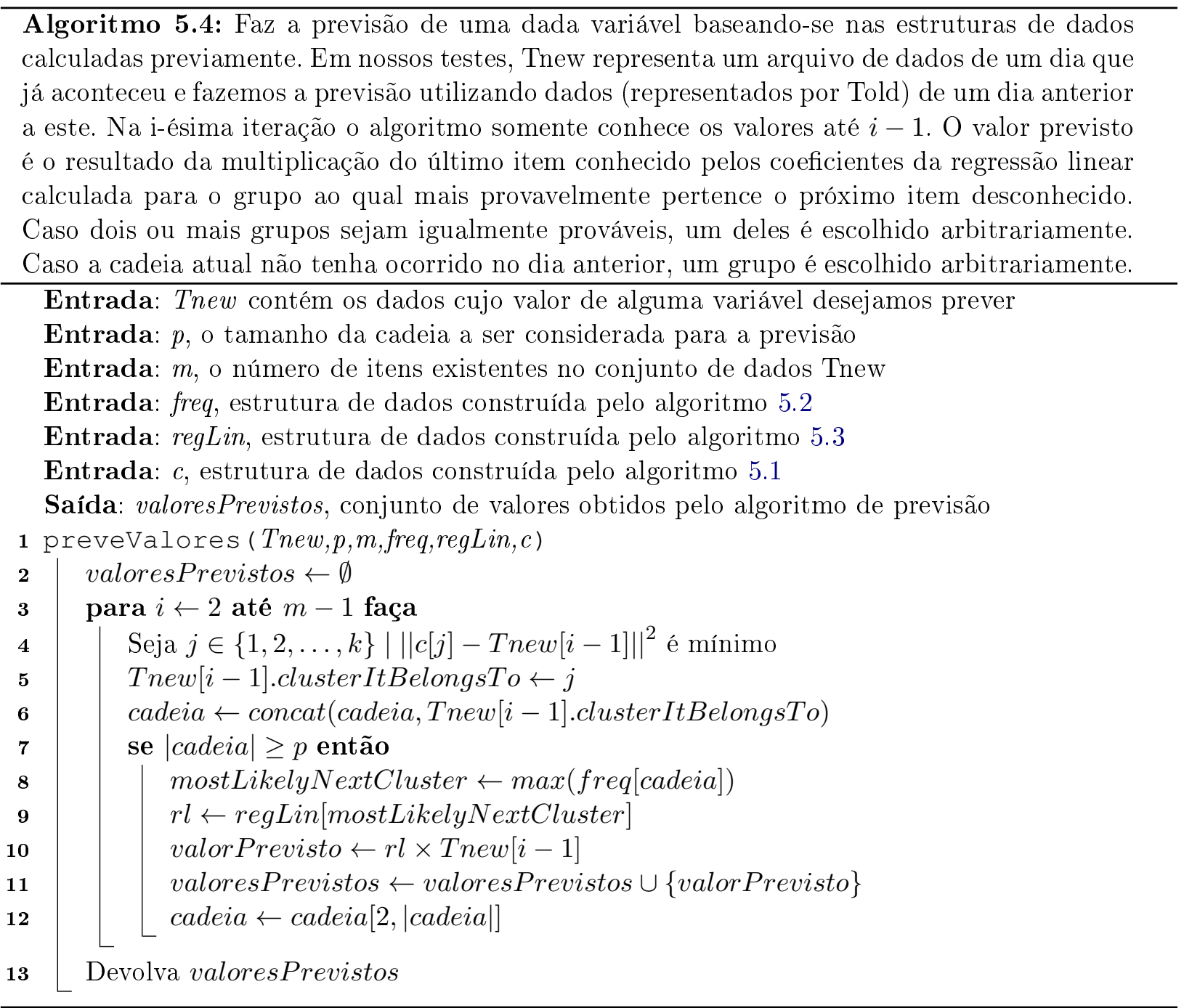

Assim finaliza-se o algoritmo de predição de valores e a estrutura devolvida por ele contém os preços previstos, calculados com base no passado. Na seção 5.2 é feita uma discussão sobre a origem do algoritmo de predição e proposta uma alteração em seu funcionamento. Na seção 5.3 são exibidos resultados obtidos pelo ao executar-se o algoritmo de predição sobre dados de diferentes dias e instrumentos financeiros. 


\subsection{Considerações sobre o algoritmo}

O algoritmo de predição de valores descrito na seção 5.1 faz uso de agrupamento e regressão linear. Nesta seção explica-se as razões pelas quais tais técnicas foram utilizadas para sua elaboração.

Um algoritmo de predição de preços pode, por exemplo, ser capaz de encontrar pontos de inflexão no gráfico de variação do preço. Estes pontos podem ser de interesse por indicarem momentos em que a tendência do mercado muda. Ou seja, um ponto de inflexão pode indicar que, naquele instante, o preço atingiu o valor mínimo ou máximo ${ }^{1}$. Se o algoritmo de predição encontra um ponto de inflexão antes que este ocorra, pode-se tomar uma decisão de compra ou venda próximo do momento em que aquele ponto acontecerá. Assim justifica-se o interesse por um algoritmo de predição de valores. O primeiro passo para a elaboração do algoritmo consiste em verificar se há algum tipo de correlação entre a variável cujo valor deseja-se prever e as demais variáveis. Neste trabalho, verificou-se a existência de correlações lineares entre a variável "preço de venda mais interessante" e diversas outras variáveis do livro de ofertas, utilizando-se o coeficiente de correlação de Pearson, descrito na seção 2.2. As figuras 5.1 , 5.2, 5.3 e 5.4 mostram a correlação linear existente para o índice DOLG11, utilizando o livro de ofertas do dia 04 de Janeiro de 2011, com diferentes valores de janela e considerando diferentes variáveis. Em geral, as variáveis referentes a preço, seja de compra ou venda, têm uma correlação bastante forte com a variável "preço de venda mais interessante". As variáveis referentes a volume de compra ou venda não mostram uma correlação tão forte assim.

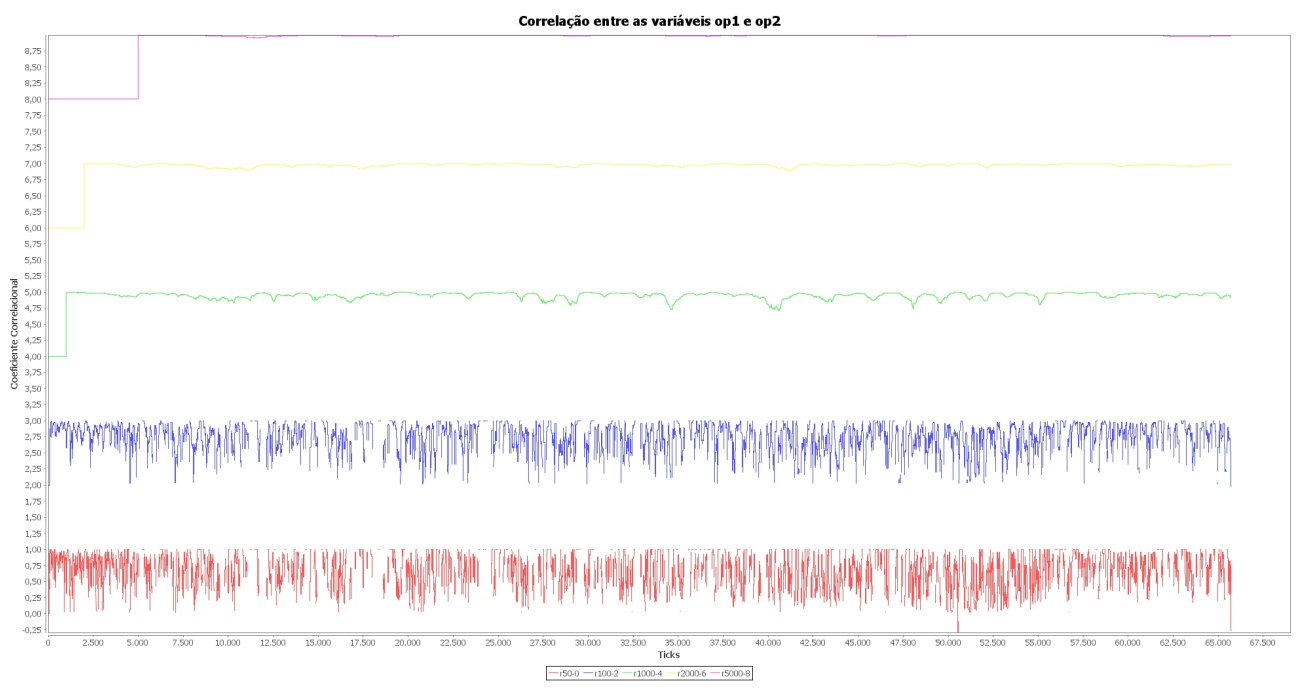

Figura 5.1: Correlação linear entre as variáveis op1 e op2, do índice DOLG11. Movimentação do dia 04 de Janeiro de 2011. A legenda indica a janela considerada para o cálculo da correlação e em seguida mostra o valor a ser considerado como o ponto zero de uma dada curva. Assim, para quaisquer $j$ e $n$, rj-n quer dizer que aquele gráfico se refere ao coeficiente correlacional calculado utilizando uma janela de $j$ itens e que seu ponto zero é $n$.

\footnotetext{
${ }^{1}$ não necessariamente globais
} 


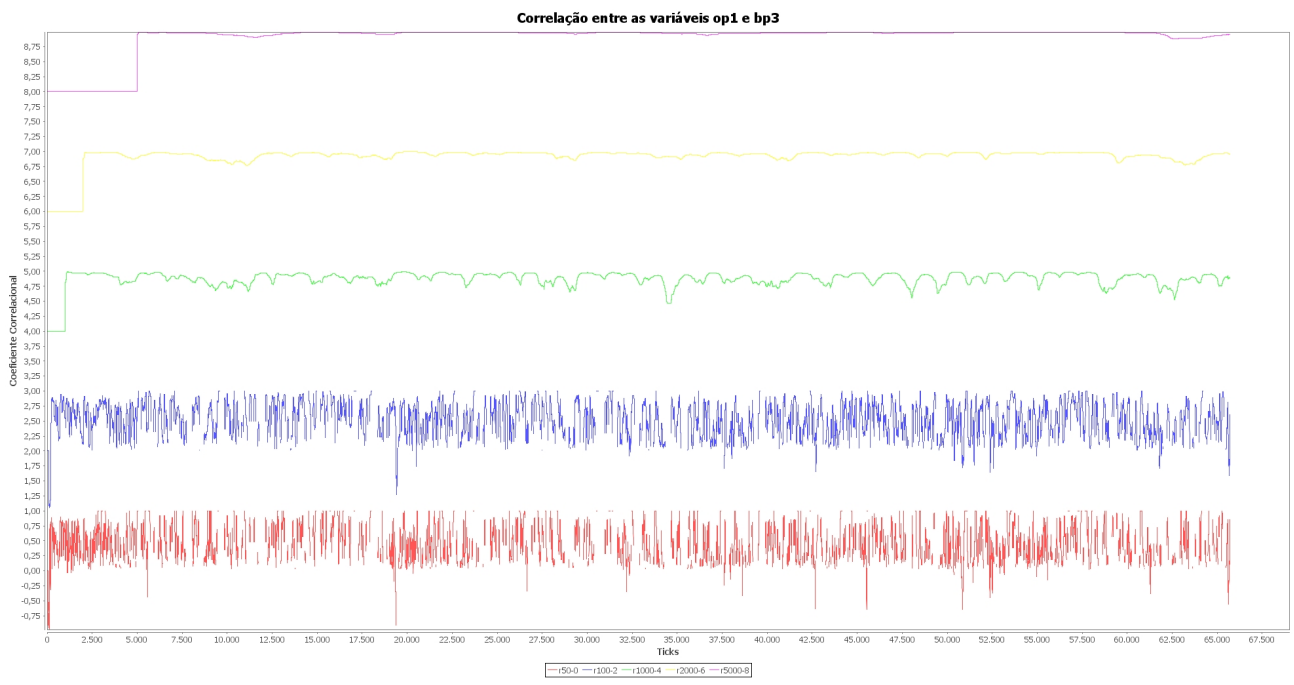

Figura 5.2: Correlação linear entre as variáveis op1 e bp3, do indice DOLG11. Movimentação do dia 04 de Janeiro de 2011. A legenda indica a janela considerada para o cálculo da correlação e em seguida mostra o valor a ser considerado como o ponto zero de uma dada curva. Assim, para quaisquer $j$ e $n$, rj-n quer dizer que aquele gráfico se refere ao coeficiente correlacional calculado utilizando uma janela de $j$ itens e que seu ponto zero é $n$.

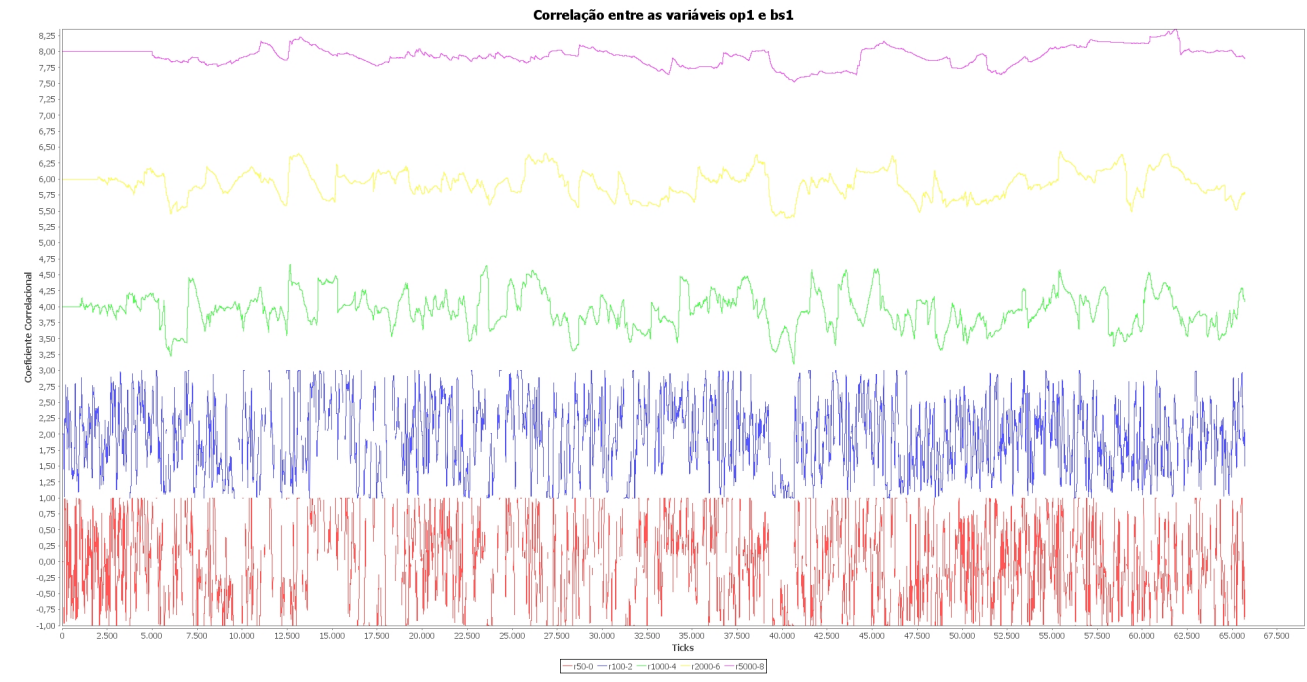

Figura 5.3: Correlação linear entre as variáveis op1 e bs1, do indice DOLG11. Movimentação do dia 04 de Janeiro de 2011. A legenda indica a janela considerada para o cálculo da correlação e em seguida mostra o valor a ser considerado como o ponto zero de uma dada curva. Assim, para quaisquer $j$ e $n$, rj-n quer dizer que aquele gráfico se refere ao coeficiente correlacional calculado utilizando uma janela de $j$ itens e que seu ponto zero é $n$.

A utilização do método de regressão linear baseia-se nesta análise. Para todos os dias e índices testados, é notável a existência de uma forte correlação linear, positiva ou negativa, entre boa parte das variáveis que compõem o livro de ofertas. Além disso, diante da discussão que existe no mercado financeiro sobre a influência que um dia anterior pode exercer sobre o dia atual, parece razoável executar o método de regressão linear utilizando dados de um ou mais dias anteriores e verificar o quão bem o modelo obtido se adequa ao dia atual. Considerando estas premissas, um algoritmo de predição razoável seria similar ao algoritmo 5.5. 


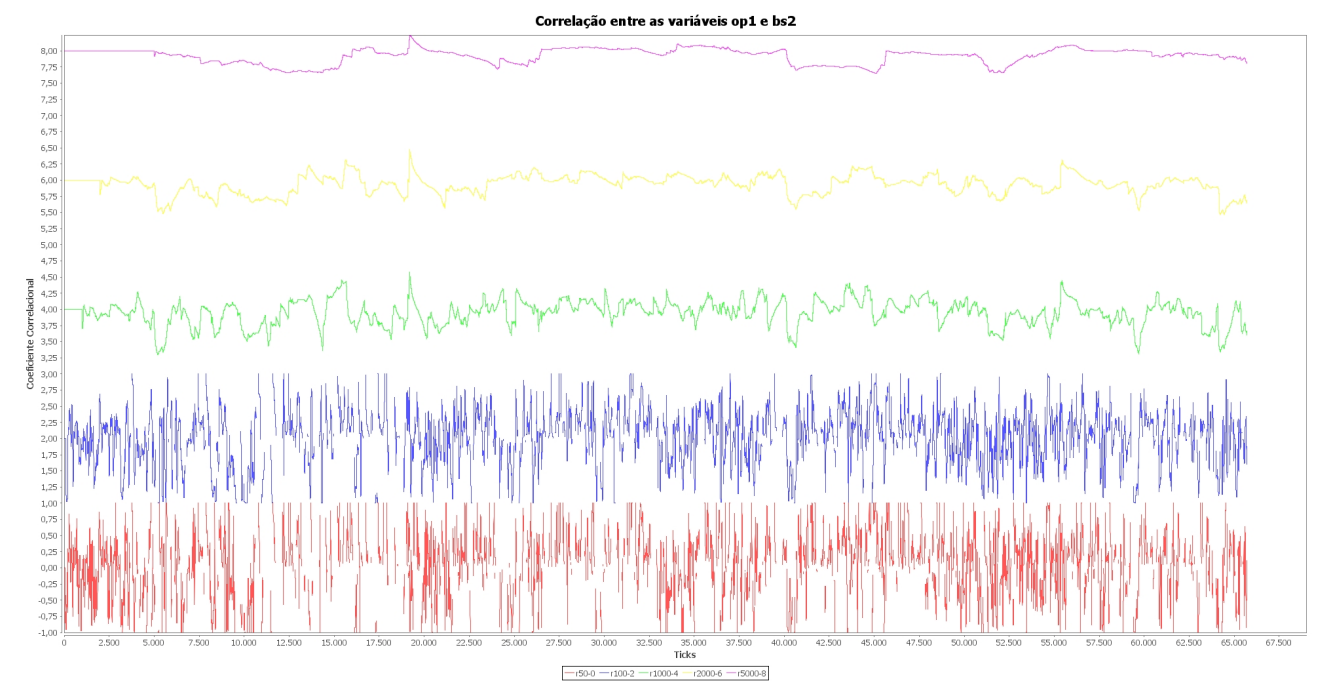

Figura 5.4: Correlação linear entre as variáveis op1 e bs2, do índice DOLG11. Movimentação do dia 04 de Janeiro de 2011. A legenda indica a janela considerada para o cálculo da correlação e em seguida mostra o valor a ser considerado como o ponto zero de uma dada curva. Assim, para quaisquer $j$ e $n$, rj-n quer dizer que aquele gráfico se refere ao coeficiente correlacional calculado utilizando uma janela de $j$ itens e que seu ponto zero é $n$.

Algoritmo 5.5: Executa o método de regressão linear sobre dados antigos para obter um modelo que será utilizando para predição de valores no dia atual

1 construir um modelo utilizando o método de regressão linear que indique o valor da variável cujo valor deseja-se prever em função das demais variáveis, utilizando os dados do dia anterior

2 Para cada momento conhecido no dia atual, multiplicar os valores do último tick conhecido pelos coeficientes do modelo obtido no passo anterior, obtendo o preço previsto

Dois ticks têm, em geral, valores muito parecidos para todas as suas variáveis quando ocorrem em sequência. Por essa razão, o algoritmo 5.5 utilizaria os valores do último tick conhecido para prever o valor desejado do tick que ocorrerá em seguida, multiplicando-os pelos coeficientes obtidos pela regressão linear.

Embora o algoritmo 5.5 seja razoável, o modelo obtido pela regressão linear, ao minimizar a soma de erros, pode não ser razoável para alguns instantes, pois estes podem ter valores muito diferentes daqueles que pertencem à reta estabelecida pela regressão linear.Diante deste cenário, observa-se que utilizar um único modelo pode não ser a ideia mais apropriada. Ao invés disso, pode ser interessante construir múltiplos modelos utilizando, para cada um, um subconjunto de ticks similares entre si. Assim, emprega-se a técnica de agrupamento para obter-se grupos de ticks similares entre si. A quantidade de grupos a se obter, como descrito no algoritmo 5.1, deve ser estabelecida a priori. Em todos os testes realizados o número de grupos foi cinco. Uma vez que tenham sido obtidos os grupos, realiza-se uma regressão linear para cada um deles, possivelmente obtendo modelos mais apropriados para cada grupo, ao invés de se obter um único modelo que tenta descrever todos os dados de uma única vez. É o que mostra a figura 5.5.

Com esta estrutura construída, o algoritmo de predição verifica qual o grupo com maior probabilidade de acontecer dado o ocorrido até o momento e então escolhe o modelo mais apropriado para calcular o valor do preço previsto, multiplicando as variáveis do último tick conhecido pelos coeficientes do modelo escolhido. 


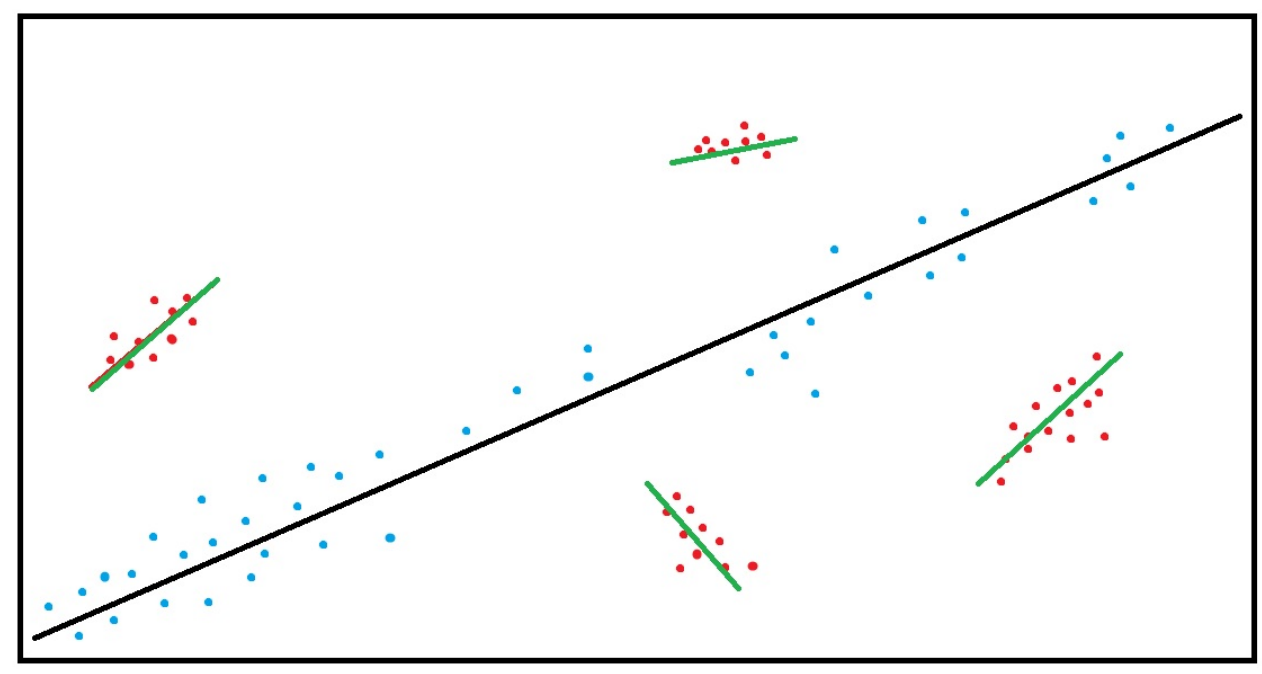

Figura 5.5: Um gráfico fictício ilustrando a motivação para o uso de agrupamento antes de se executar o método de regressão linear. A reta preta mostra o modelo obtido utilizando-se todos os dados. Os pontos azuis são aqueles para os quais este modelo pode ser bom o bastante. Os pontos vermelhos estão distantes da reta estabelecida pelo modelo. As semi-retas verdes mostram o que poderiam ser modelos mais apropriados para estes grupos de pontos. 


\subsection{Análise do algoritmo}

Nesta seção apresenta-se alguns resultados obtidos ao executar-se o algoritmo de predição de valores para prever valores de diferentes variáveis do livro de ofertas. O algoritmo foi executado para fazer a predição das variáveis $b p 2, b p 1, o p 1$ e $o p 2$, dos livros de ofertas dos índices INDG11, DOLG11 e WING11 referentes a diferentes dias no período de Janeiro de 2011.

Em geral, o modelo para predição foi construído utilizando-se dados de um dia específico e então a predição foi realizada para um dia posterior a este. Também foram realizados testes utilizandose dados referentes a somente a metade de um dia para construir-se o modelo para predição e mesclando-se dados referentes a dois dias. Em geral, os resultados obtidos com o modelo construído utilizando-se somente a metade de um dia mostram-se razoavelmente piores do que os demais.

Após efetuada a predição, é interessante comparar o resultado obtido com os valores reais, considerando-se alguns aspectos. Todos os testes foram realizados sobre dados históricos. Por exemplo, foi feita a predição de valores para o dia $x+1$ construindo-se o modelo utilizando dados do dia $x$. Os dados reais de cada um dos dias já são previamente conhecidos (o algoritmo de predição obviamente não faz uso de dados que seriam desconhecidos até o momento em que realiza uma predição) e assim, após realizada uma predição para o dia $x+1$, pode-se comparar os valores obtidos com os valores reais. A figura 5.6 mostra a diferença entre o valor obtido e o valor real para um modelo construído utilizando-se dados do índice DOLG11,com base no dia 10 de Janeiro de 2011 para fazer a previsão dos valores ocorridos no dia 17 de Janeiro de 2011. A variável cujo valor foi previsto é op1. A figura 5.7 mostra a diferença para estes mesmos dias, mas inclui os valores reais ocorridos no dia bem como os valores obtidos pelo algoritmo.

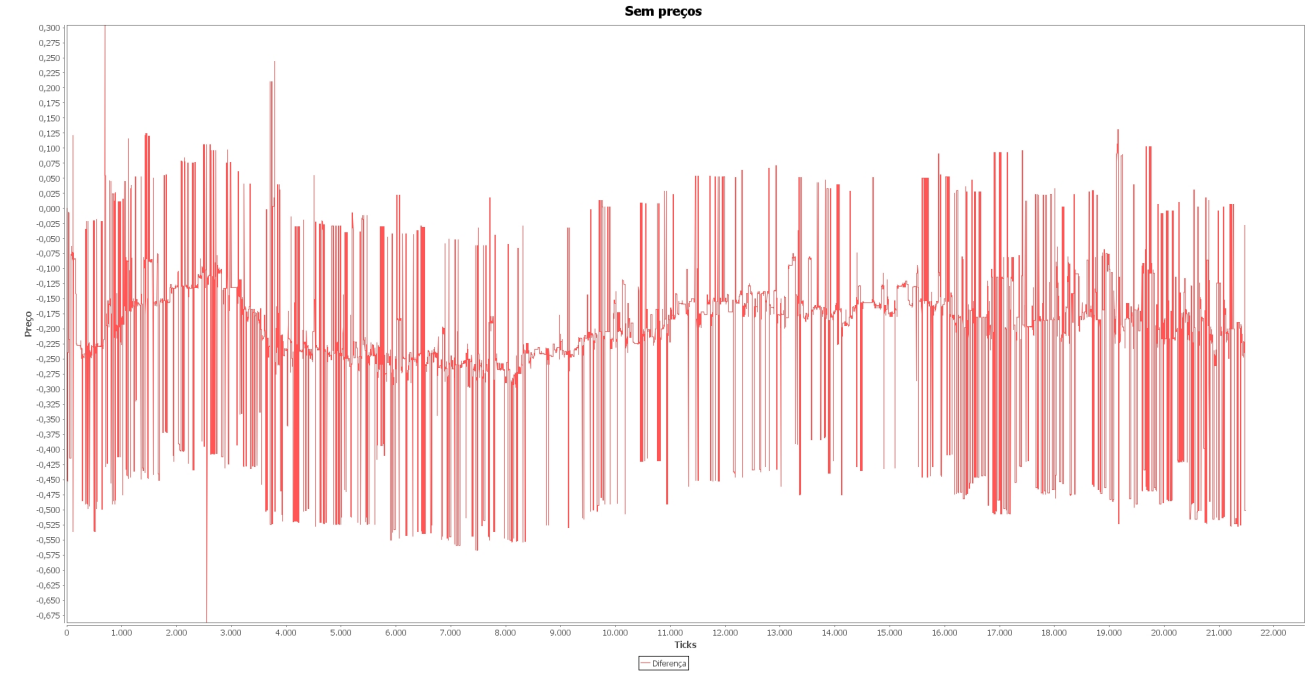

Figura 5.6: Diferença entre os valores previsto pelo algoritmo e os valores reais. Modelo construído com dados do dia 10 de Janeiro de 2011 e previsão feita para o dia 17 de Janeiro de 2011.

Em média, excetuando-se alguns momentos de pico em que a diferença entre valor previsto e valor real fica bastante grande, os resultados obtidos mostram que esta diferença é sempre menor do que $0.05 \%$ do valor absoluto para cada momento.

Um outro aspecto considerado durante a comparação entre valor previsto e valor real foi a correlação linear entre essas duas variáveis. Como mostram as figuras 5.8 e 5.9, a correlação linear mantem-se praticamente estável bem próximo do valor 1, quando considerada uma janela de tamanho suficientemente grande. Este fato mantém-se verdadeiro para diferentes índices e variáveis.

O algoritmo de predição de valores pode ser particularmente útil quando utilizado para se fazer 


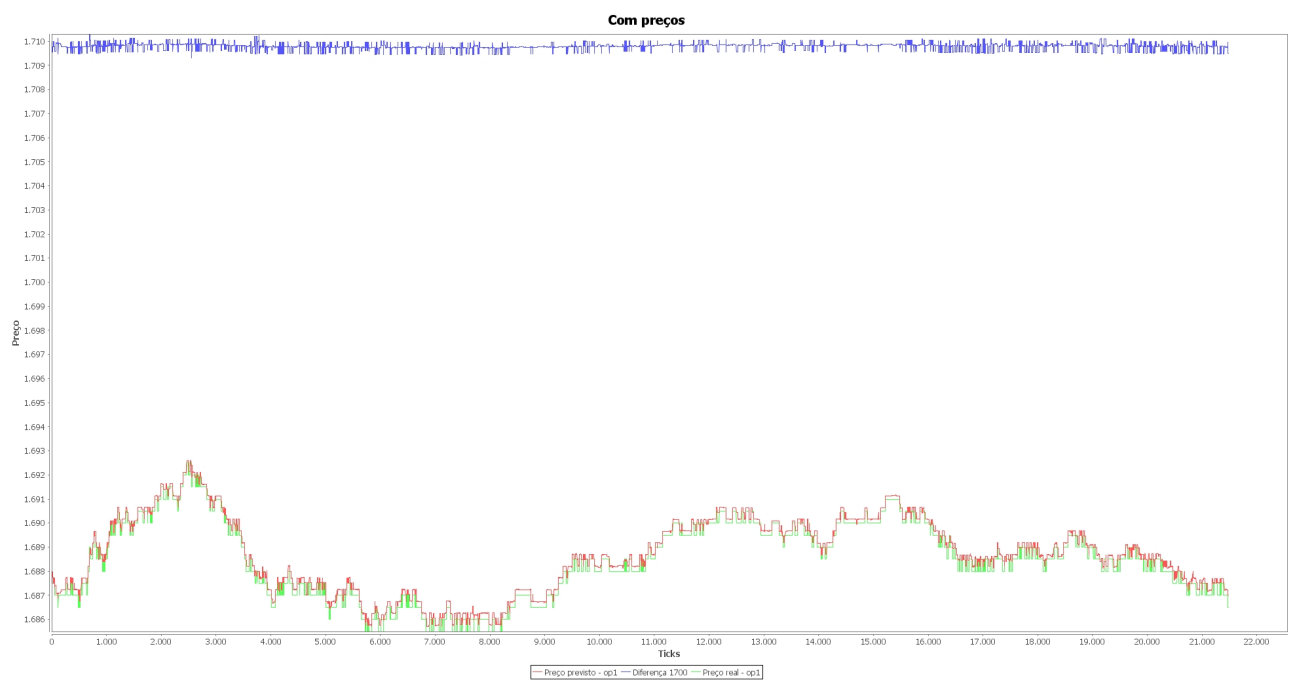

Figura 5.7: Diferença entre os valores previsto pelo algoritmo e os valores reais. Modelo construído com dados do dia 10 de Janeiro de 2011 e previsão feita para o dia 17 de Janeiro de 2011. Inclui também os valores reais ocorridos no dia bem como os valores obtidos pelo algoritmo

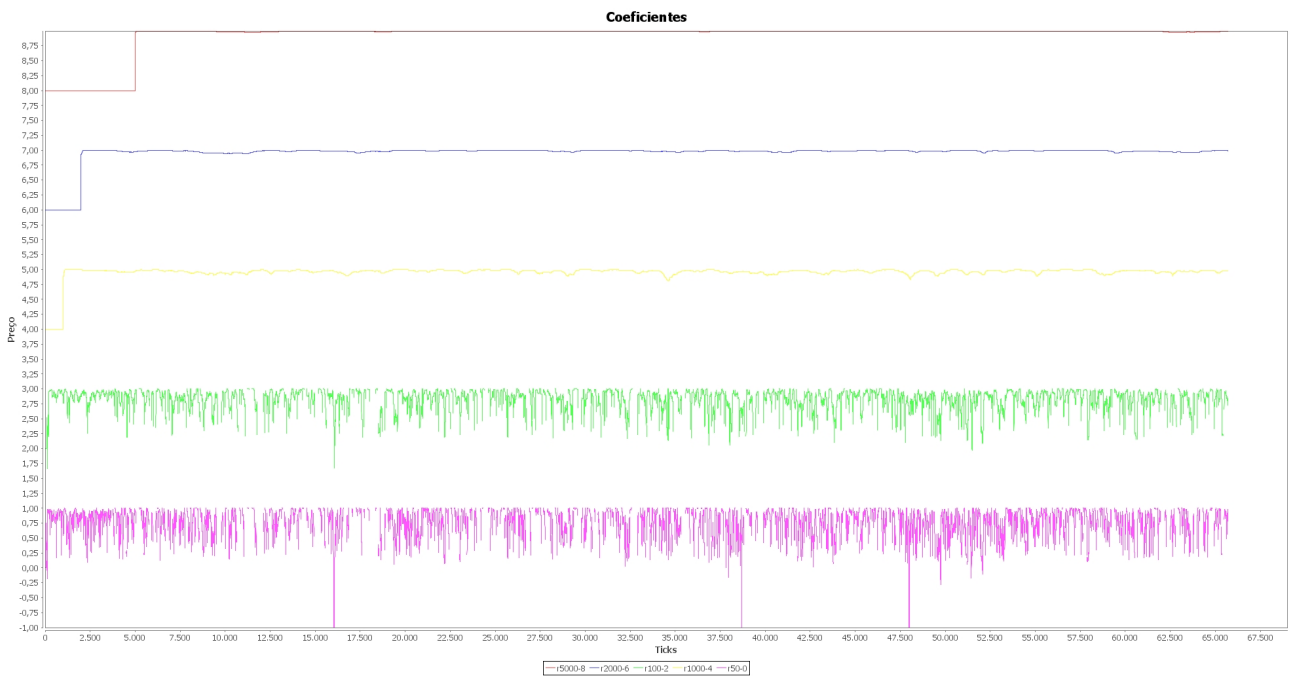

Figura 5.8: Correlação linear entre valor previsto e valor real para a variável op1, do índice DOLG11. Execução realizada considerando-se dados do dia 03 de Janeiro de 2011 para a predição de valores do dia 04 de Janeiro de 2011.

a predição de preços. Conforme discutido, uma predição pode indicar que nos instantes seguintes pode ser interessante realizar uma compra ou venda de determinado ativo. Obviamente, a predição somente será útil se a diferença entre o valor previsto e o valor real for significativamente pequena. Além disso, dada a natureza do mercado de alta frequência, um algoritmo utilizado para fazer predições de preço teria sua aplicabilidade comprometida caso levasse muito tempo para fazer uma predição. Dentro deste contexto, um intervalo de tempo de apenas um segundo pode ser considerado grande demais, pois um intervalo assim pode conter múltiplos ticks. Assim, um outro aspecto importante que foi verificado é o tempo que o algoritmo leva para a predição do valor de uma dada variável. Os testes foram realizados em um computador comum utilizando apenas processamento serial. Os resultados obtidos mostram que, em geral, o tempo levado para se fazer uma predição é muito menor do que um milissegundo. Os gráficos mostram alguns picos que raramente ultrapassam cem milissegundos, o que pode indicar que naquele instante uma troca de contexto foi realizada pelo sistema operacional e o processo responsável pela execução do algoritmo foi temporariamente pausado para que um outro processo qualquer pudesse fazer uso do processador. 


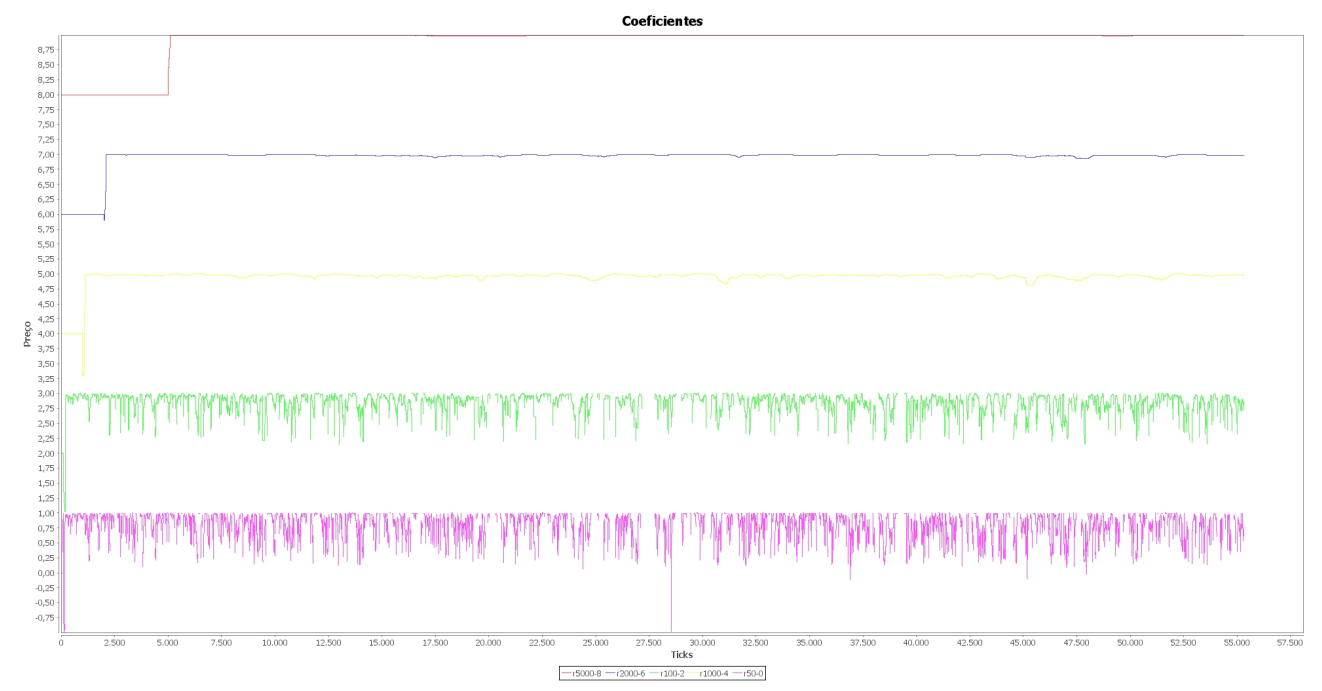

Figura 5.9: Correlação linear entre valor previsto e valor real para a variável op1, do índice DOLG11. Execução realizada considerando-se dados do dia 04 de Janeiro de 2011 para a predição de valores do dia 05 de Janeiro de 2011.

Na seção 5.1 o algoritmo de predição de valores foi separado em quatro partes principais: agrupamento de dados históricos, cálculo de frequência de grupos dado um passado fixo, obtenção de expressões utilizando o método de regressão linear para cada grupo e finalmente a predição de valores propriamente dita. Para realizar a medição de tempo de cada predição realizada pelo algoritmo, somente a última etapa foi considerada, já que as três etapas anteriores podem ser realizadas $a$ priori, por exemplo, antes de o dia cujos valores deseja-se prever iniciar-se. O algoritmo 5.4 contém os passos cujo tempo de execução deseja-se prever. Estes são os seguintes:

- obter o próximo tick

- verificar a qual grupo o último tick conhecido pertence

- Quando a cadeia de grupos tiver o comprimento desejado, consultar a estrutura de dados construída de modo a se verificar a qual grupo $c$ o próximo tick (ainda não conhecido) pertencerá com maior probabilidade, dado o passado

- utilizar a regressão linear associada ao grupo c, multiplicando seus coeficientes pelos valores to último tick conhecido, obtendo o valor previsto

Nos testes realizados, obter o próximo tick significa simplesmente fazer a leitura de uma linha de um arquivo regular armazenado no sistema de arquivos. Em um ambiente real, este item poderia requerer uma conexão direta com o ambiente da bolsa, possivelmente de fibra ótica de modo que os ticks sejam obtidos o mais rápido possível. Verificar a qual grupo o último tick conhecido pertence é uma tarefa muito simples: basta calcular a distância entre este e cada centróide de cada grupo. Manter a cadeia de grupos com tamanho adequado é também uma tarefa muito simples, realizada por algoritmos de processamento de cadeias conhecidos. Obter o grupo que mais provavelmente contém o próximo tick é uma tarefa que pode levar tempo razoável. Na implementação utilizada nos testes aqui descritos, as cadeias foram armazenadas em uma tabela de hash, de modo que as próprias cadeias são as chaves da tabela e um conjunto de $k$ (o número de grupos) inteiros é armazenado como valor associado à cada cadeia. Neste conjunto, cada inteiro representa a quantidade de vezes que um dado grupo ocorreu nos dados históricos, dado que a cadeia atual tenha acontecido. Obter este conjunto de inteiros é realizado em tempo independente do número de chaves que existe na tabela. Fazer a multiplicação de coeficientes por valores é também uma atividade trivial. Fazer a predição de um dado valor, dado que as estruturas apropriadas tenham sido construídas previamente envolve 
portanto somente atividades triviais. Conforme mostram as figuras 5.10 e 5.11, o tempo levado para se fazer uma predição é razoável e revela que o algoritmo descrito neste capítulo tem aplicabilidade.

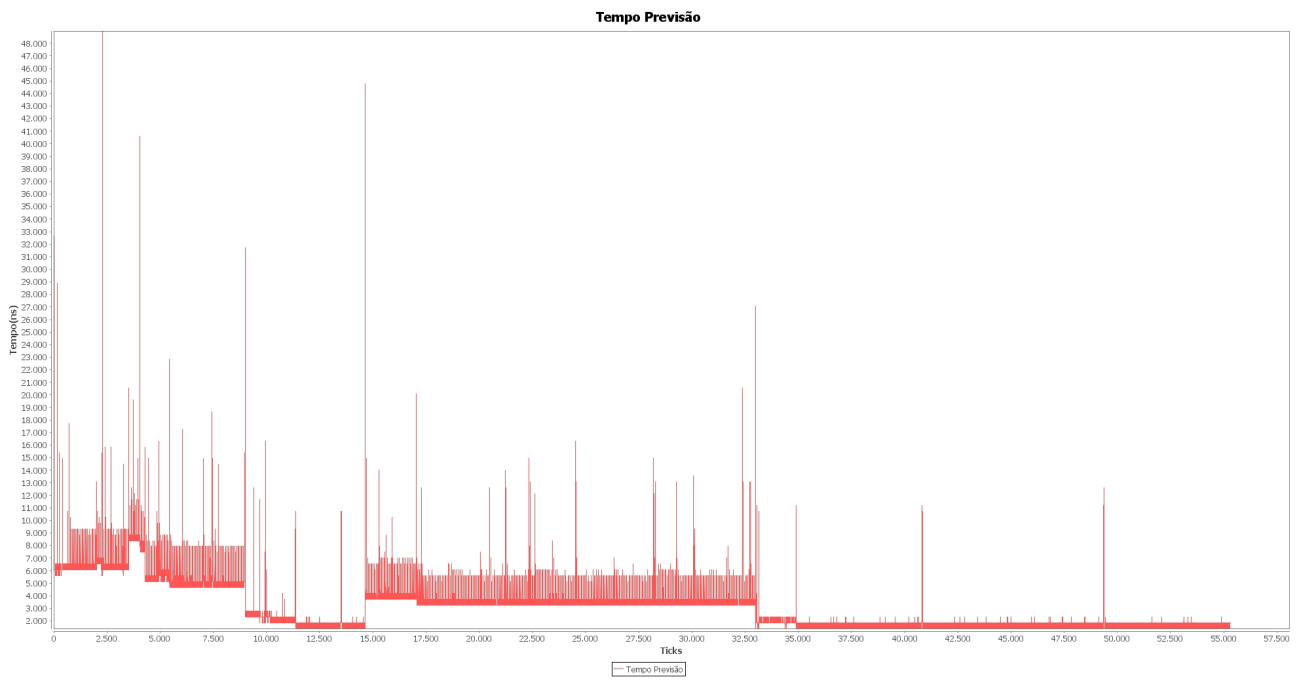

Figura 5.10: Tempo levado para se fazer predições da variável bp1 DOLG11. Execução realizada considerando-se dados do dia 04 de Janeiro de 2011 para a predição de valores do dia 05 de Janeiro de 2011.

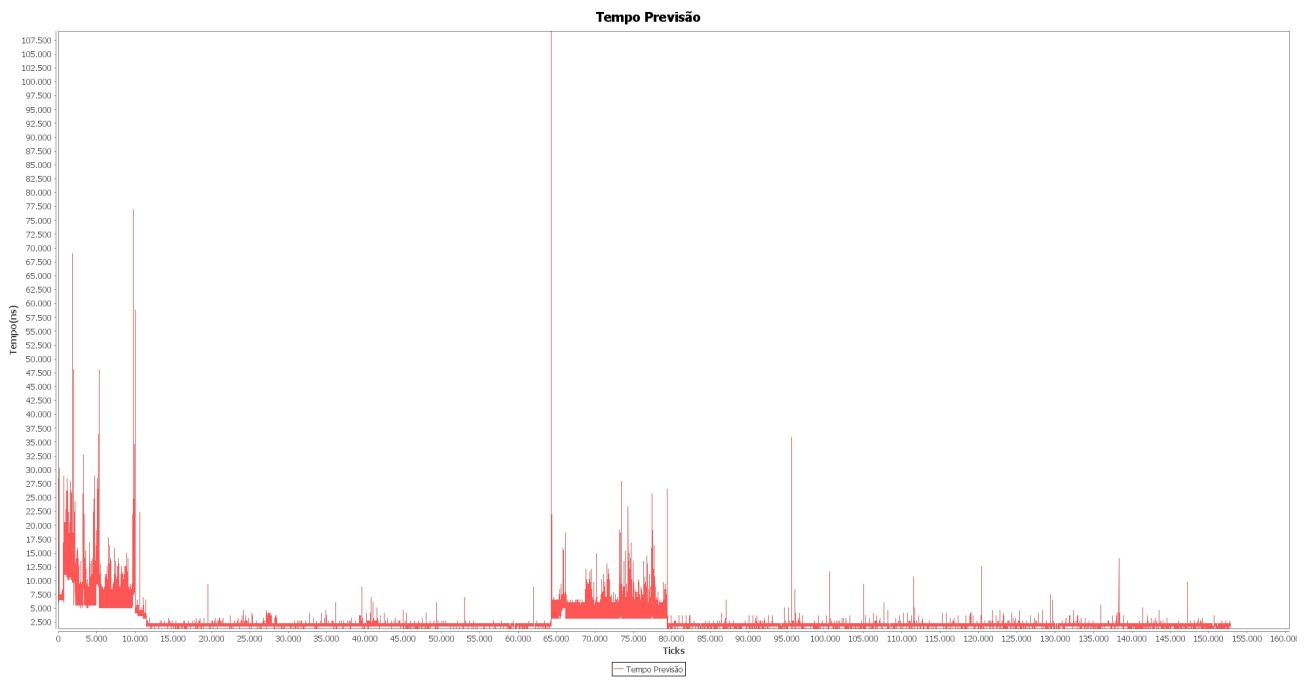

Figura 5.11: Tempo levado para se fazer predições da variável bp1 do índice INDG11. Execução realizada considerando-se dados do dia 07 de Janeiro de 2011 para a predição de valores do dia 13 de Janeiro de 2011. 


\section{Capítulo 6}

\section{Análise dos resultados e trabalhos futuros}

Neste capítulo discute-se sobre os principais resultados obtidos durante o desenvolvimento deste trabalho. Aspectos relacionados à construção do livro de ofertas e sobre o funcionamento do algoritmo de predição de valores proposto são considerados. É proposta uma mudança no algoritmo de predição, de modo que este faça uso mais apropriado dos grupos obtidos pela fase de agrupamento. Também incluem-se sugestões sobre possíveis trabalhos futuros.

\subsection{Sobre a construção do livro de ofertas}

Os dados de alta frequência disponibilizados pela Bovespa são de interesse por possibilitarem análises estatísticas que podem revelar informações interessantes sobre o funcionamento do mercado financeiro. Análises baseadas nestes dados podem dar origem a estratégias e algoritmos de compra e venda de ativos. Tratam-se de dados brutos, que contém informações interessantes bem como partes que podem ser descartadas dependendo do interesse envolvido. Desta forma, antes de obter-se resultados interessantes, faz-se necessário um trabalho de pré-processamento sobre estes dados. Em geral, o livro de ofertas é considerado como o item de maior interesse para o mercado, por conter os valores de ofertas principais ordenados por ocorrência. Neste trabalho realizou-se o pré-processamento de dados de futuros e de ações, de modo a obter-se o livro de ofertas a partir da troca de mensagens registrada. Os dados de futuros são fornecidos pela Bovespa utilizando-se o conhecido protocolo Fix, o que facilita bastante o trabalho envolvendo estes dados. O protocolo Fix organiza as mensagens de uma forma razoavelmente simples e que se mostrou interessante para a construção do livro de ofertas. Em particular, a cada mensagem que representa uma oferta, seja de compra ou venda, inclui-se um campo que determina o quão competitiva é aquela oferta para o mercado no momento em que a mensagem foi enviada. Durante a construção do livro de ofertas envolvendo estes dados, este campo revelou-se particularmente útil e possibilitou o uso de estruturas de dados bastante simples para representar o livro de ofertas. Um outro campo que mostrou-se fundamental para a construção do livro de ofertas foi aquele que representa o status da oferta. Utilizando este campo é possível determinar a forma como cada mensagem tratada influencia o conteúdo da estrutura de dados que representa o livro de ofertas. Por exemplo, uma dada mensagem pode indicar que uma oferta de compra deve ser removida do livro ou que um negócio foi concretizado. Isto é feito utilizando este campo. O trabalho mostra e discute sobre estruturas de dados que podem ser apropriadas para a representação de uma mensagem de acordo com o protocolo Fix. Em particular, esta análise possibilitou a obtenção de um algoritmo para construção do livro de ofertas que oferece uma melhora significativa (considerando tempo de execução e consumo de memória) quando comparado ao algoritmo proposto em [dMGU12].

Os dados de ações oferecidos pela Bovespa não estão de acordo com o protocolo Fix. Apesar disso, existem similaridades entre estes dados e os dados de acordo com o protocolo Fix a se consi- 
derar. Por exemplo, cada mensagem possui um campo que indica seu status, o que deve ser usado para que a construção do livro de ofertas se dê corretamente. Embora os dados de ações contenham este campo, não está claro exatamente o significado de cada possível status de mensagem. Acreditase que seja possível fazer a extração do livro de ofertas utilizando-se estes dados utilizando um algoritmo similar ao algoritmo 4.2, bastando-se para isso o entendimento sobre o campo de status presente nestes dados. A evidência de que o algoritmo 4.2 ainda não está completo é que o livro de ofertas obtido contém entradas em que a oferta de compra mais interessante possui valores maiores do que aqueles da oferta de venda mais interessante.

Diferentemente dos dados de futuros, os dados de ações não contém um campo que indica a competitividade de cada oferta. Assim, faz-se necessário o estabelecimento de algum critério de competividade entre as ofertas. O critério utilizado envolve o valor da oferta, bem como o momento em que esta aconteceu: ofertas de venda com valores mais baixos são mais interessantes e caso haja empate é considerada mais interessante aquele que ocorreu primeiro. Analogamente, ofertas de compra com valores mais altos são as mais interessantes e o critério de desempate é o mesmo.

Também diferente dos dados de futuros, os dados de ações não contém múltiplas ofertas em uma única mensagem. Cada mensagem contém uma única oferta (ou informação de negócio concretizado). Assim, é dispensável a construção de uma estrutura de dados que permita a manipulação eficiente de uma única mensagem, assim como proposto para os dados de futuros.

\subsection{Sobre o algoritmo de predição de valores}

O algoritmo de predição proposto neste trabalho e descrito na seção 5.1 utiliza técnicas de mineração de dados como agrupamento e regressão linear para fazer predições de valores de uma variável escolhida. Esta predição é realizada utilizando-se os valores de outras variáveis que possuam razoável correlação linear com a variável cujos valores deseja-se prever. O algoritmo foi testado utilizando-se livros de ofertas de dados de futuros somente. Os livros de ofertas são sempre compostos por ticks ordenados de acordo com sua ocorrência. Para a execução do algoritmo, os ticks foram considerados como compostos pelas seguintes variáveis:

- cinco ofertas de compra mais interessantes, juntamente com seus volumes associados

- cinco ofertas de venda mais interessantes, juntamente com seus volumes associados

Para a execução do algoritmo, uma destas variáveis é escolhida como aquela cujos valores desejase prever. Durante as fases de agrupamento e cálculo de coeficientes utilizando o método de regressão linear, a variável escolhida não é considerada. Ou seja, a predição é feita somente utilizando-se os valores das demais variáveis que compõem os ticks. Esta estratégia foi escolhida de modo a averiguar-se a influência que o contexto como um todo tem sobre uma dada variável. Por exemplo, pode-se indagar se as variações de determinadas variáveis têm influência direta na variação de uma variável escolhida. As execuções realizadas e relatadas neste trabalho mostram que uma variável escolhida pode ter seu valor previsto em função de todas as demais. A maneira como o algoritmo de predição foi projetado, permite que seja escolhida a variável cujos valores deseja-se prever bem como as variáveis cujos valores deseja-se considerar durante a predição. Por exemplo, pode-se informar a priori que somente parte das variáveis que compõem o livro de ofertas sejam consideradas para realizar-se a predição de valores de uma variável escolhida.

Quando a variável cujo valor deseja-se prever é op1, os coeficientes calculados utilizando-se o método de regressão linear mostram sempre uma característica em comum. Os coeficientes associados às variáveis $o p 2$ e $b p 1$ têm valores bem próximos de 0.5 enquanto os coeficientes associados às demais variáveis têm, em geral, valor menor do que um décimo. O mesmo ocorre quando a predição 
é realizada para diferentes variáveis. Algumas poucas variáveis têm peso alto enquanto as demais têm peso quase irrelevante.

Para a execução dos testes, um dia foi escolhido como aquele cujos valores deseja-se prever e um outro dia, em geral anterior a este, foi escolhido como o histórico a ser considerado para a construção do modelo utilizado na predição. Três formas diferentes de execução foram consideradas.

- execução do algoritmo de predição utilizando-se um modelo construído com base nos dados de um único dia anterior completo

- execução do algoritmo de predição utilizando-se um modelo construído com base em dois dias anteriores

- execução do algoritmo de predição utilizando-se um modelo construído com base em apenas metade dos dados de um dia anterior

Para a execução que considera o modelo construído utilizando-se somente metade dos dados de um dia anterior, foram removidos o primeiro e o quarto quartos das mensagens. Para a execução que considera os dados de dois dias, estes dados foram unidos um após o outro, sem a remoção de qualquer item.

As execuções baseadas em um ou dois dias completos mostram resultados bastante similares. Os resultados pioram bastante (por exemplo, a diferença entre preço previsto e preço real aumenta) quando considera-se somente metade de um dia anterior para a construção do modelo de predição.

\subsubsection{Uma proposta de alteração para o algoritmo de predição}

O algoritmo de predição apresentado neste trabalho sugere que faça-se uso de agrupamento de modo a se obter equações que melhor descrevam o valor da variável cujo valor deseja-se prever pertencente ao tick que está por ocorrer. Por exemplo, se o próximo tick mais provavelmente pertence a um grupo $j$, então utilizam-se os coeficientes associados a este grupo para que o valor previsto seja calculado. Presume-se que o tick que está por ocorrer está próximo daqueles que pertencem ao grupo $j$ e portanto a equação associada a este grupo é a que melhor descreve a relação entre a variável cujos valores deseja-se prever e as demais variáveis. Apesar disso, o algoritmo proposto multiplica o último tick conhecido pelas coeficientes desta equação, o que talvez não seja ideal já que o algoritmo desconsidera o grupo a que pertence o último tick conhecido. Ou seja, em determinados momentos pode ser que o algoritmo multiplique os valores de um tick pertencente a um grupo $i$ pelos coeficientes associados a um grupo $k \operatorname{com} i \neq k$. Desta forma, sugere-se uma alteração para o algoritmo. $\mathrm{O}$ algoritmo deve armazenar, para cada grupo, o último tick que pertence àquele grupo. Assim, ao realizar a predição, o algoritmo não mais multiplica os valores do último tick conhecido pelos coeficientes associados ao cluster ao qual o próximo tick mais provavelmente pertence. Ao invés disso, ele multiplica os coeficientes pelos valores do último tick conhecido que pertença àquele grupo. O último tick conhecido que pertença ao grupo ao qual o próximo tick mais provavelmente pertence intuitivamente está próximo a este tick. E a equação associada ao grupo ao qual estes pertencem é aquela que melhor descreve a relação entre suas variáveis. Assim, presume-se que esta estratégia permite que se obtenha valores previstos mais próximos dos valores reais. Esta sugestão é mostrada pelo algoritmo 6.1 . 


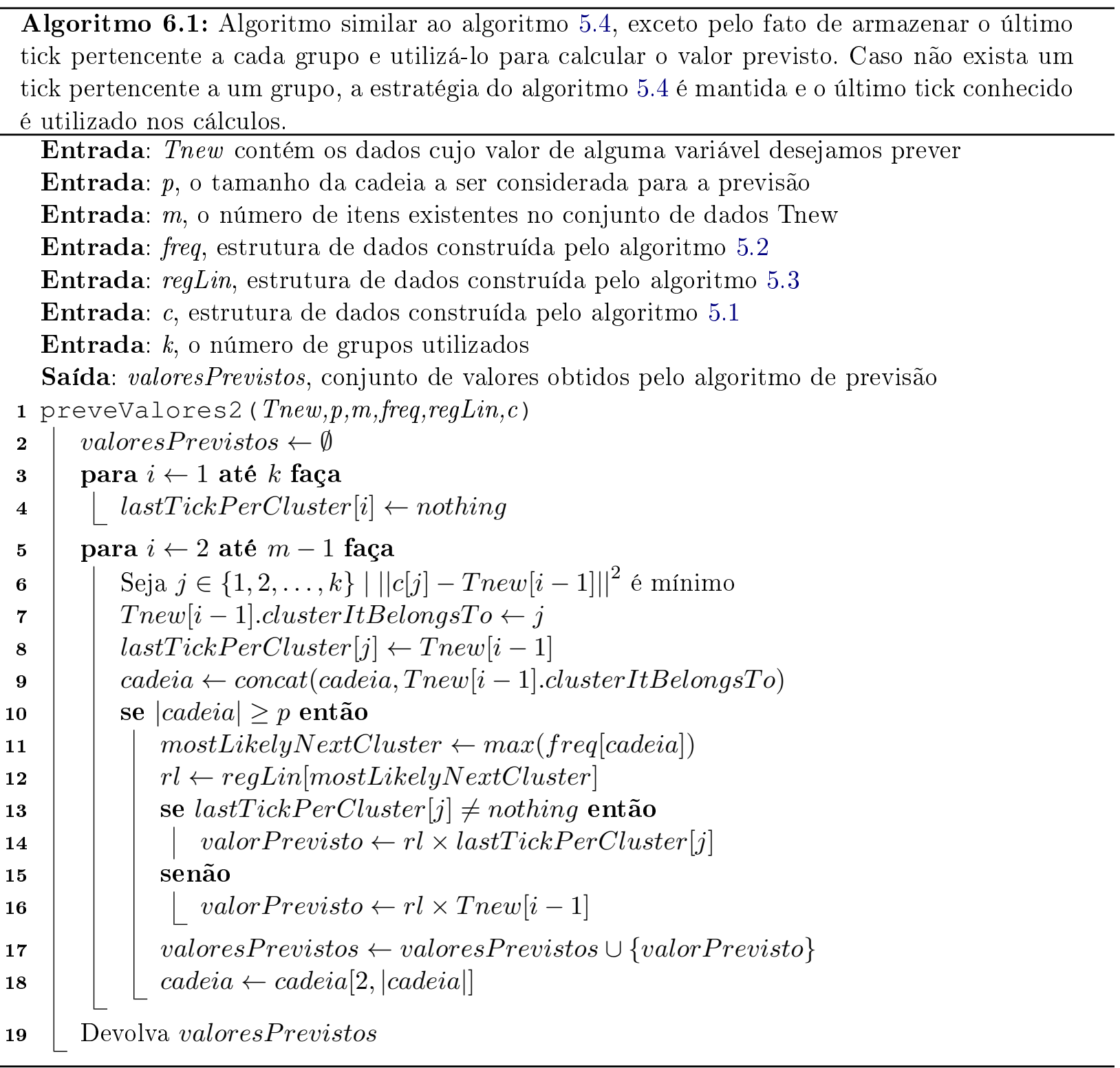

O algoritmo 6.1 é idêntico ao algoritmo 5.4 exceto pelo fato de armazenar o último tick conhecido para cada grupo. Para calcular o valor previsto, verifica-se se existe um tick armazenado como sendo o último ocorrido que pertence ao grupo de interesse. Caso exista, este é utilizado. Caso contrário, o funcionamento do algoritmo 6.1 é exatamente o mesmo do algoritmo 5.4 e o último tick conhecido é utilizado para calcular-se o valor previsto.

\subsection{Trabalhos futuros}

O presente trabalho oferece um algoritmo eficiente para a construção do livro de ofertas a partir de dados de alta frequência de que estejam de acordo com o protocolo Fix. Poder-se-ia averiguar se alguma outra estrutura de dados se mostra apropriada para a representação de uma mensagem de acordo com o protocolo Fix e então verificar se o desempenho computacional do algoritmo foi melhorado considerando-se tempo de execução e consumo de memória. 
Enquanto a construção do livro de ofertas de dados de futuros foi feita adequadamente, o mesmo não é verdade para os dados de ações. O campo de status das mensagens destes dados parece ser o último impecilho para que se possa fazer a construção do livro de ofertas com sucesso. Assim, pode-se pesquisar mais a fundo sobre estes dados e identificar os status de ofertas que indicam que estas devem ou não ser incluídas no livro de ofertas.

Quanto ao algoritmo de predição, faz-se algumas observações. Os testes de predição foram todos executados utilizando-se as vinte variáveis que compõem cada tick. Apesar disso, averiguou-se que a correlação linear entre duas variáveis que representam preços (por exemplo, op1 e op2) é sempre muito alta e estável enquanto a correlação linear entre duas variáveis que representam preço e volume (por exemplo, op 1 e os2) nem sempre é estável ou existe. Assim, sugere-se a execução do algoritmo de predição de valores utilizando-se somente um conjunto reduzido de variáveis para se fazer a predição. Observa-se que o método de regressão linear, em geral, identifica algumas poucas variáveis que têm forte influência no valor da variável prevista. Por exemplo, quando executa-se o algoritmo de predição para prever os valores da variável op 1 , invariavelmente os coeficientes obtidos para as variáveis op 2 e $b p 1$ têm valor muito superior àqueles obtidos para as demais variáveis. Diante desta observação, pode ser interessante executar-se o método de regressão linear a fim de identificar quais variáveis podem ser interessantes para a predição de valores de uma dada variável. A instável correlação entre variáveis de preço e volume pode indicar que melhores resultados podem ser obtidos se um desses conjuntos de variáveis for desconsidado na execução do algoritmo para predição de valores de uma variável do outro conjunto. Por exemplo, para realizar a predição de valores da variável $o p 1$, talvez seja interessante considerar somente variáveis de preço.

O agrupamento é realizado utilizando-se somente dados históricos. Cada tick que ocorre no dia cujos valores deseja-se prever é comparado com os centróides de cada um dos grupos obtidos a fim de verificar-se a qual grupo este tick pertenceria. Desta forma, uma vez formados os grupos, estes nunca são alterados. $\mathrm{O}$ algoritmo de predição pode ser alterado de modo a fazer com que cada tick do dia atual seja adicionado ao grupo a que pertenceria. Assim, a cada tick ocorrido, existe a possibilidade de a estrutura de grupos ser alterada. Dessa forma as variações conhecidas do dia atual passariam a ter maior impacto nas predições, eventualmente dando origem a melhores resultados. É preciso observar, porém, que tal estratégia teria grande impacto no tempo levado para se fazer uma predição, o que pode comprometer a aplicabilidade do algoritmo.

Uma outra alteração é sugerida para o algoritmo de predição de valores. Este poderia ser alterado de modo a se realizar a predição de um número maior de valores para uma dada variável. Por exemplo, ao invés de prever-se somente o próximo valor da variável escolhida, poder-se-ia realizar a predição para um número $p$ de valores. Esta alteração pode melhorar a aplicabilidade do algoritmo, pois caso um número grande de valores de uma dada variável possa ser previsto de uma só vez, podem ser encontrados pontos de máximo ou mínimo que podem indicar o momento adequado para realizar-se uma compra ou venda. 


\section{Apêndice A}

\section{Gráficos}

Este apêncice mostra gráficos obtidos durante o desenvolvimento deste trabalho. Estes são divididos de acordo com os índices e variáveis aos quais se referem bem como quanto aos aspectos considerados. Primeiro são mostrados gráficos que exibem a diferença entre o valor previsto pelo algoritmo e o valor real. Em seguida, é mostrada a correlação linear encontrada entre valor previsto e valor real. 
GRÁFICOS 36

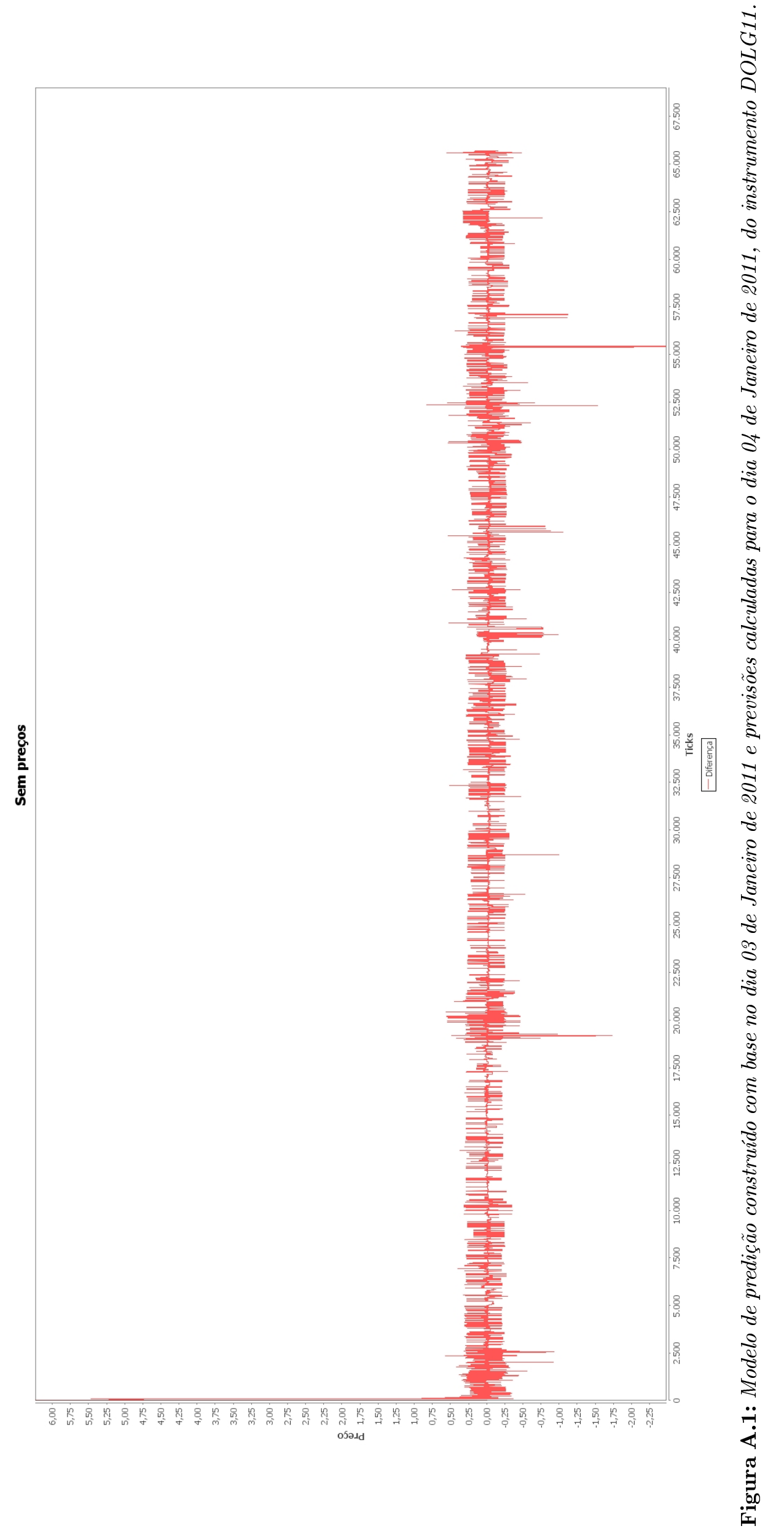


GRÁFICOS

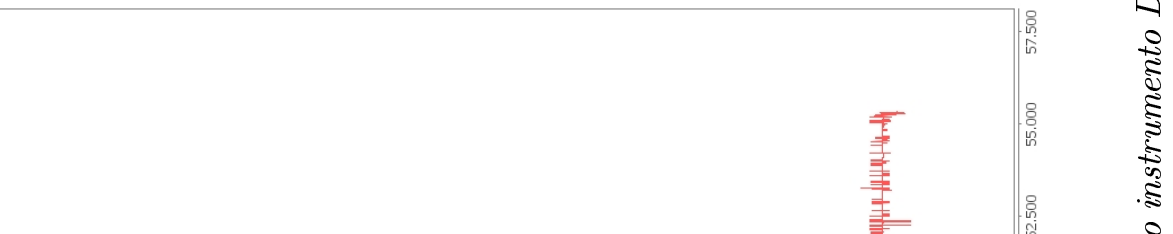

త్ 
GRÁFICOS 38

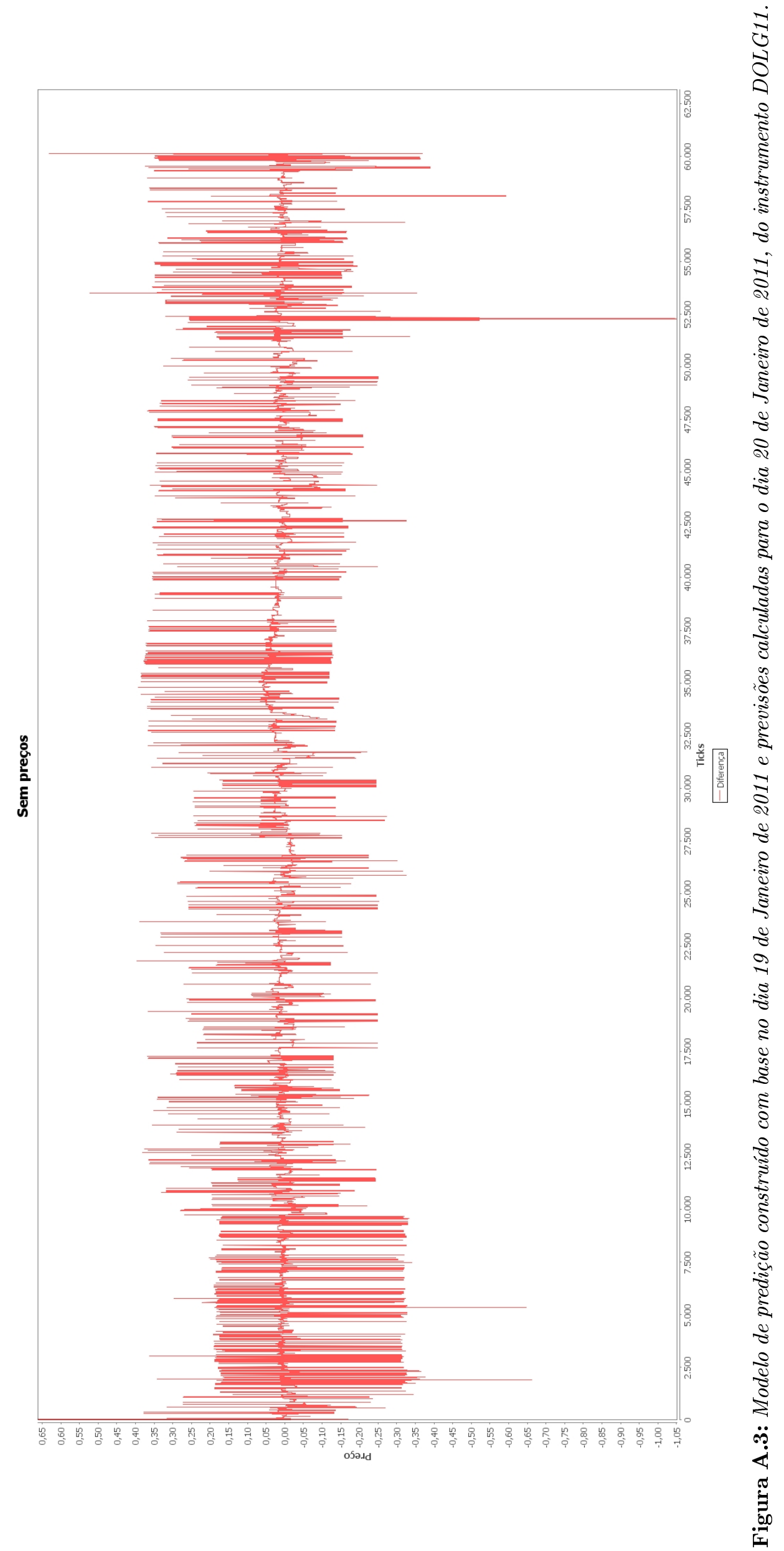


GRÁFICOS 39

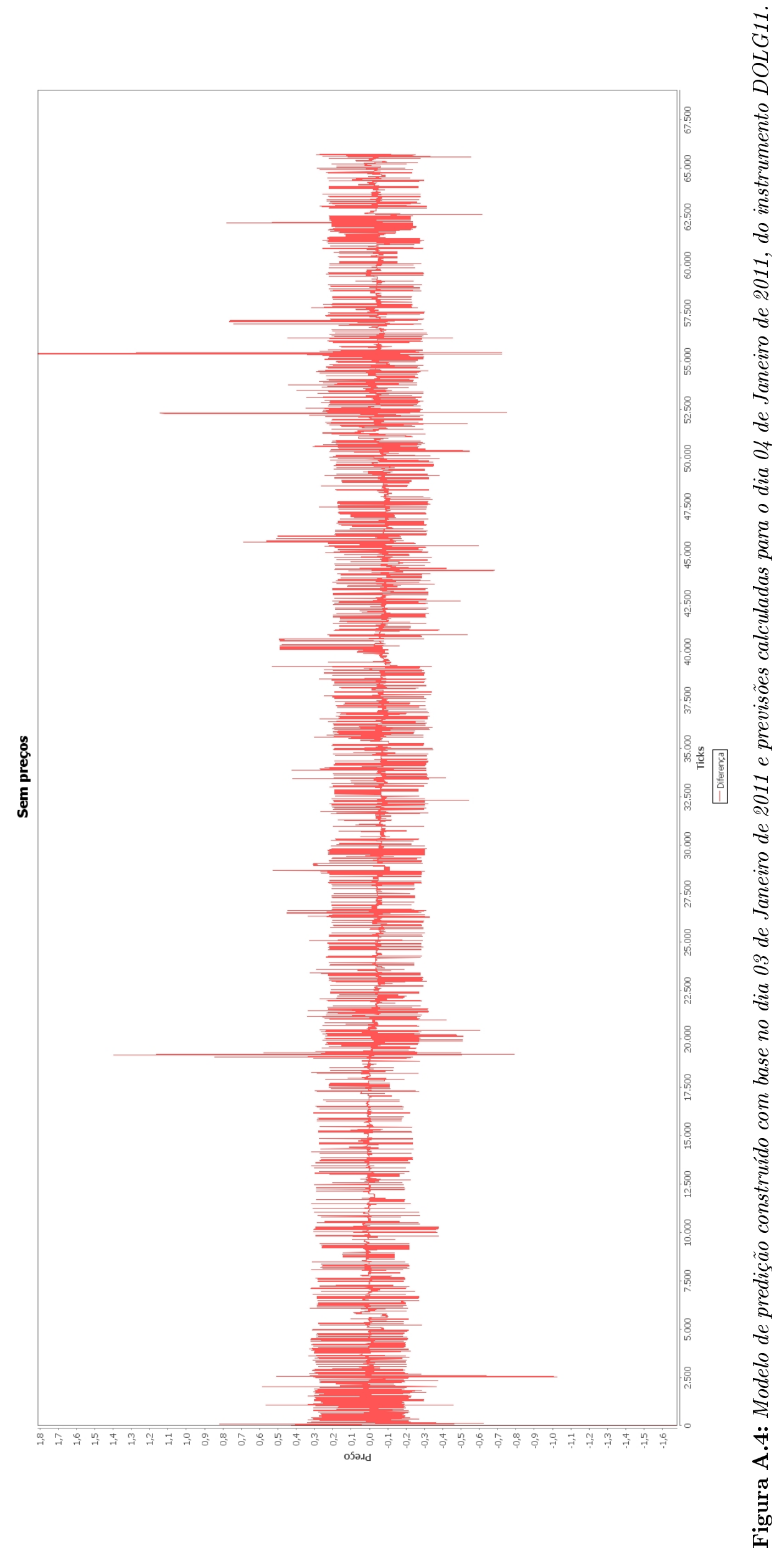


GRÁFICOS

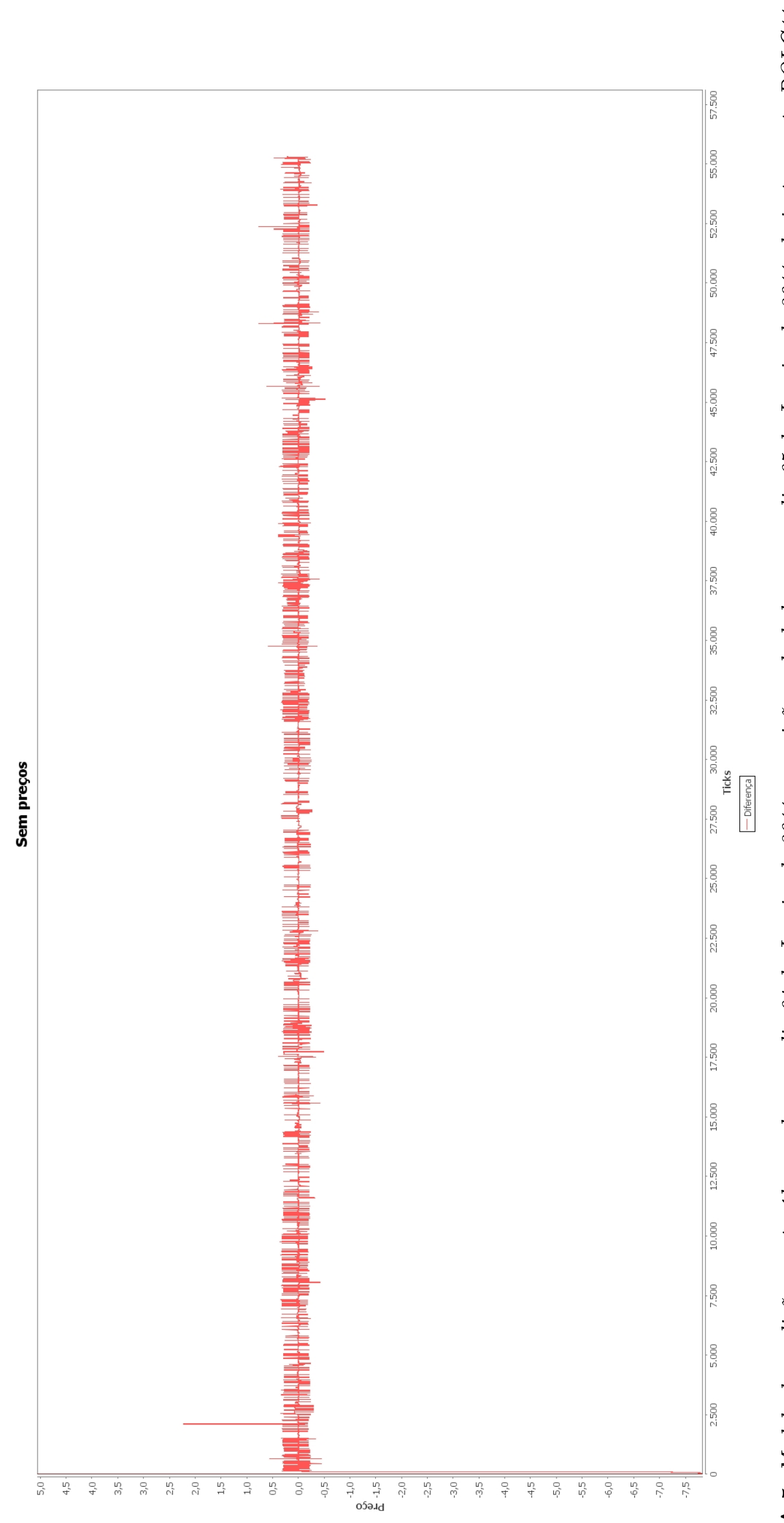

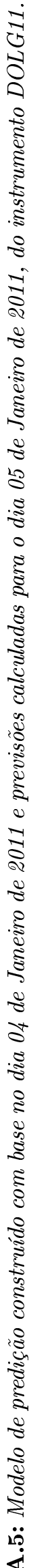


GRÁFICOS $\quad 41$

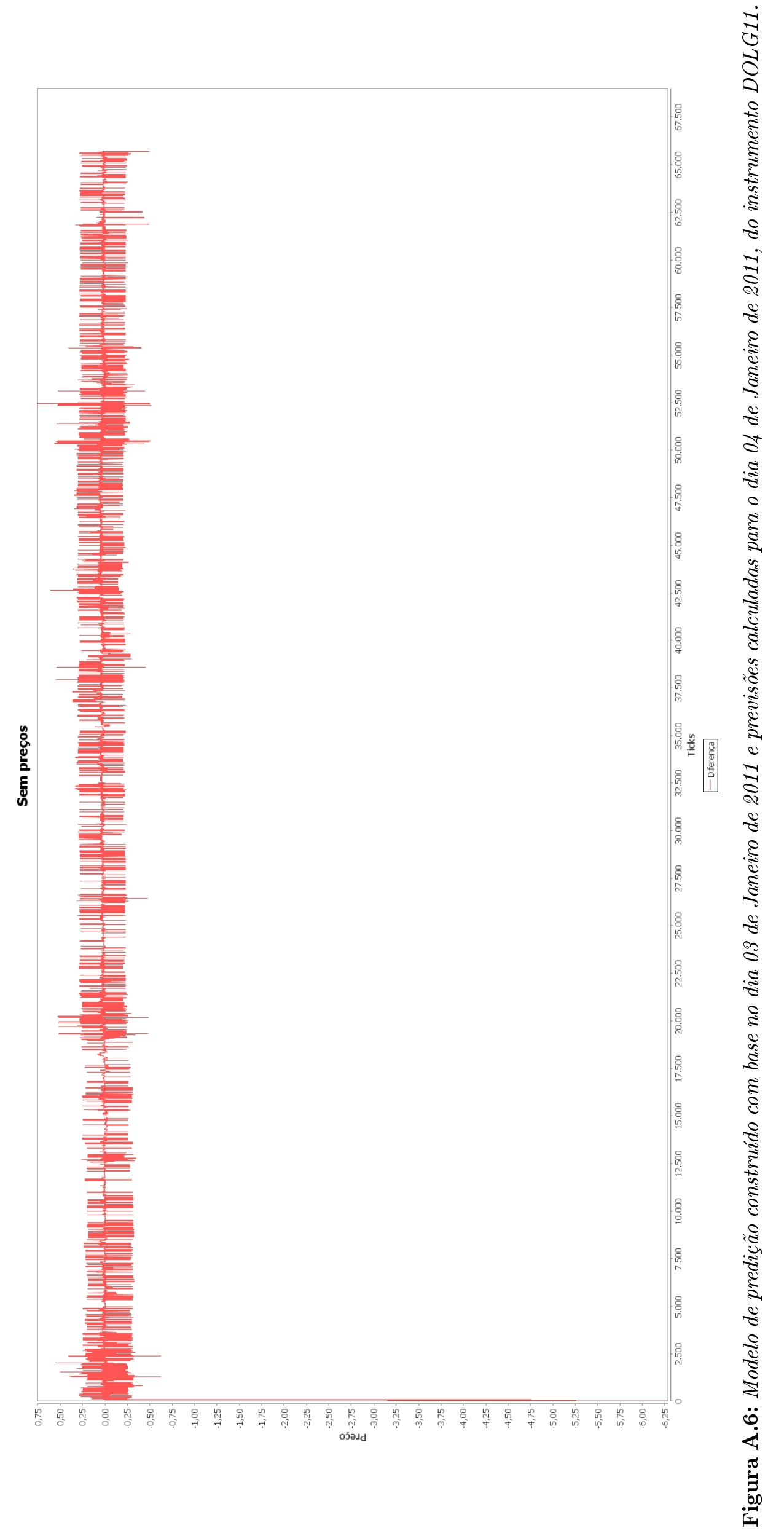




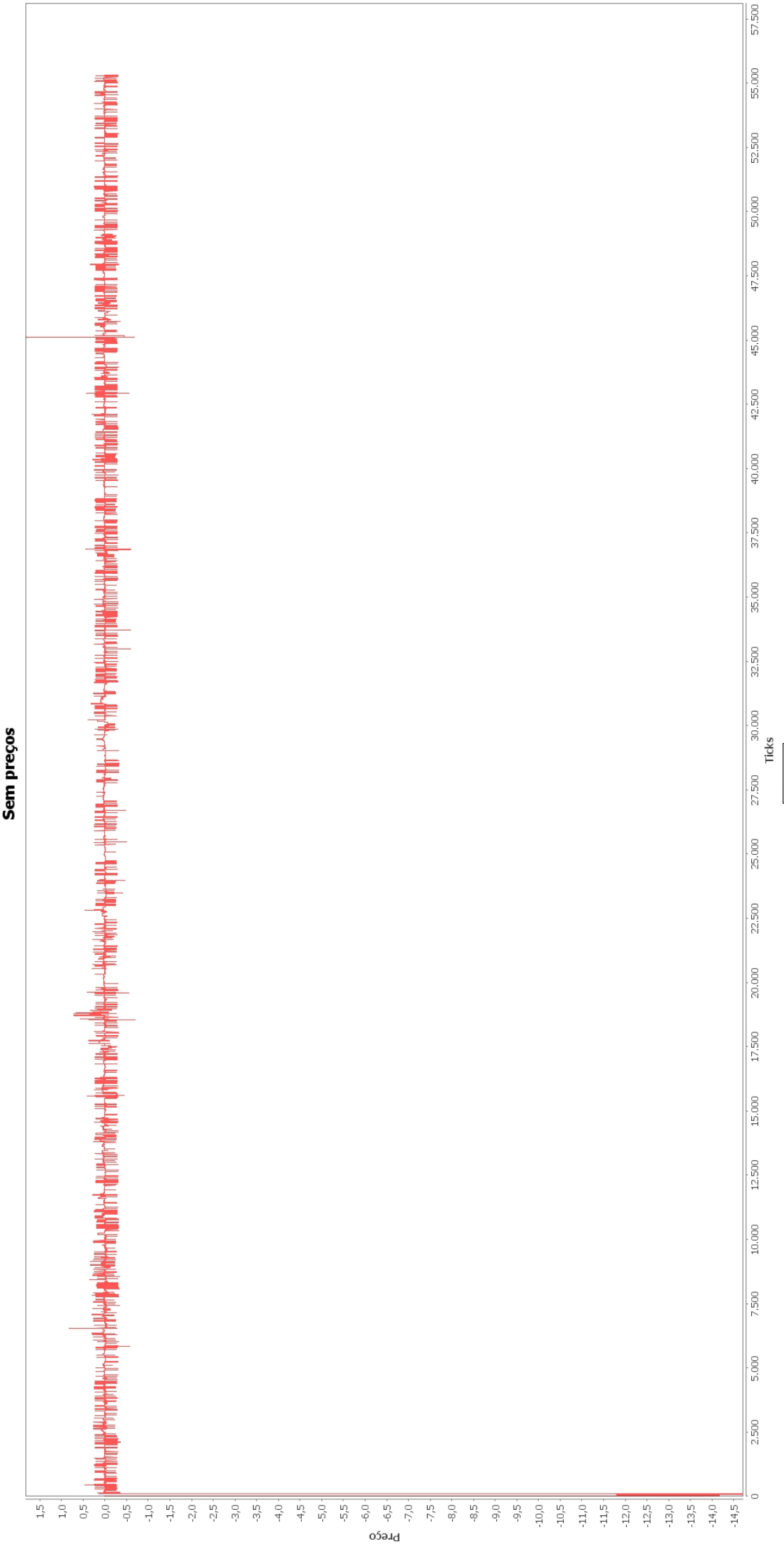




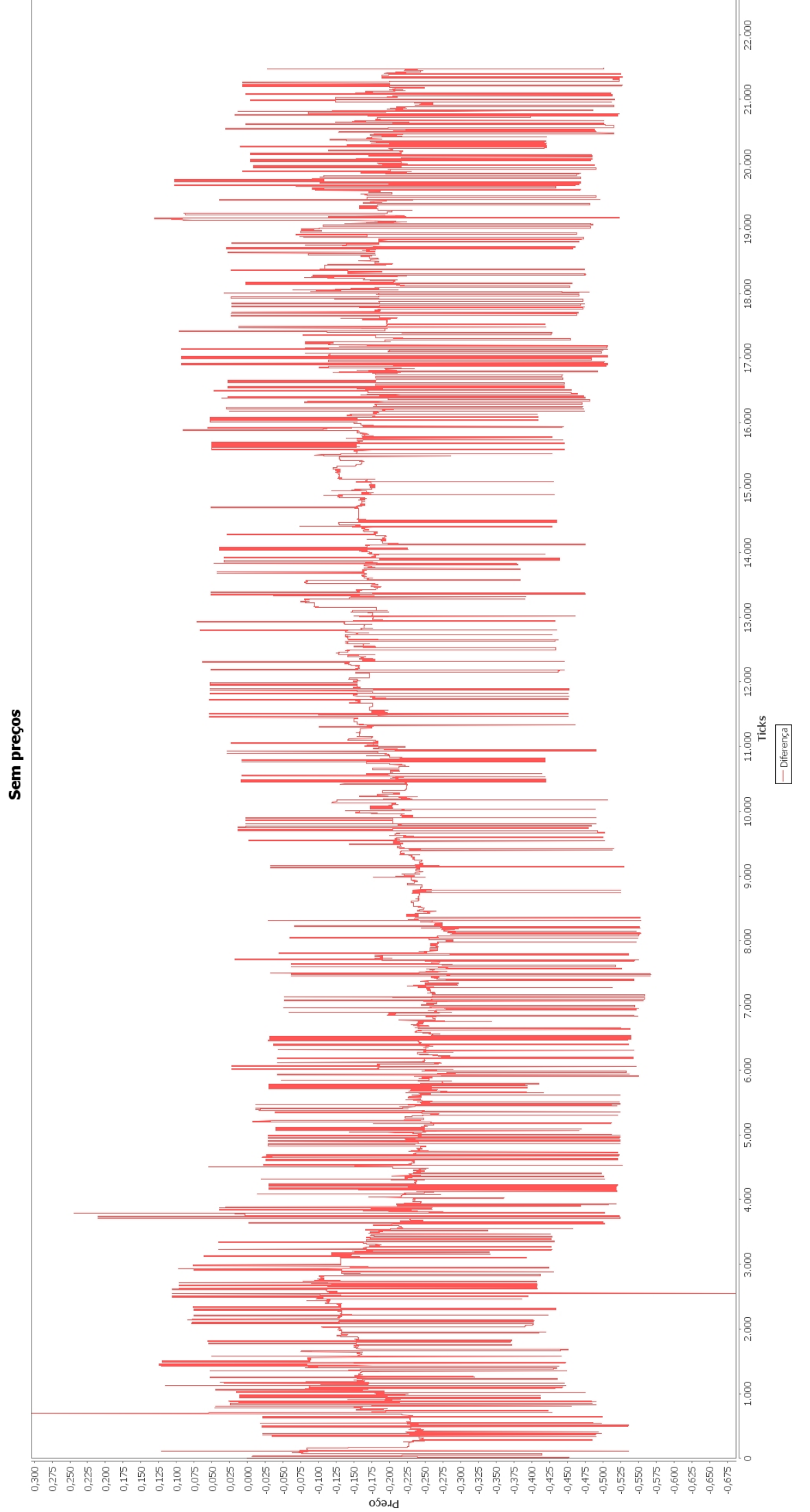


GRÁFICOS 44

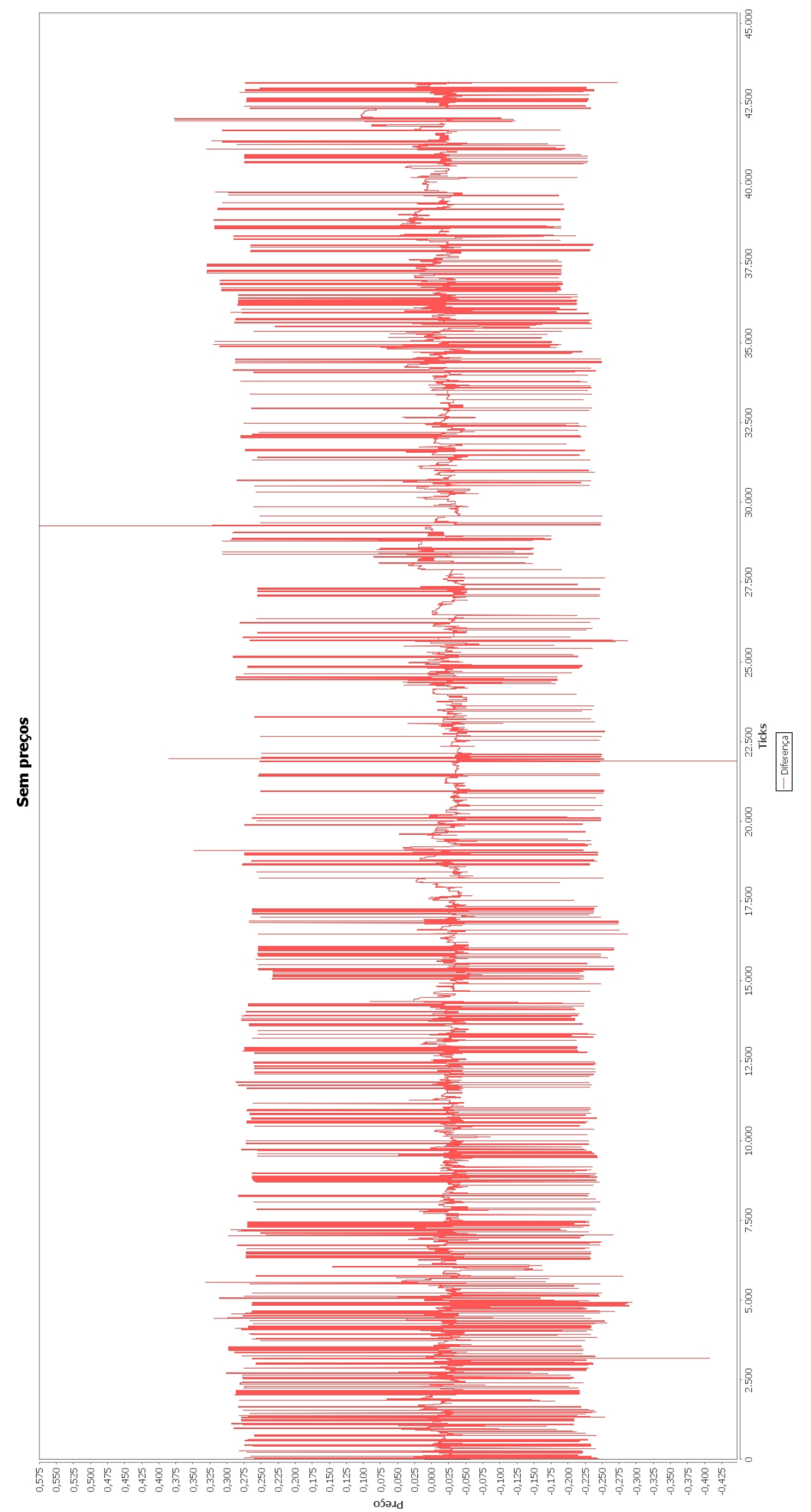




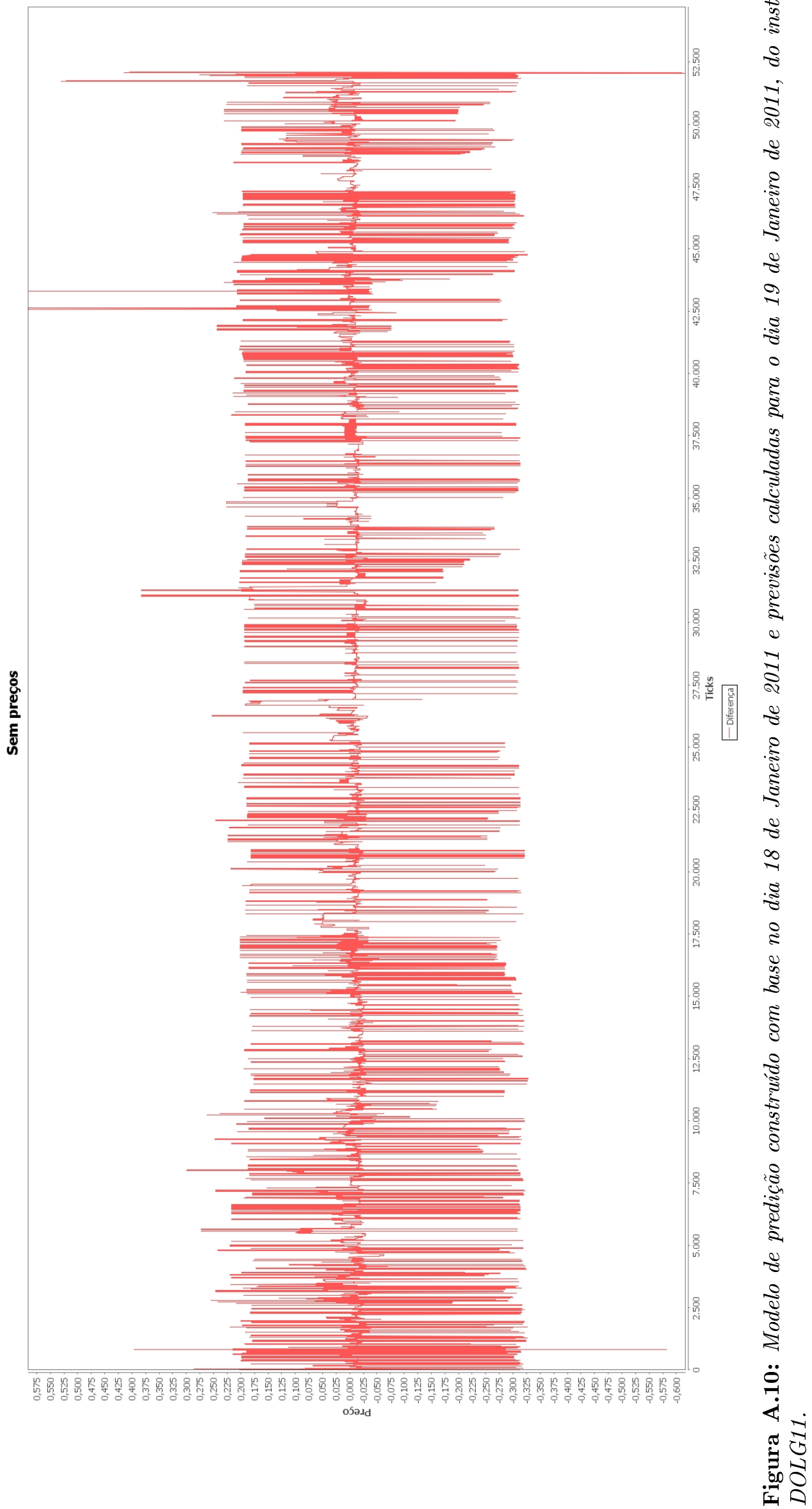


GRÁFICOS 46

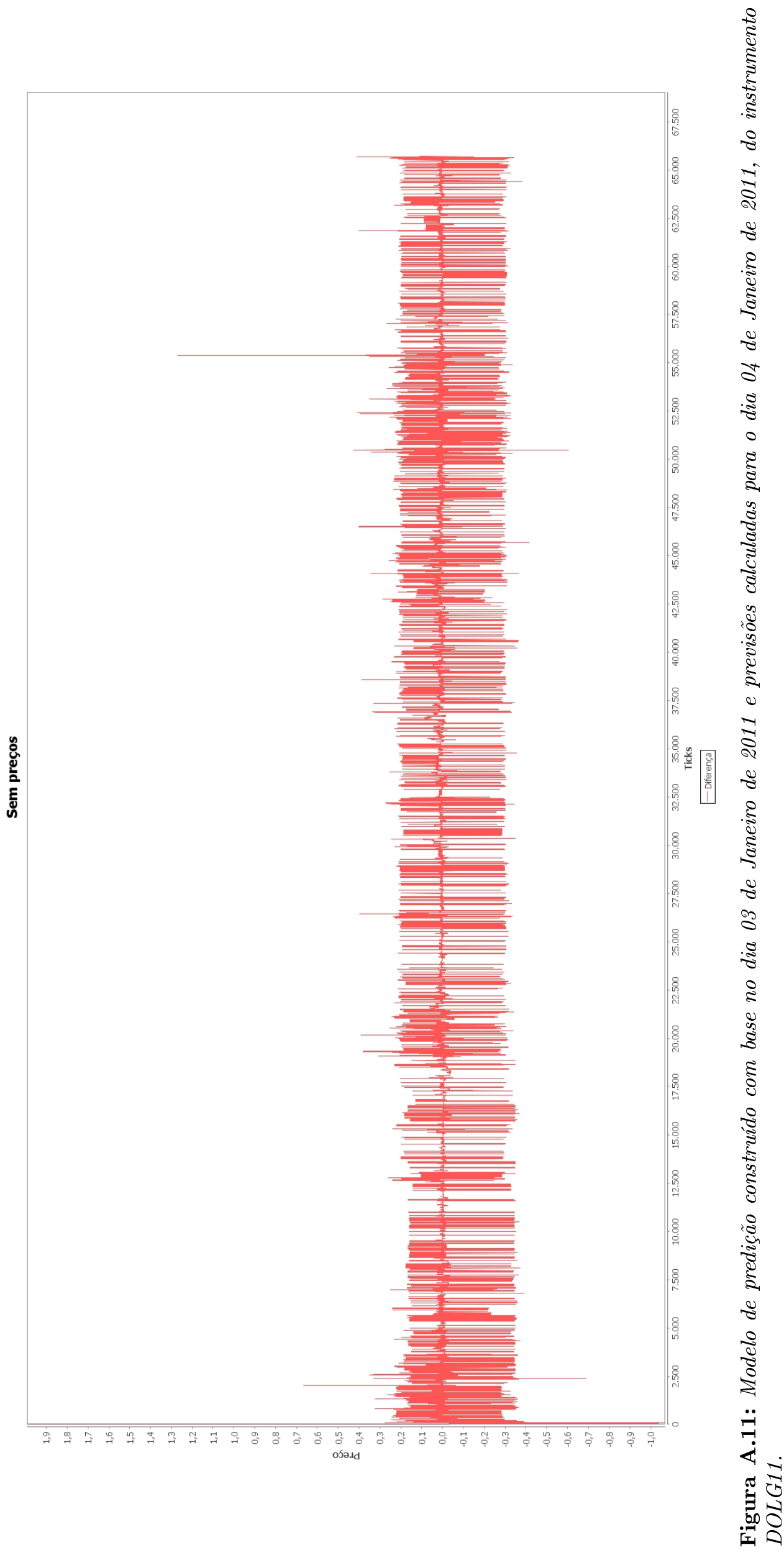




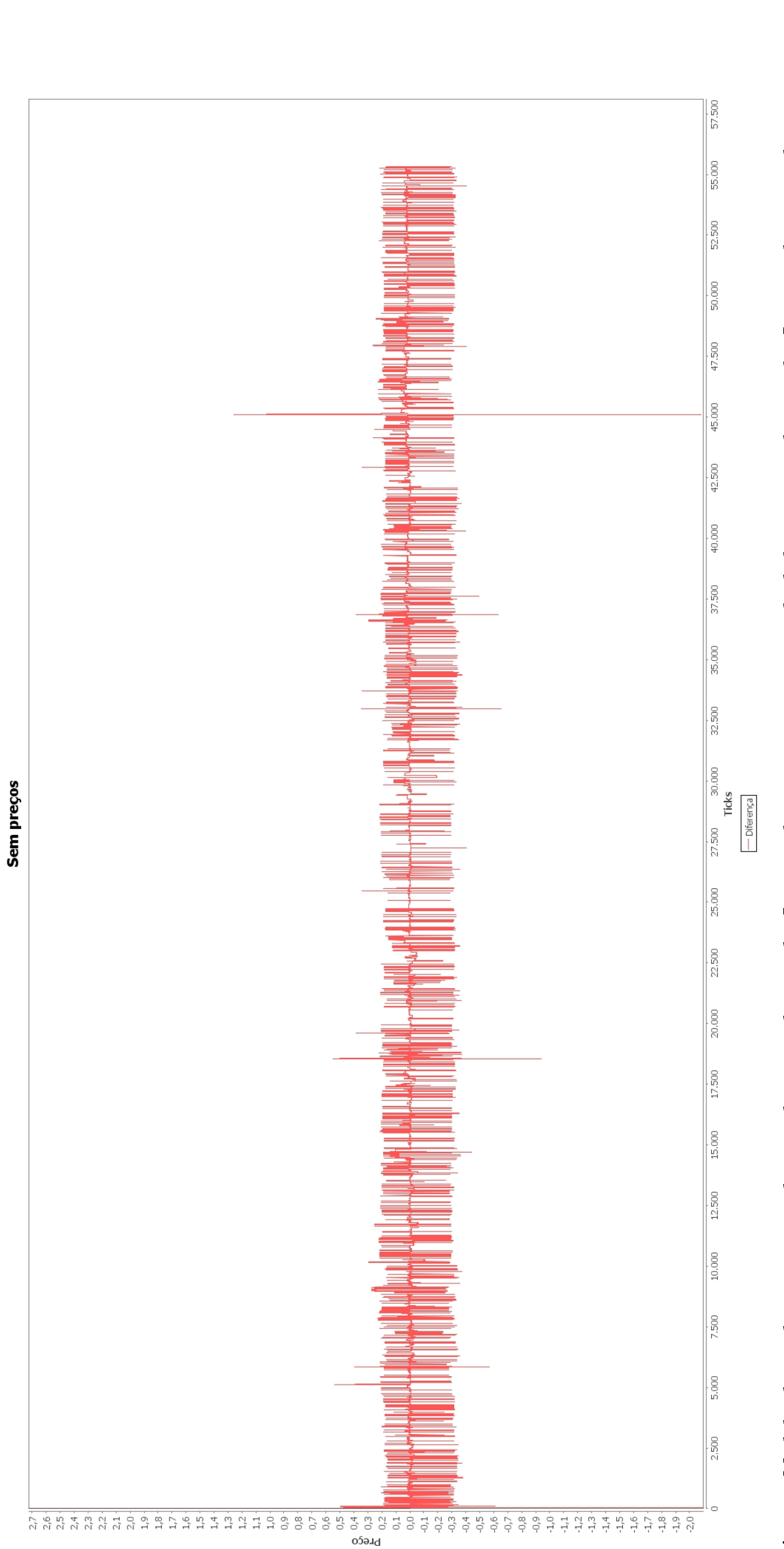


GRÁFICOS 48

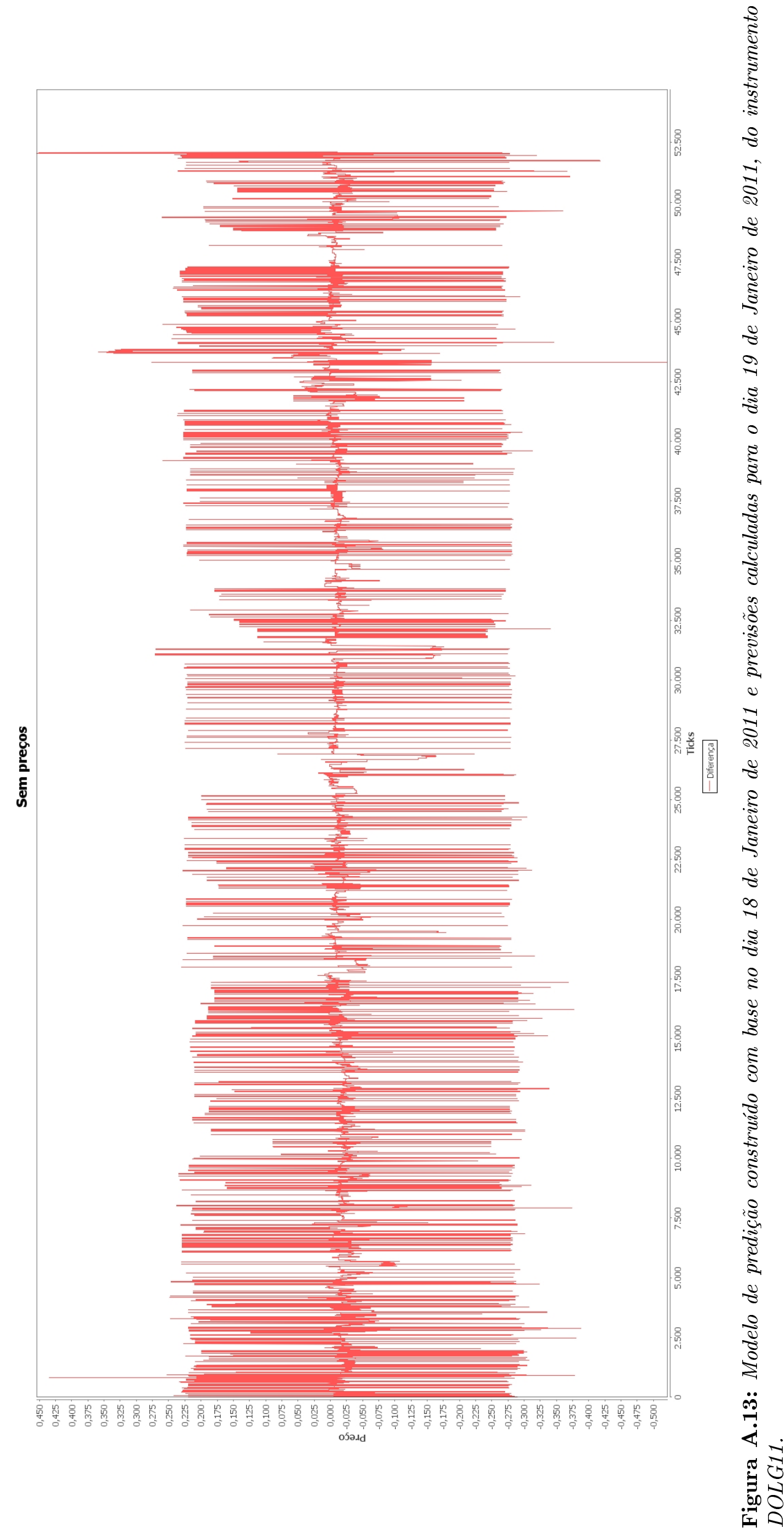


GRÁFICOS 49

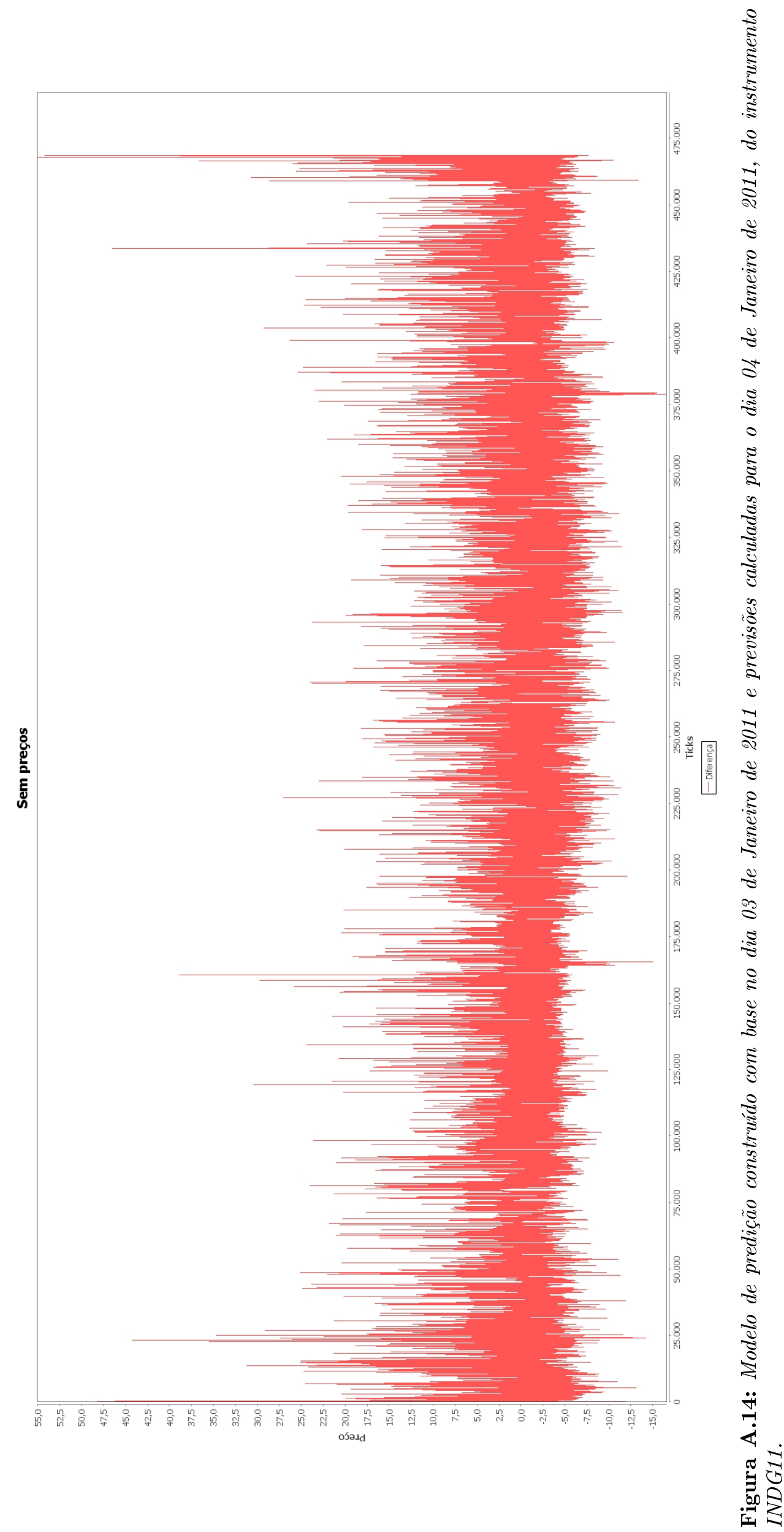


GRÁFICOS 50

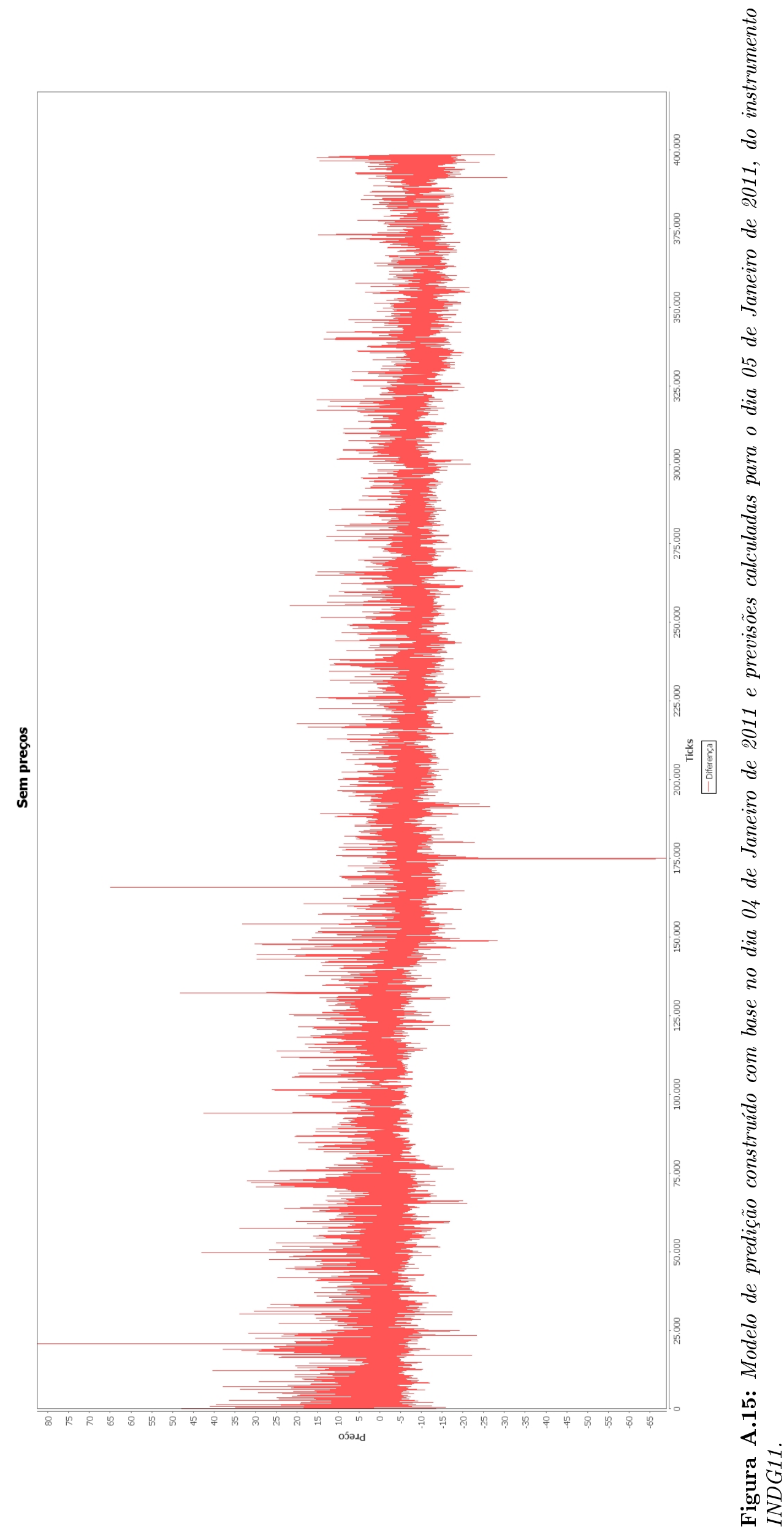


GRÁFICOS $\quad 51$

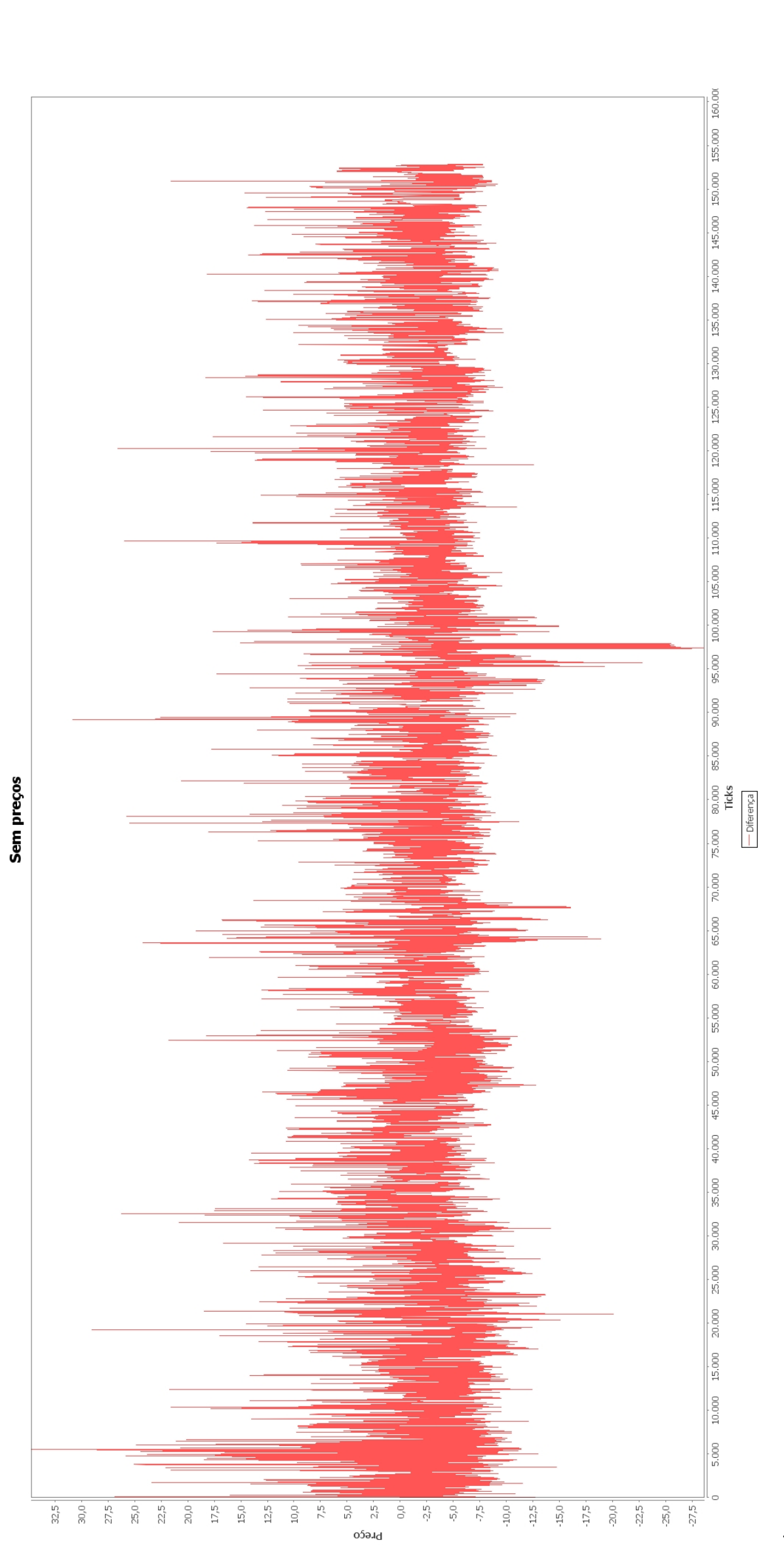


GRÁFICOS 52

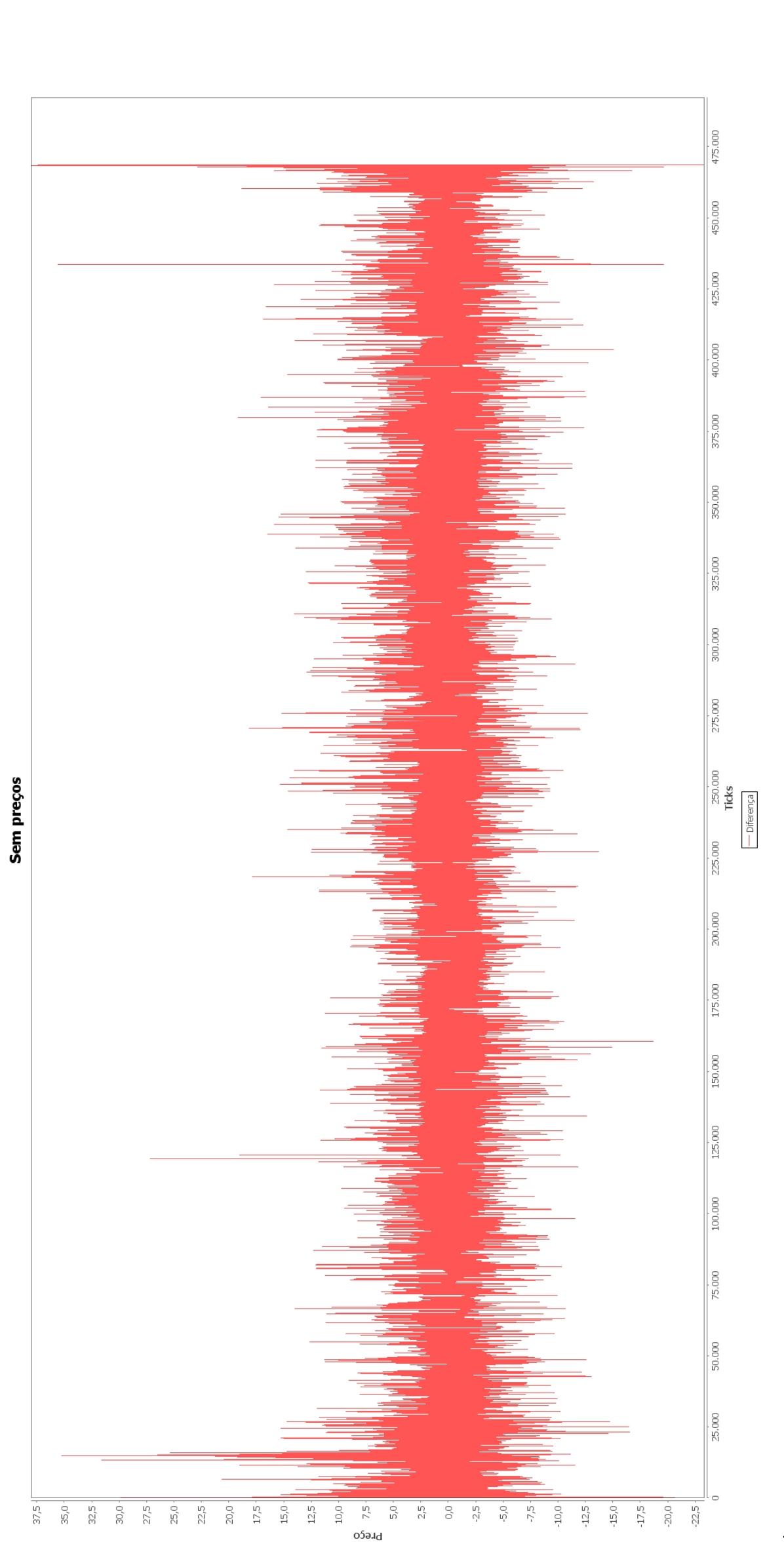

:

茫 
GRÁFICOS 53

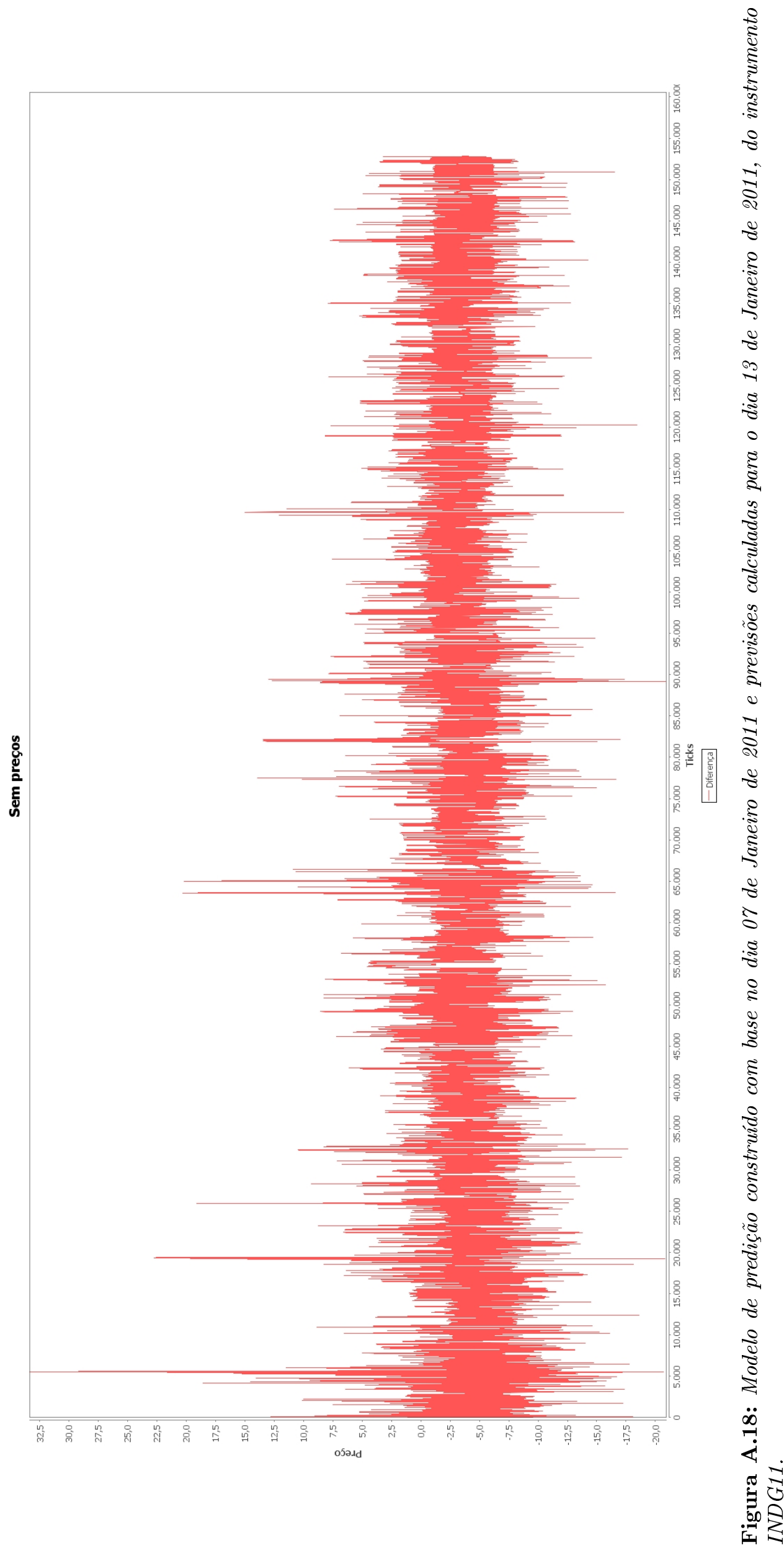


GRÁFICOS $\quad 54$

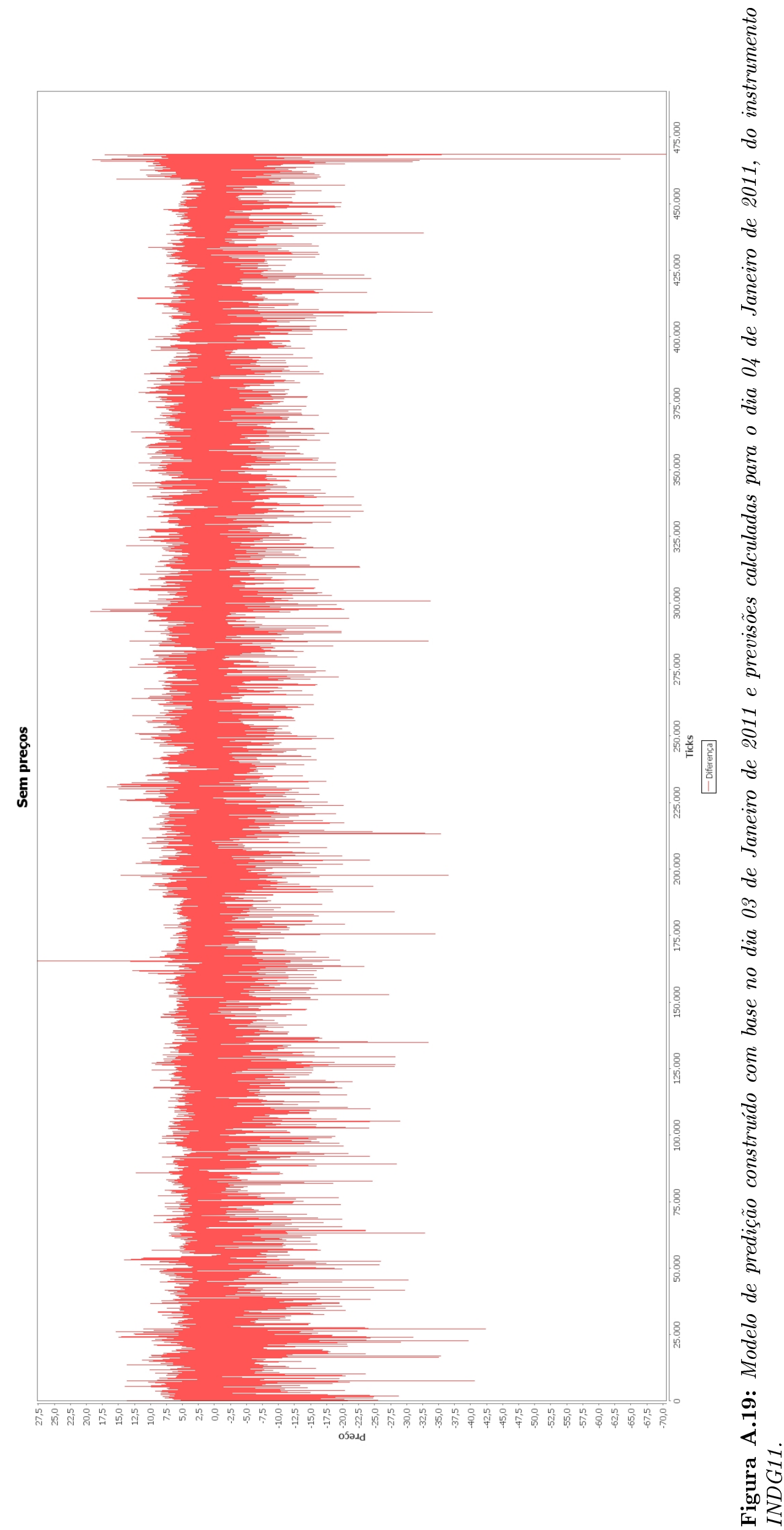


GRÁFICOS $\quad 55$
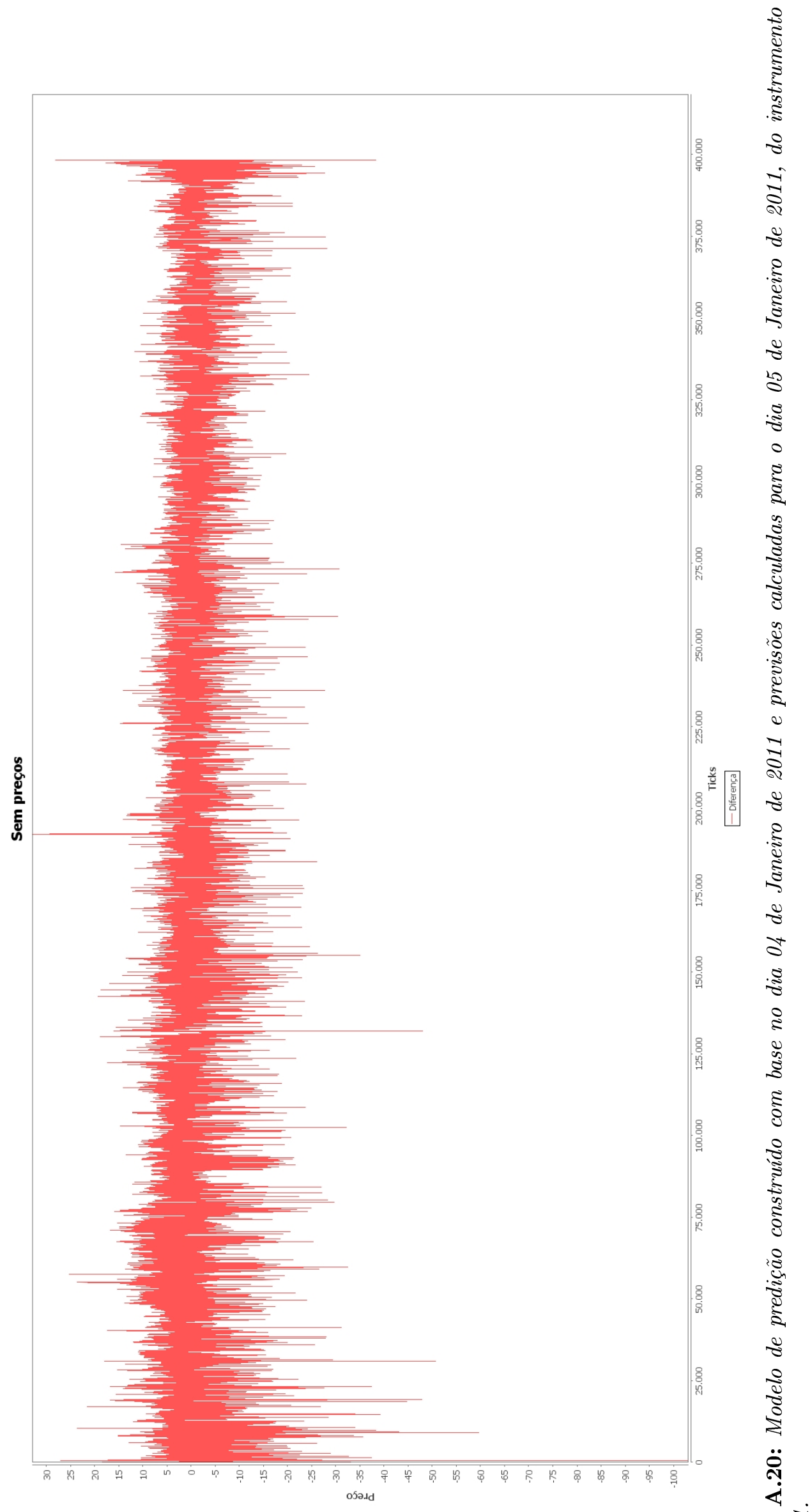
GRÁFICOS $\quad 56$

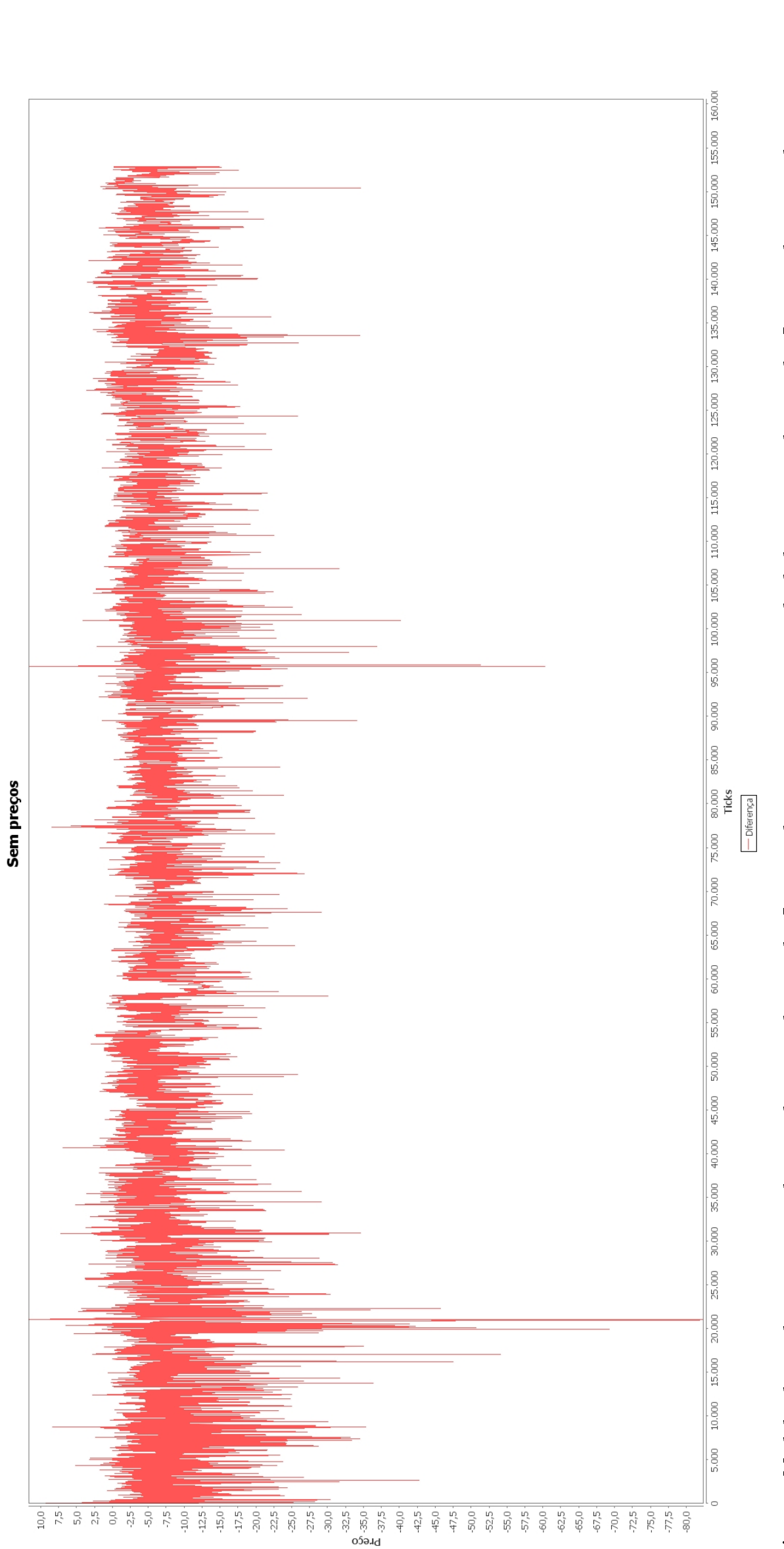


GRÁFICOS 57

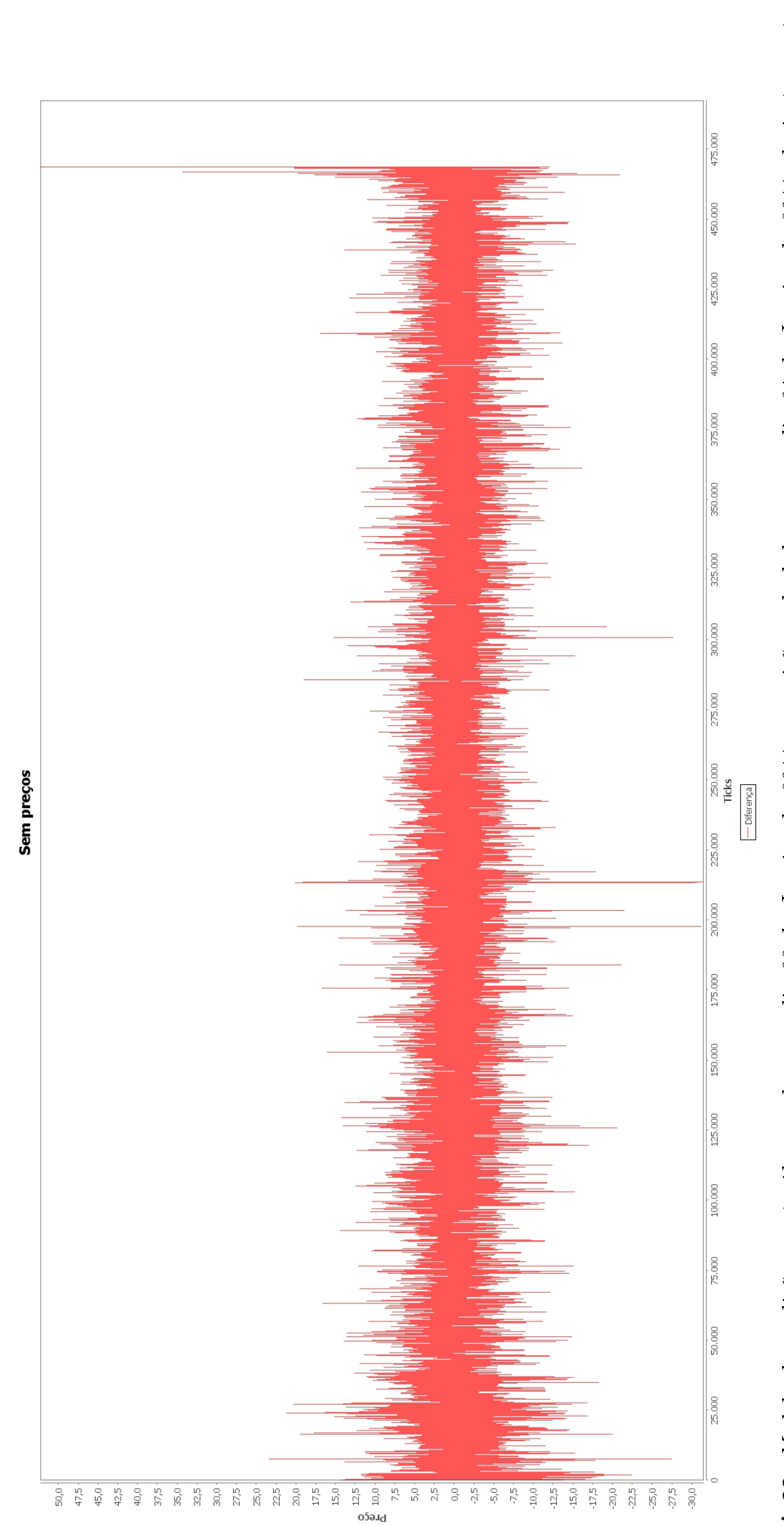


GRÁFICOS 58

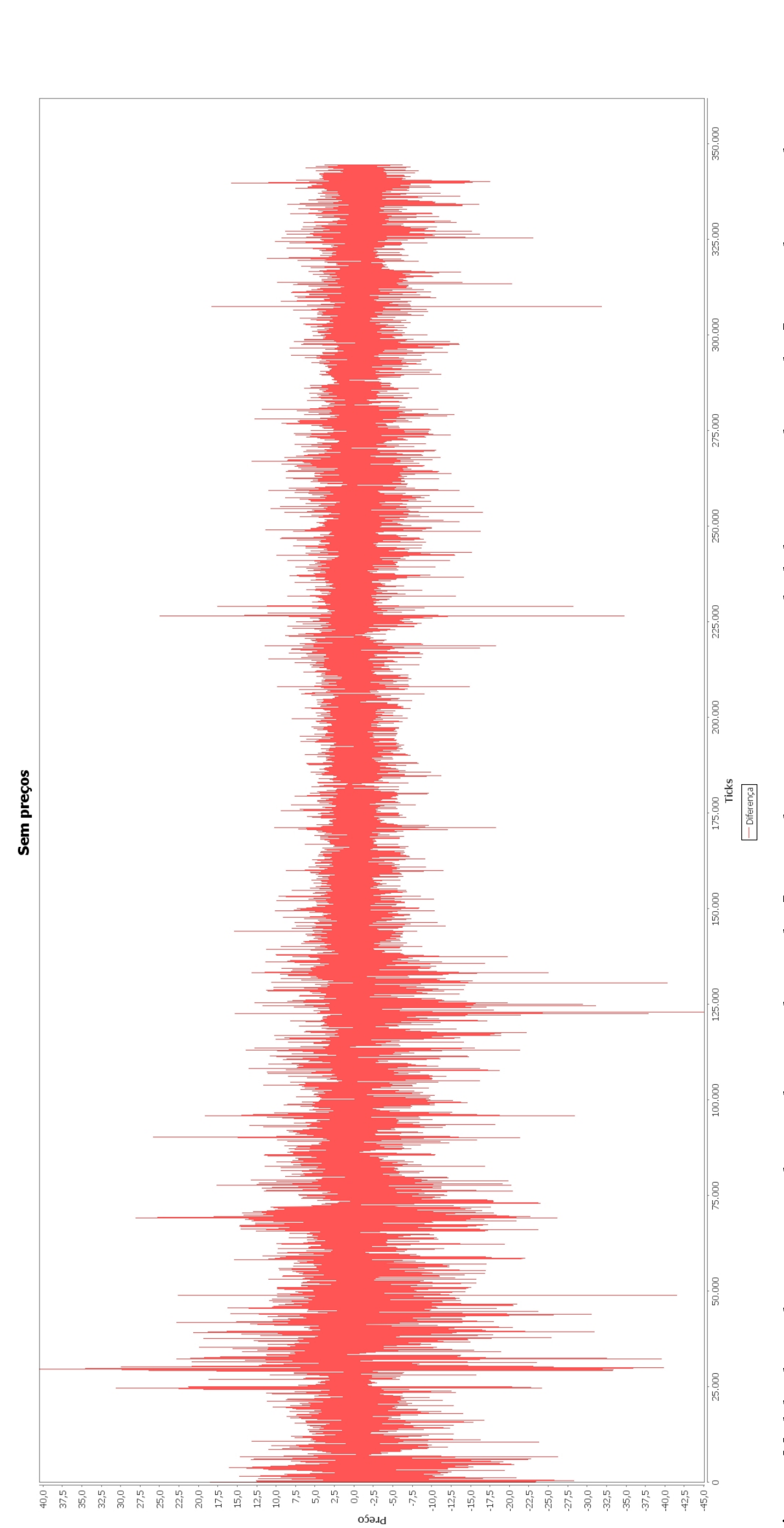


GRÁFICOS $\quad 59$

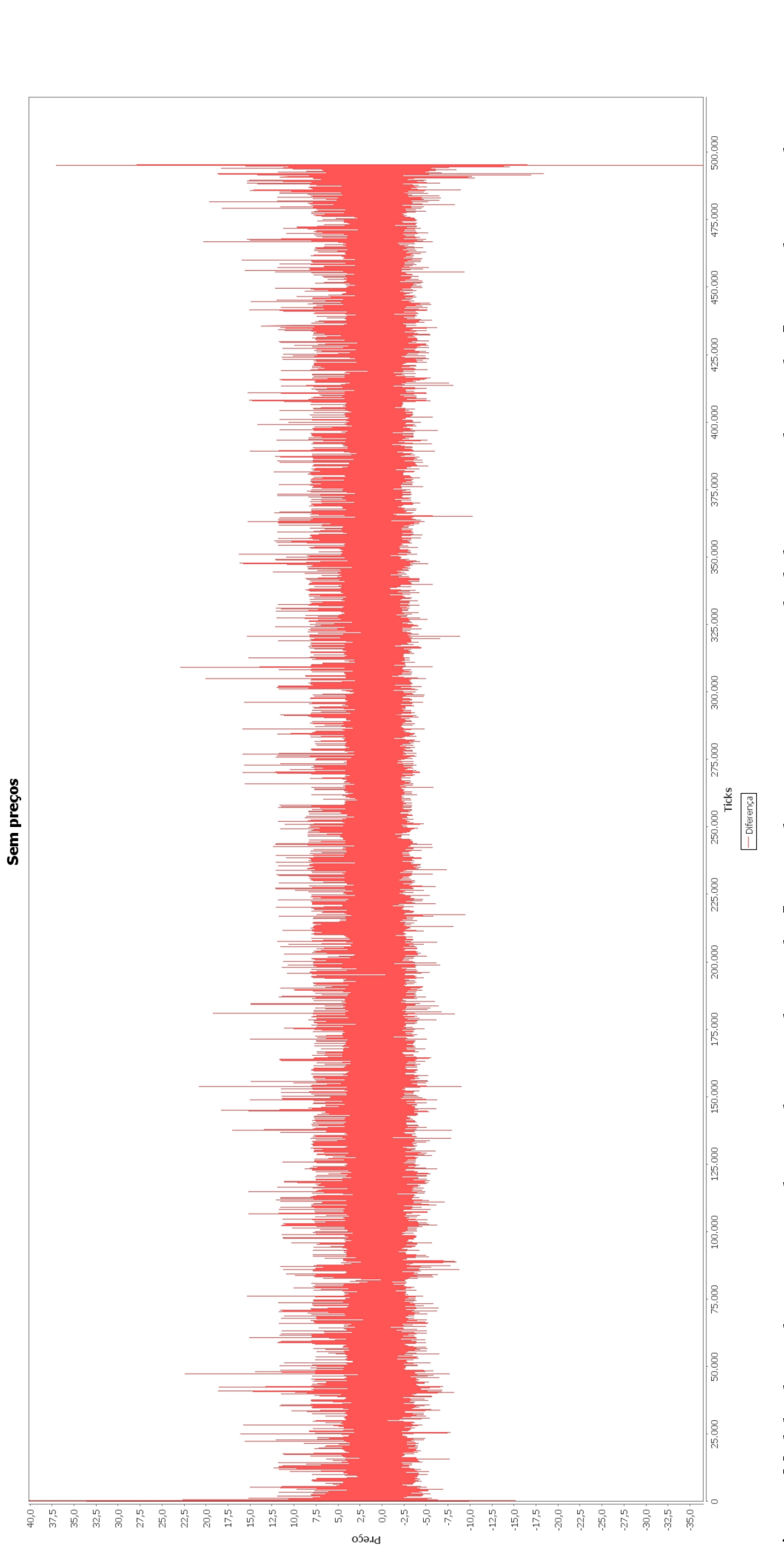

๘

ํํํ 
GRÁFICOS 60

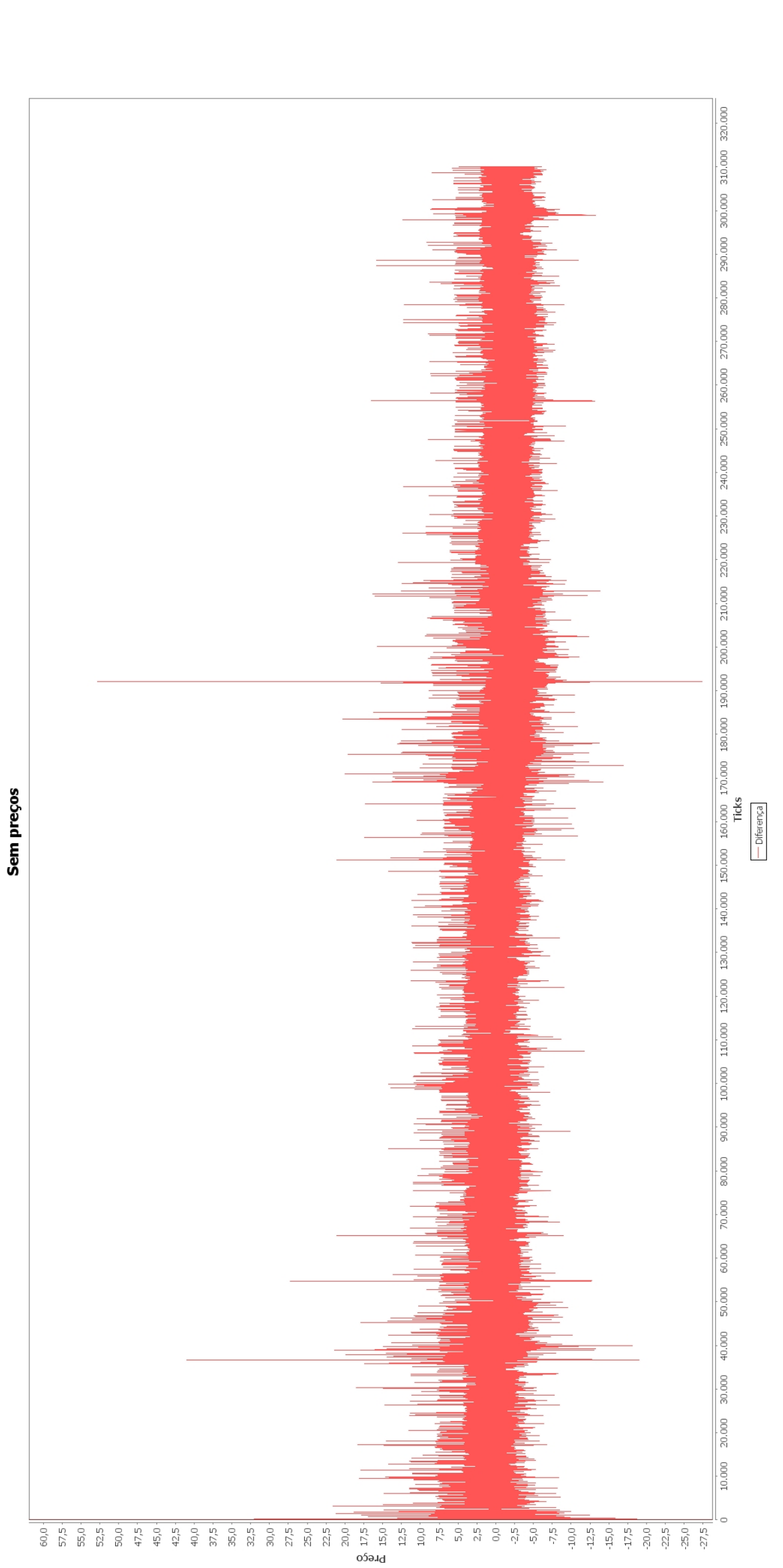




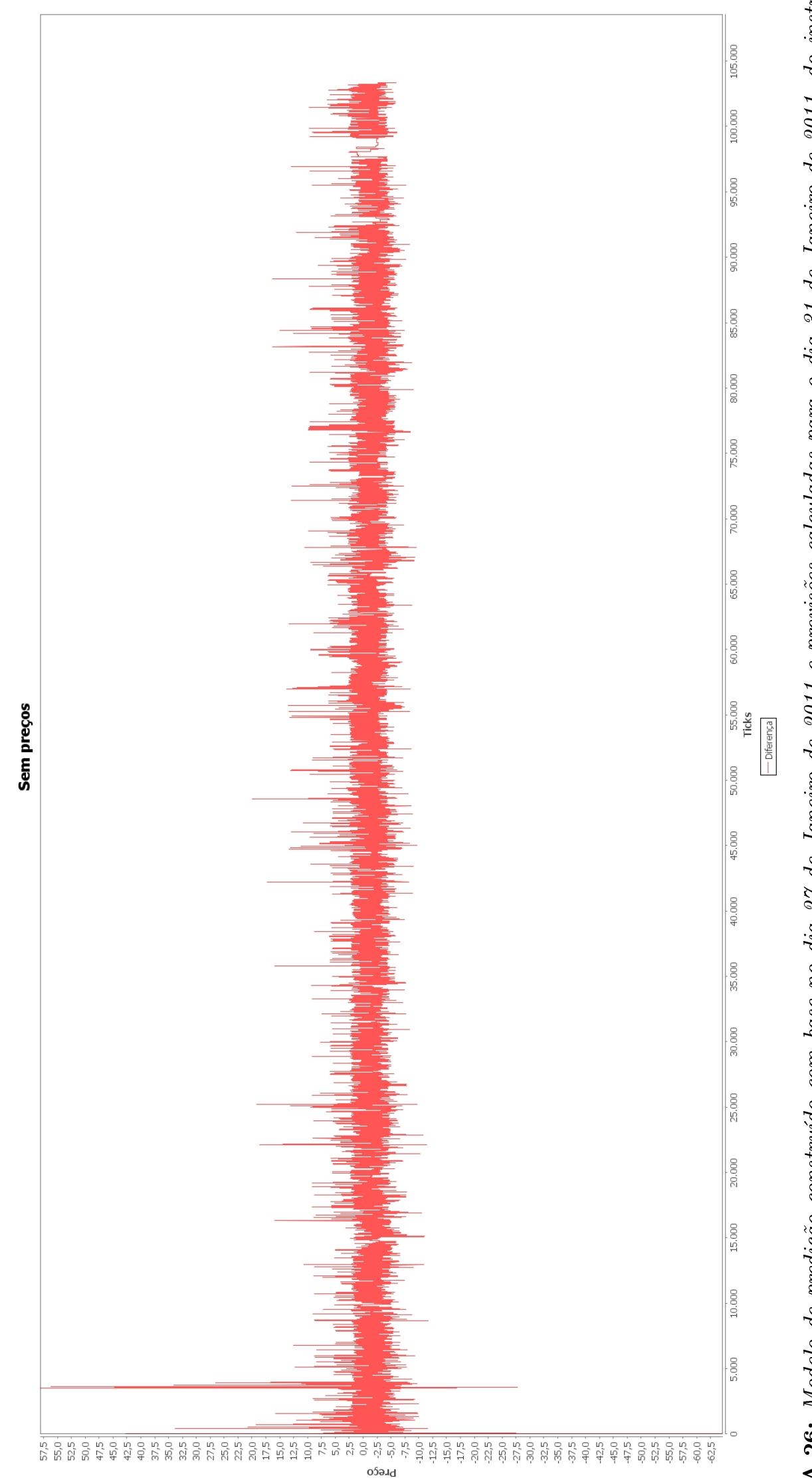


GRÁFICOS 62

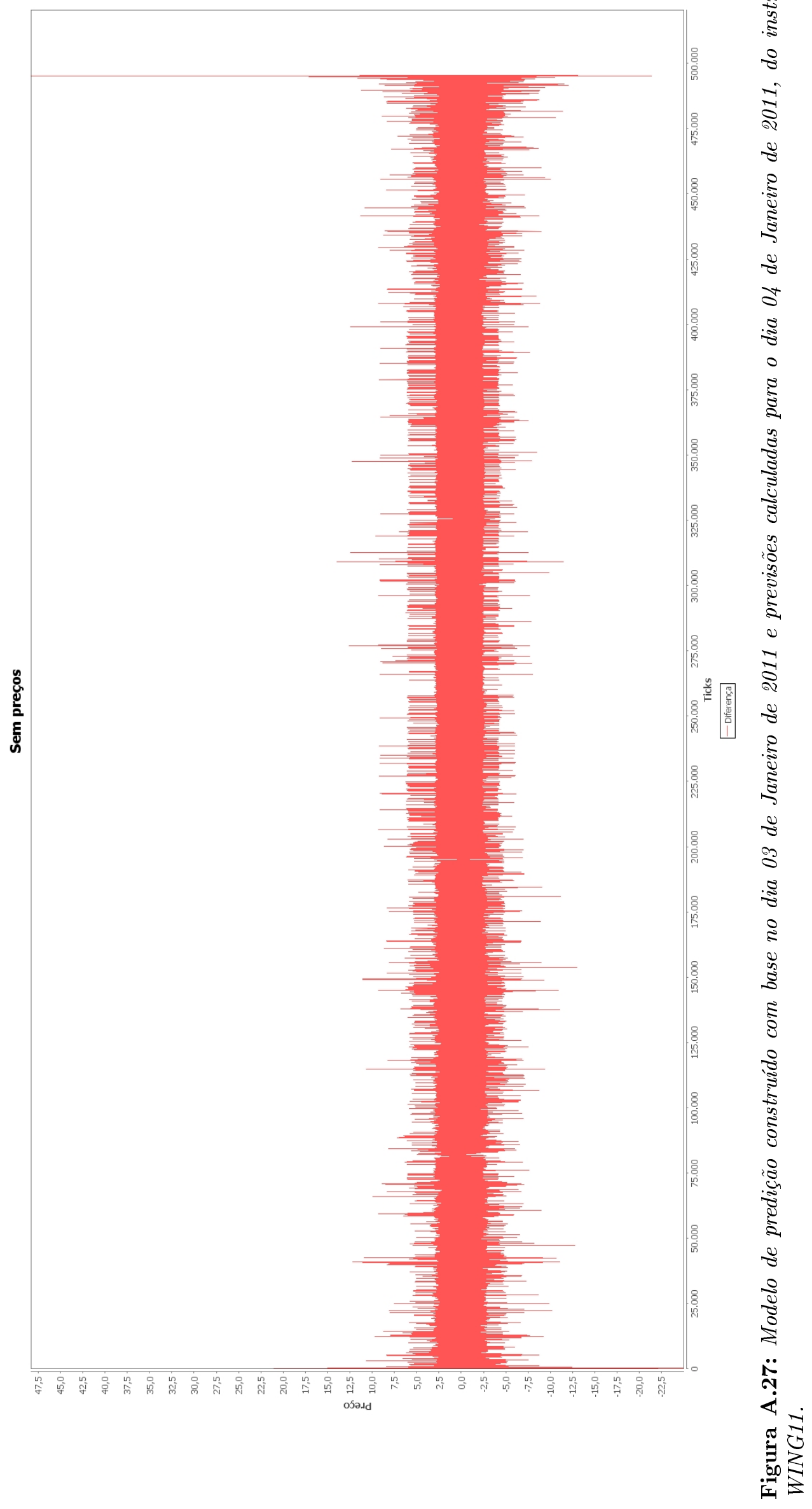




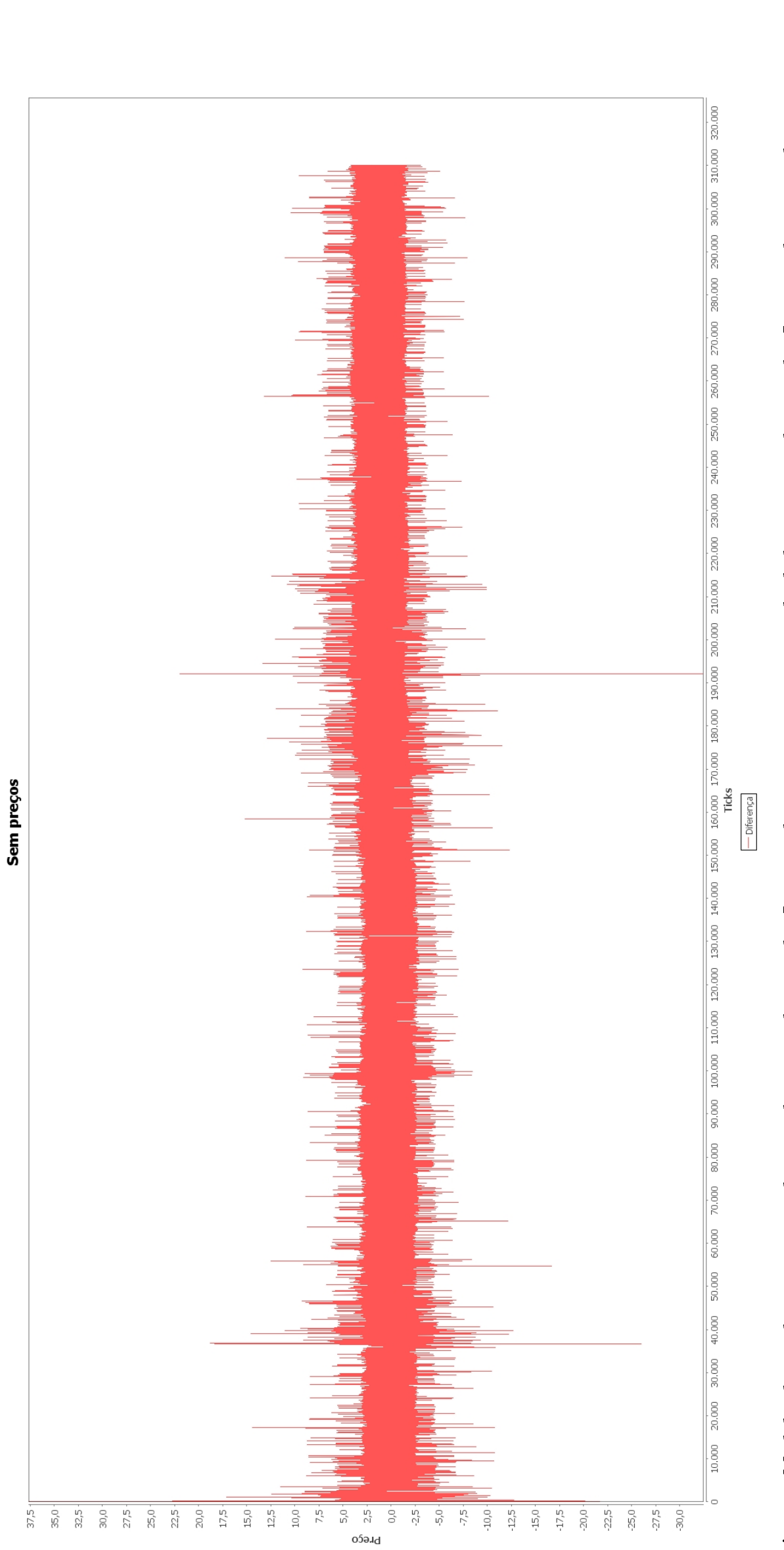




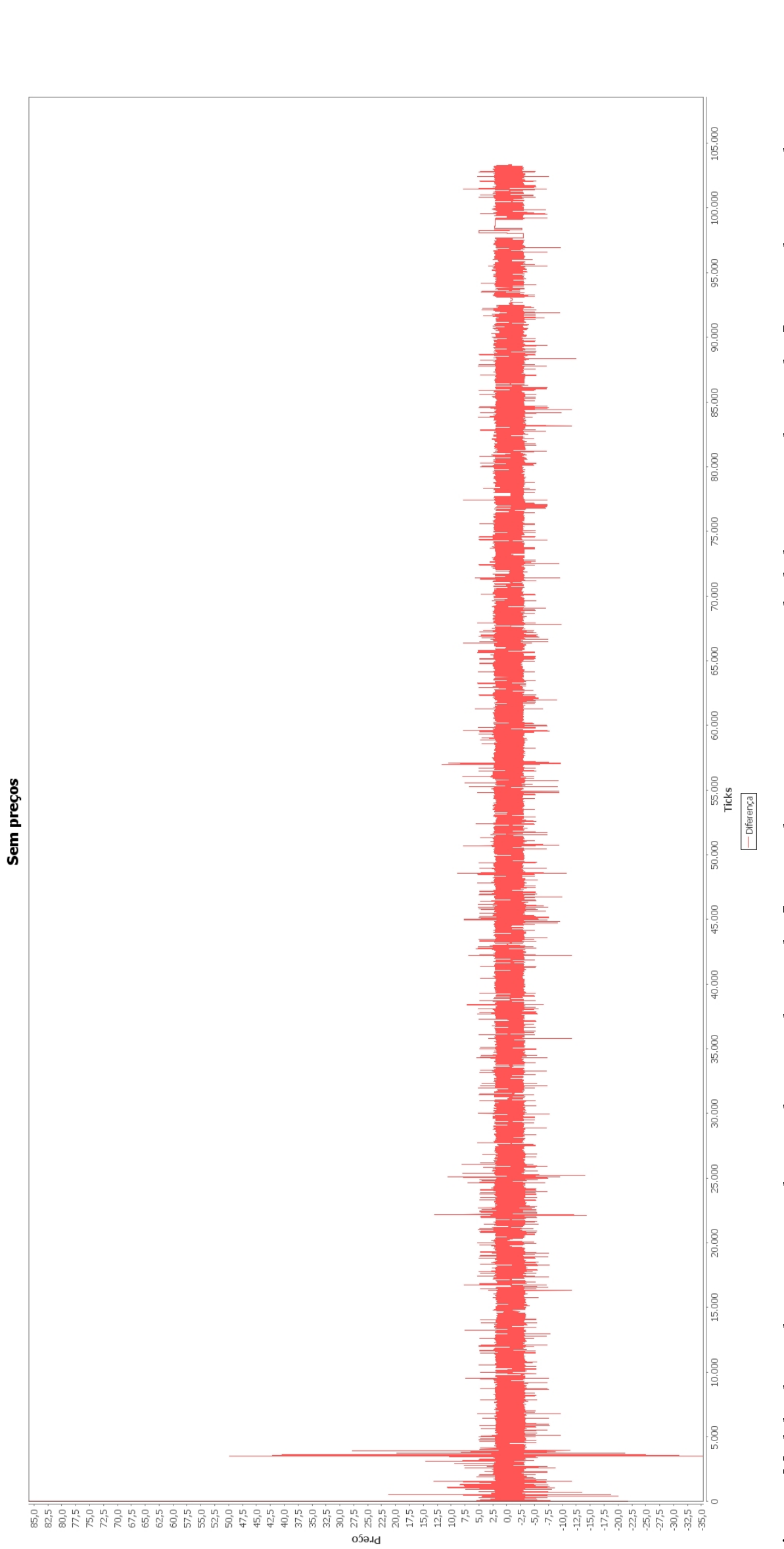



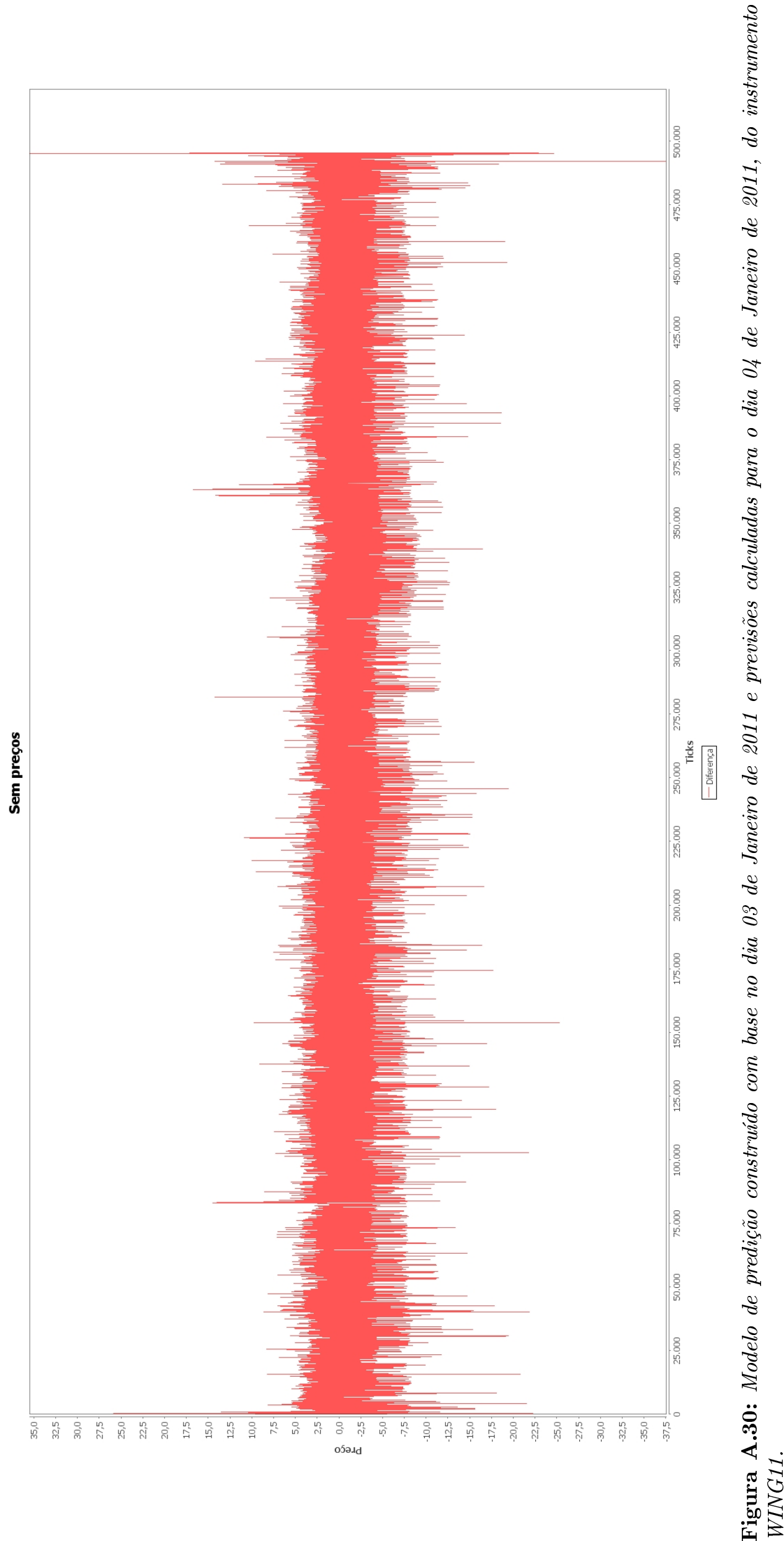
GRÁFICOS 66

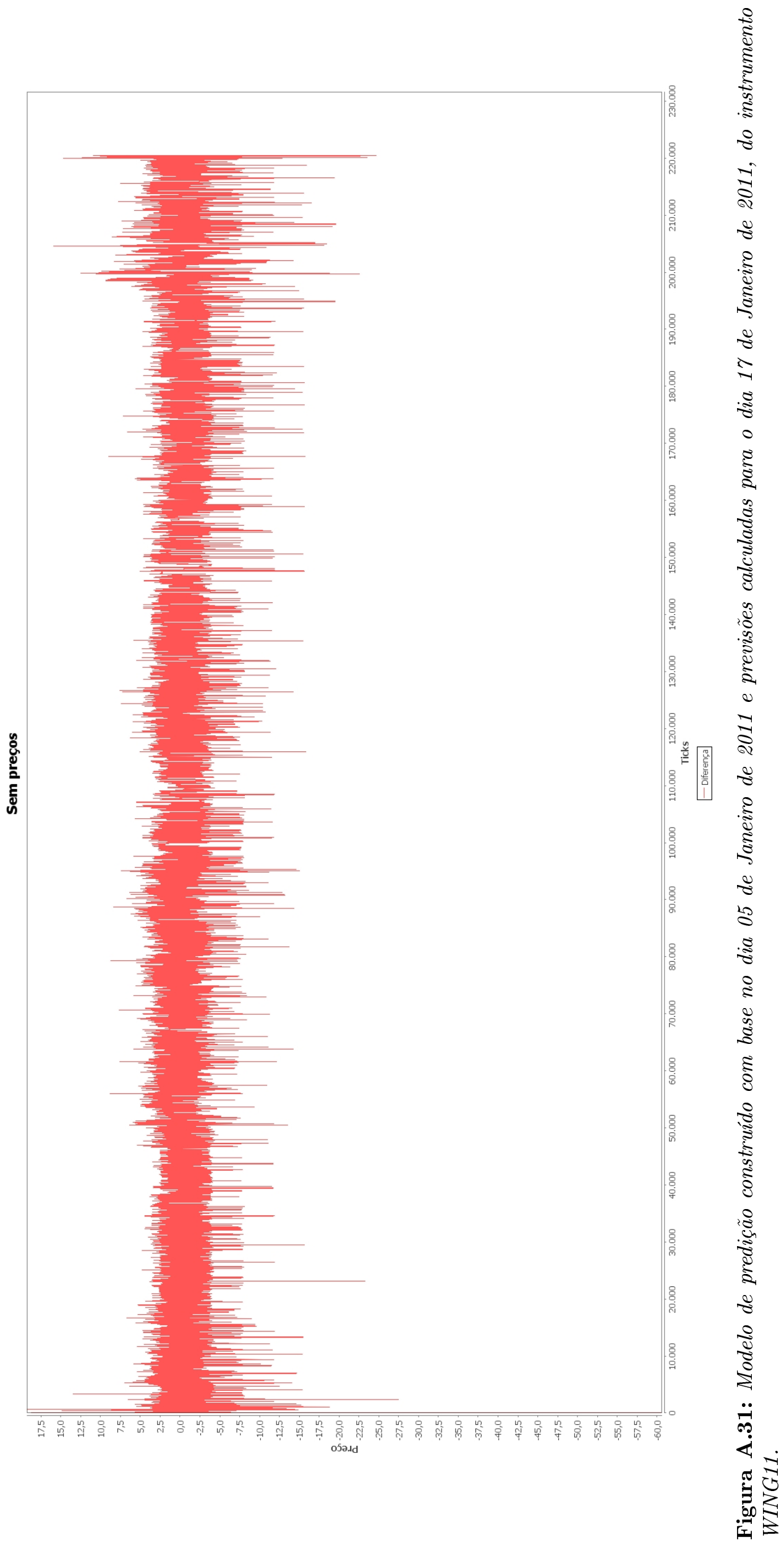


GRÁFICOS

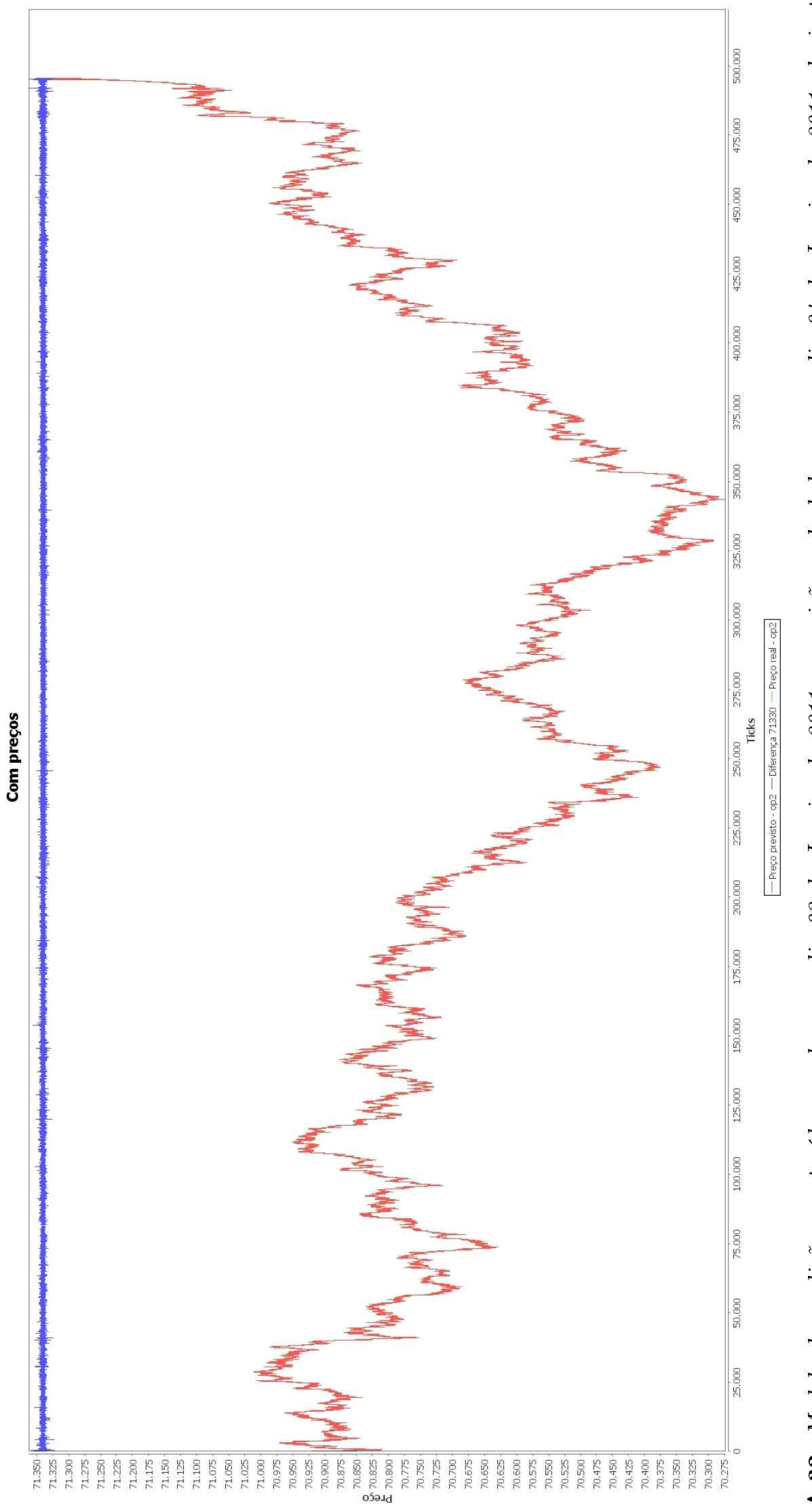

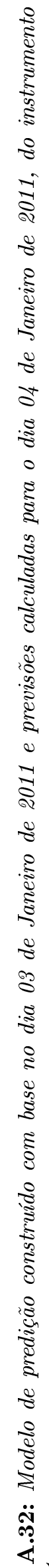


GRÁFICOS

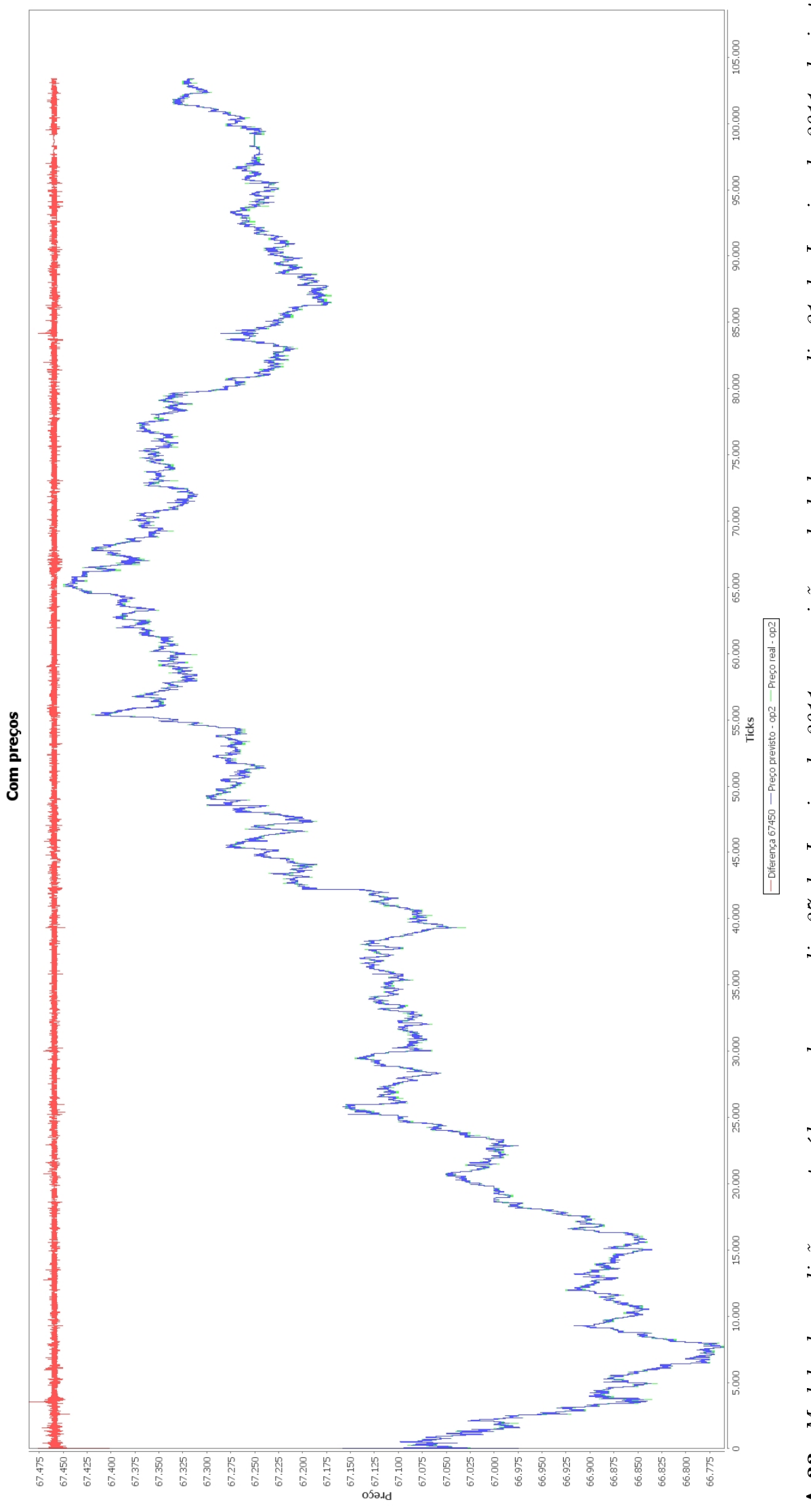

हึँّำ

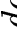

จ

$\approx$

气ี้

ช

के

:

○

है

) 


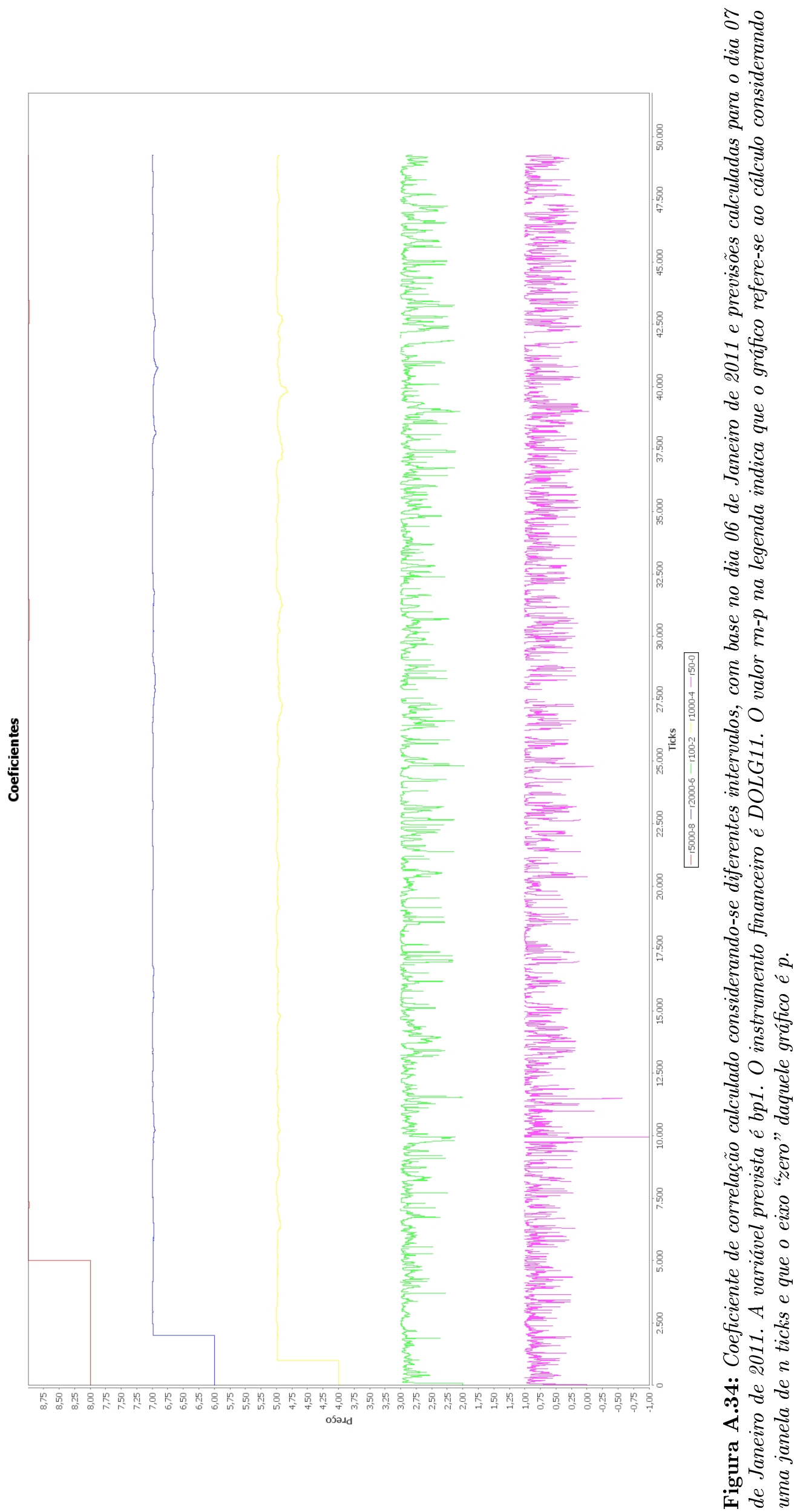


GRÁFICOS

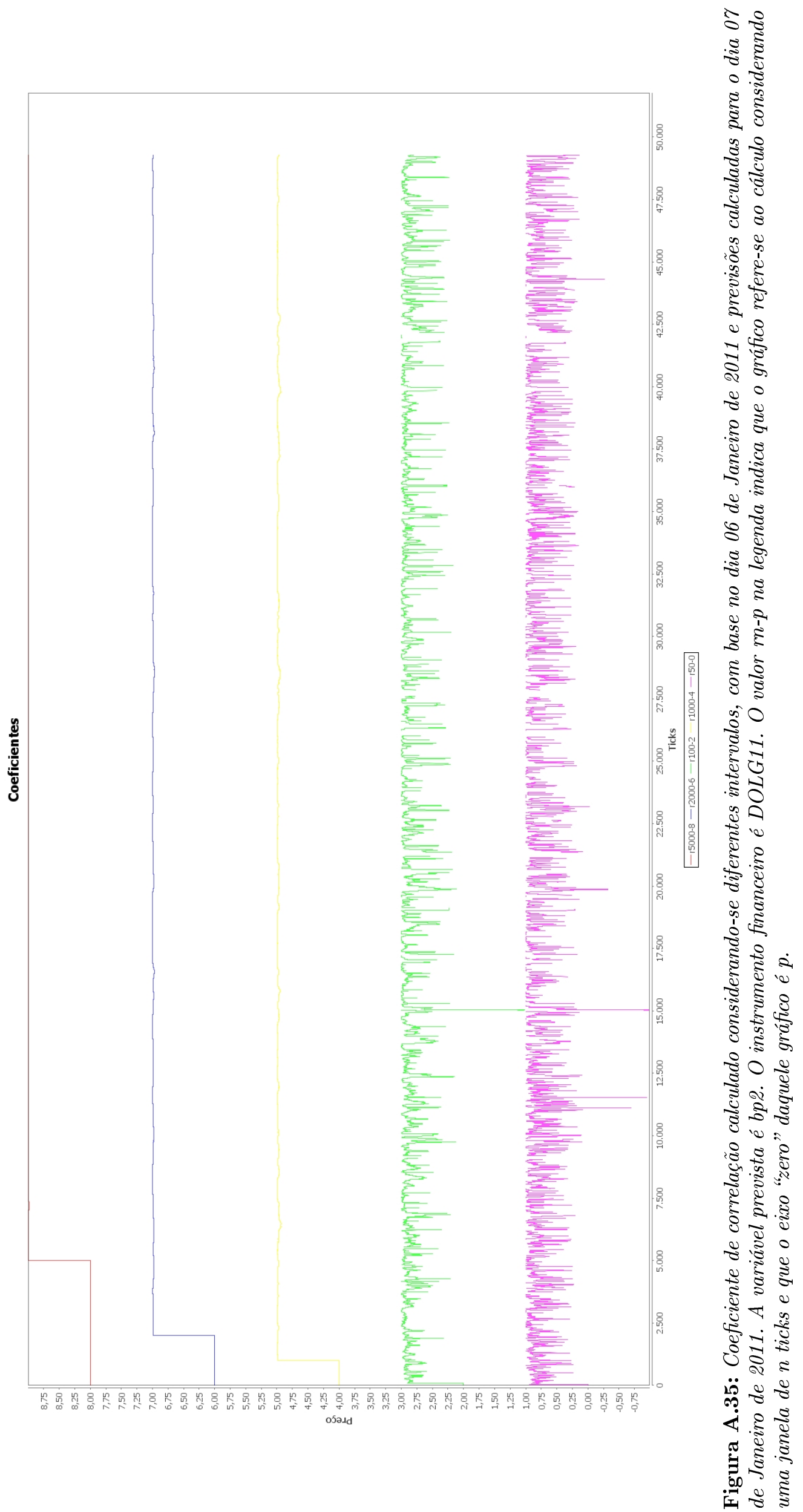




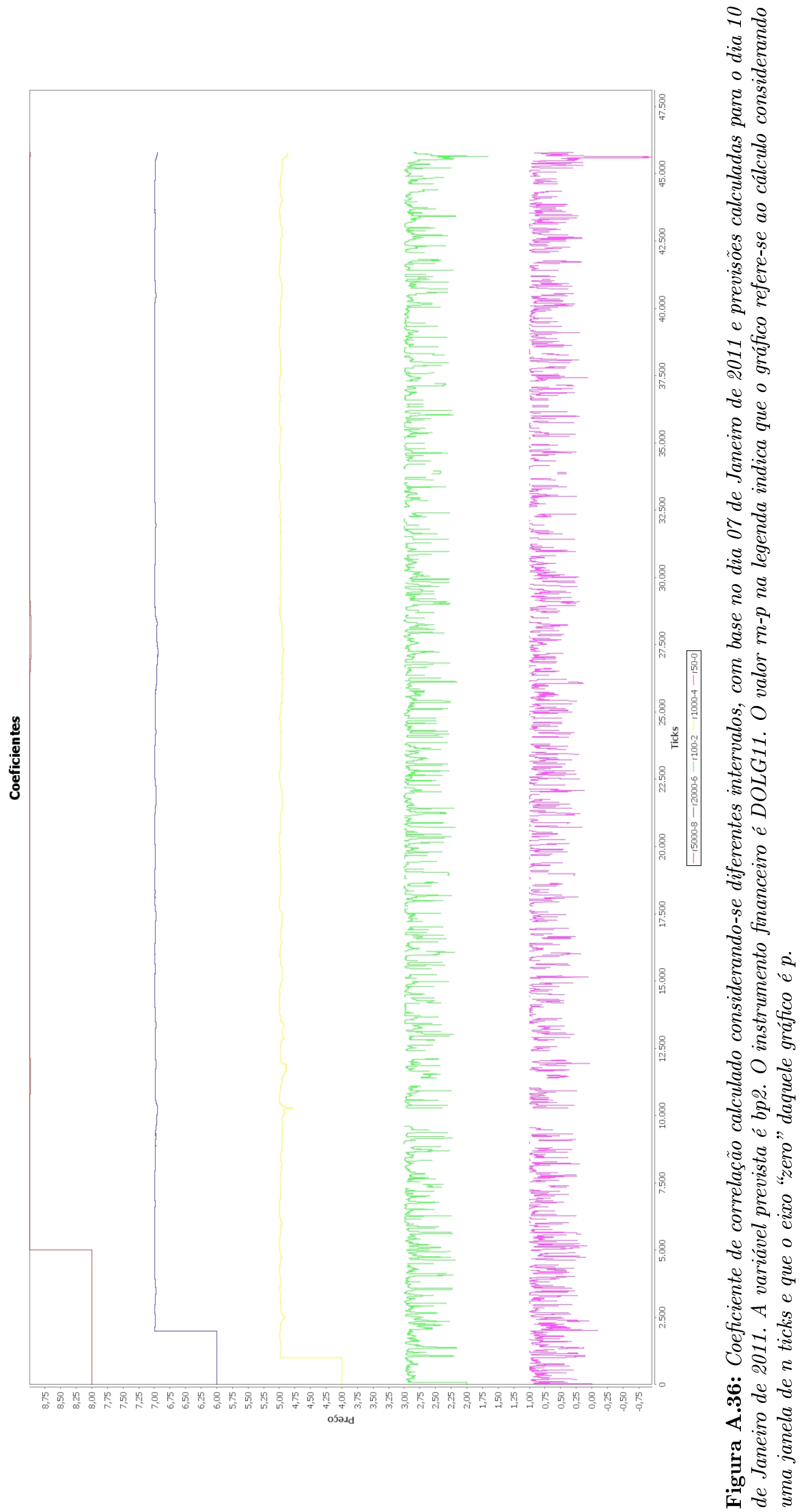




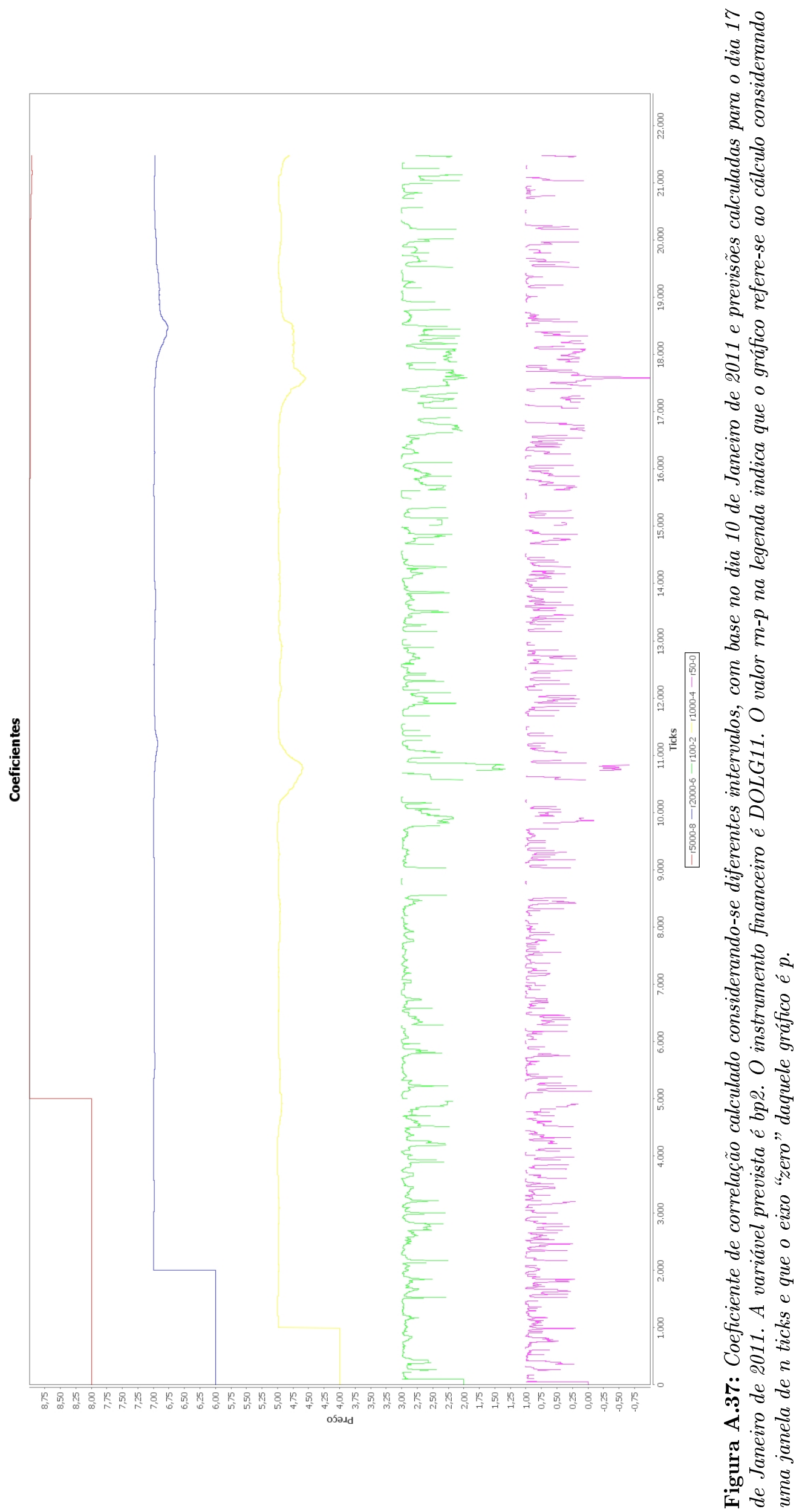




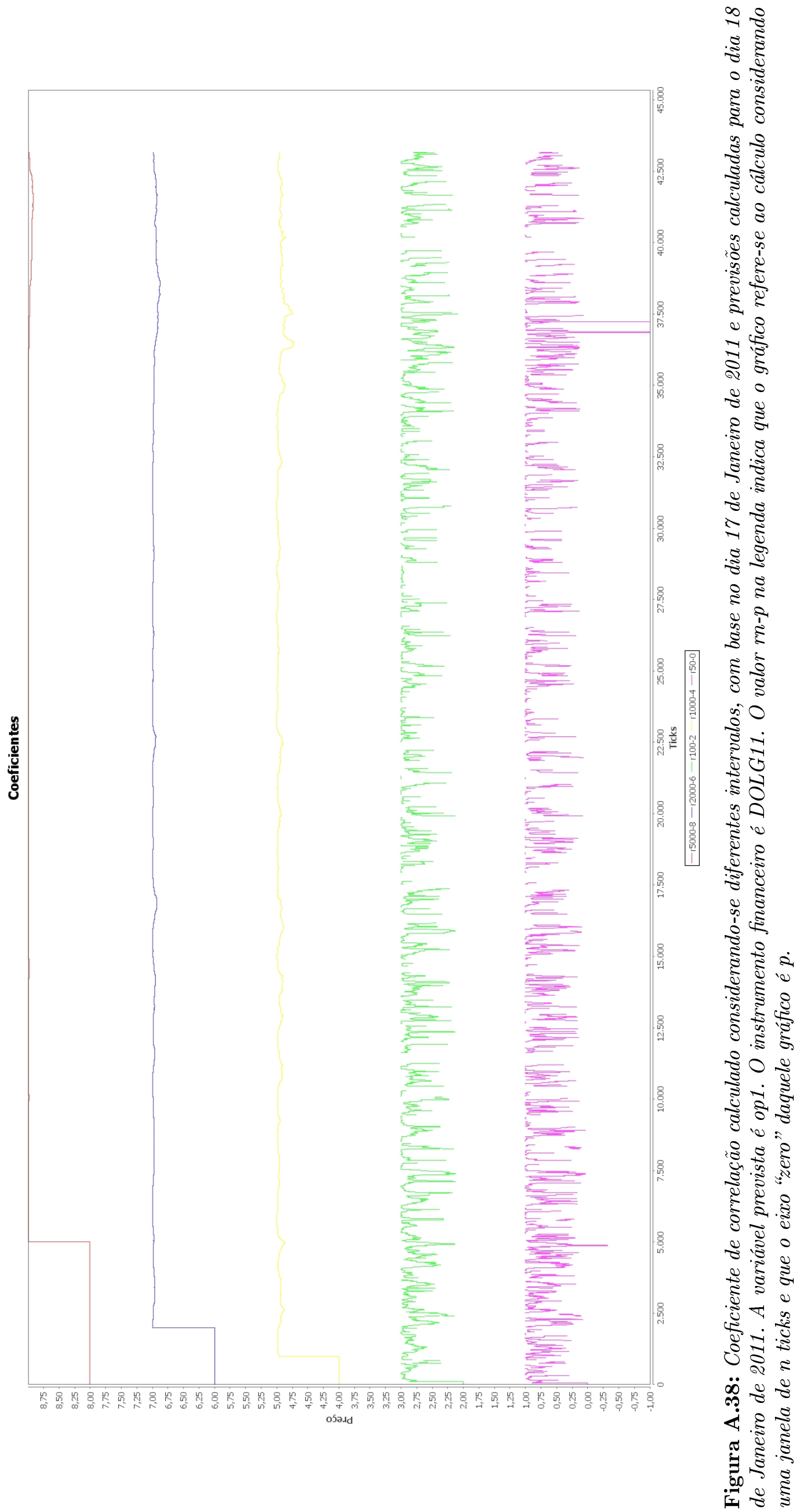




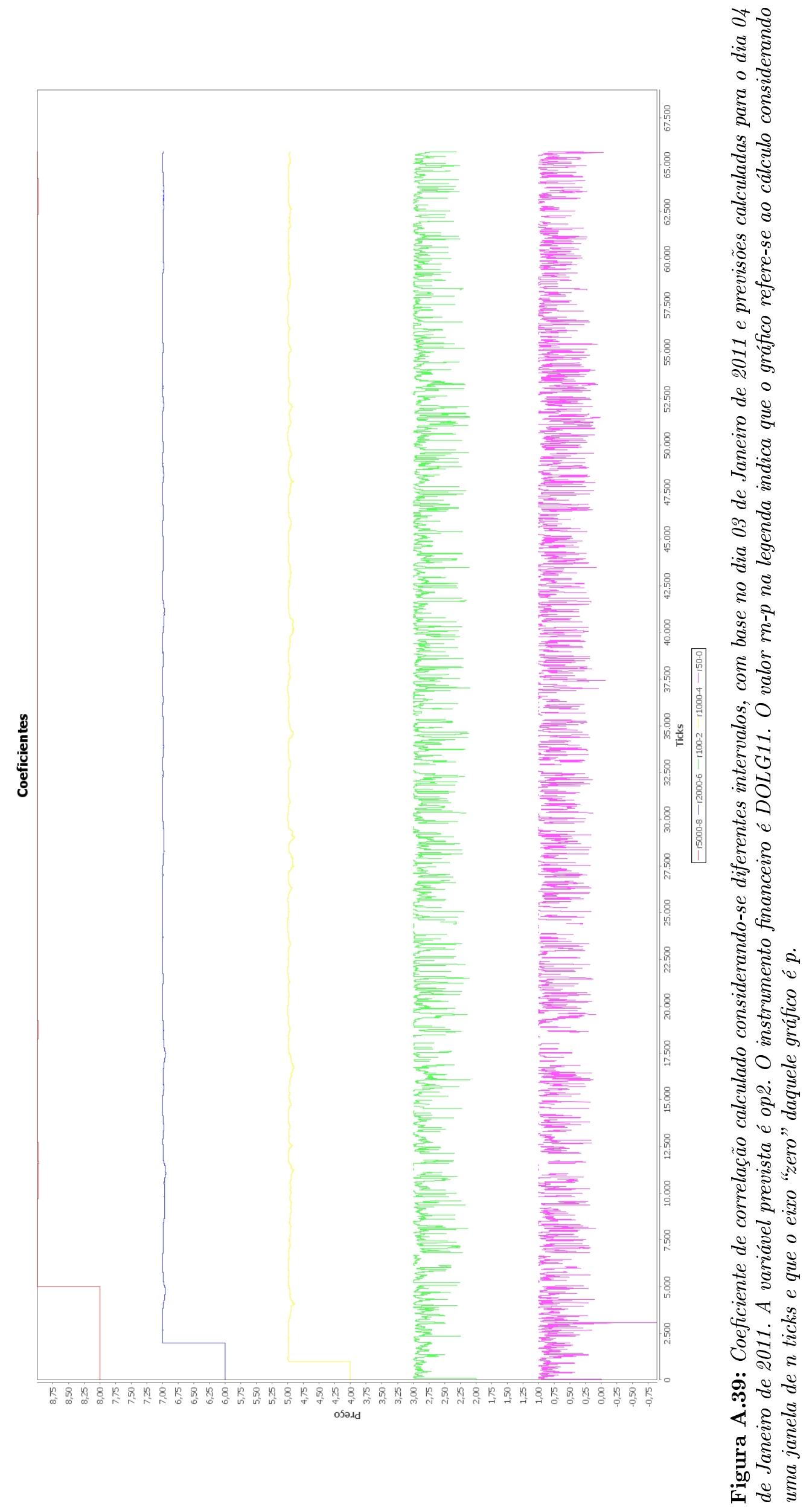




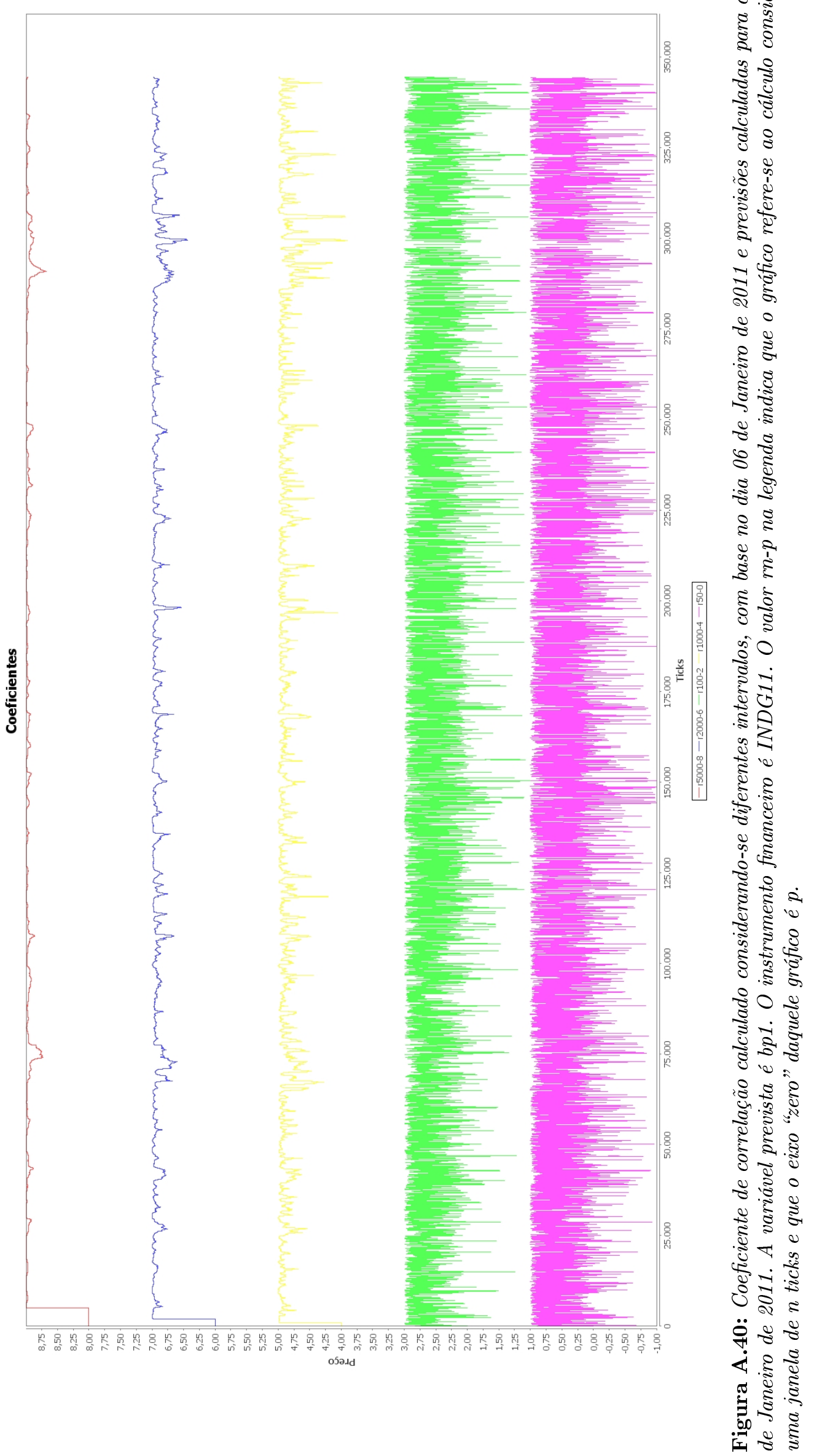

เิ

:

0

\&

용

ปั है

- 8

จ

है

8 ?

:

¿ :

ङ है

हิ่ $\frac{5}{0}$

की

हैं

क्

है

ถัँ

के

है है

है

कू

¿ $0 \div$

胥胥

8 :

岁管

हू. हี

ร 0

๑ है

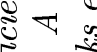

07

$\ddot{0} \approx$

४ हैँ

เ्ञ 


$$
\|
$$




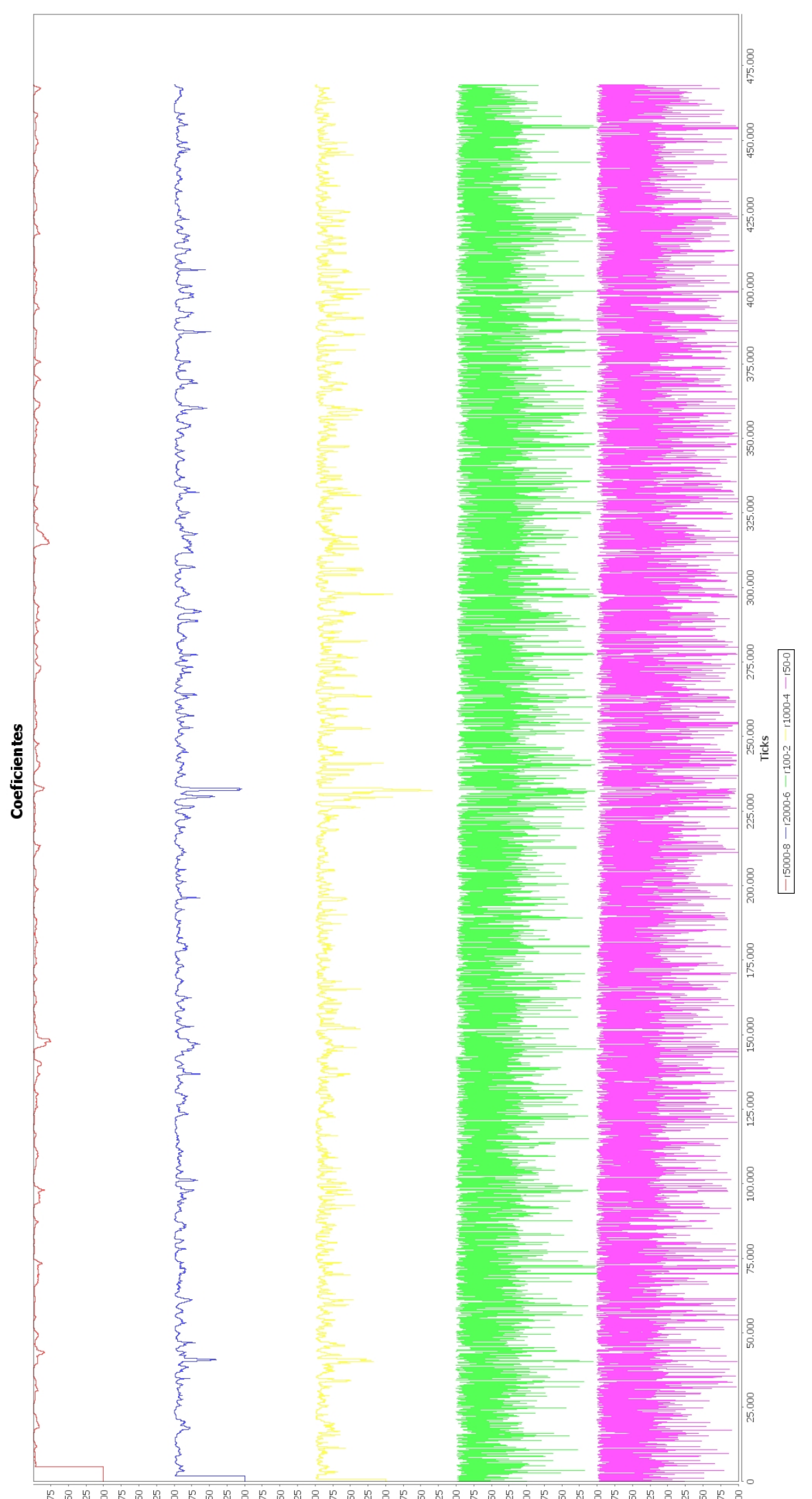




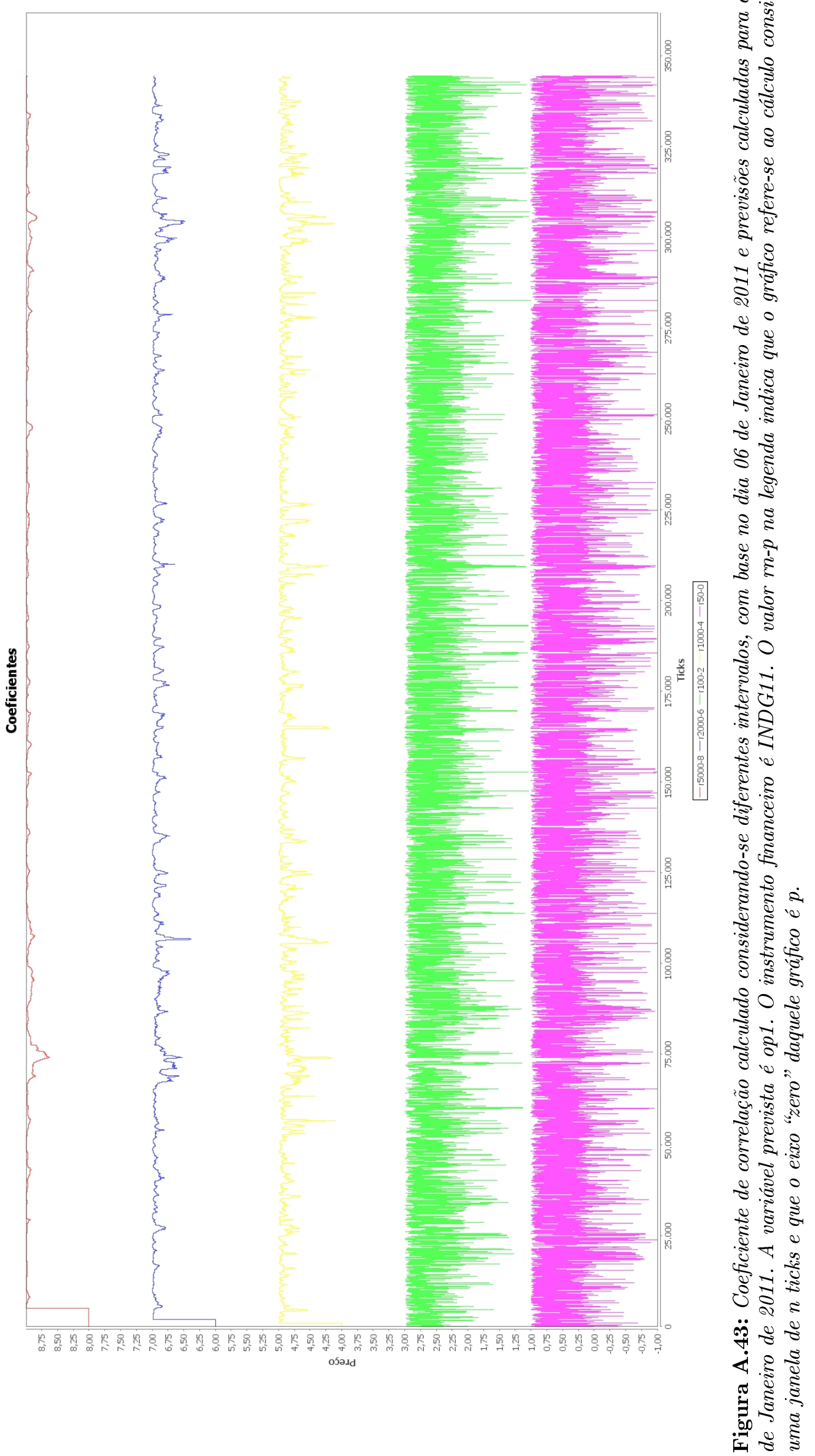

ริ ริ

:

$\circ$

ह

ํㅗำ

8

के है

ลิ है

:

है

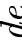

8

:

요

कू है

हิ่ $\frac{5}{5}$

30

(ำ

है

क्ष

हैँ

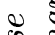

0

है त

है

व. है है

\& $0 \div$

ปี

88

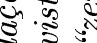

है.

ร 0

结 :

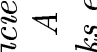

$0 \div$

$\ddot{0} \approx$

น.

เ्ञ 


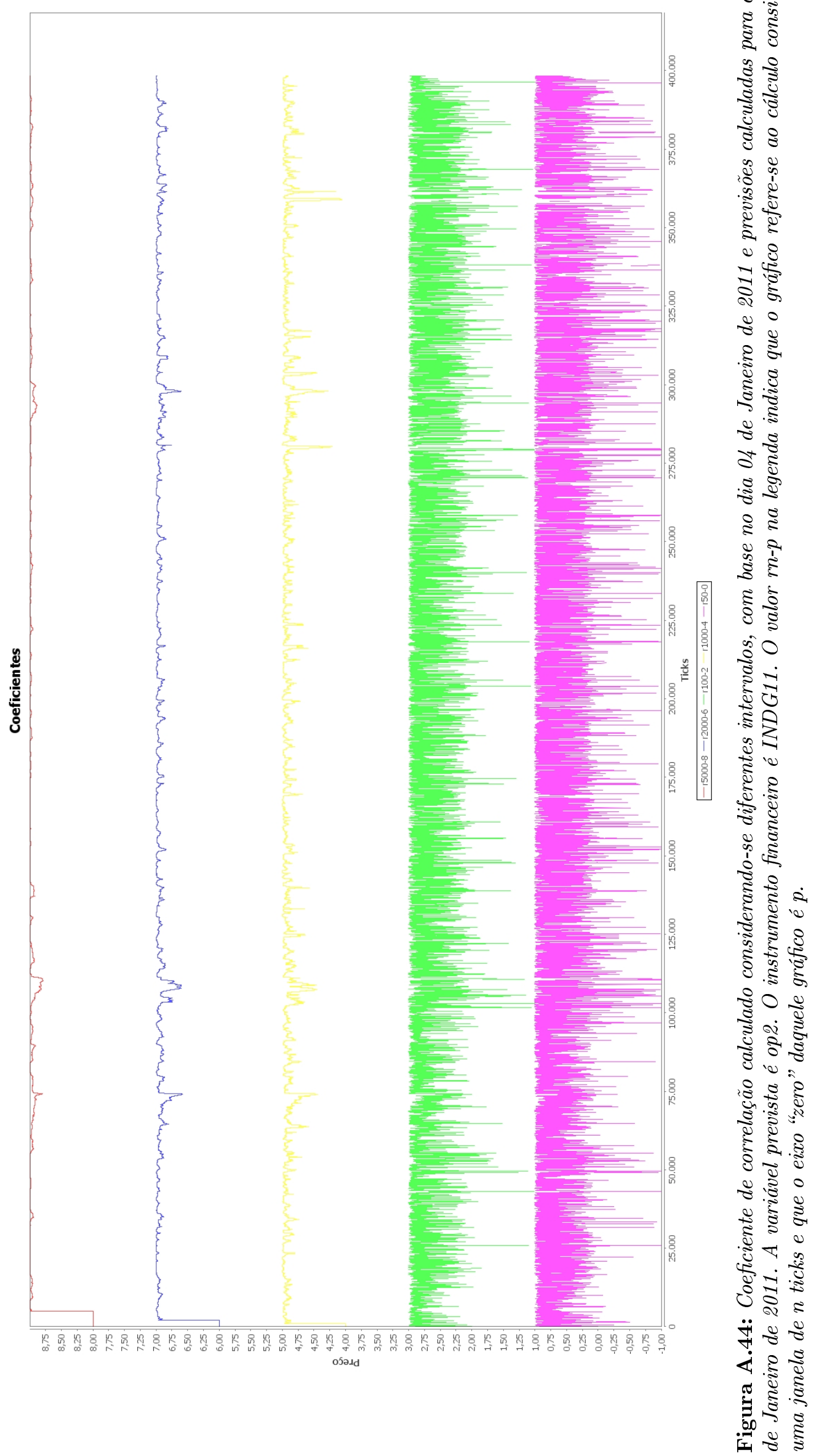


GRÁFICOS $\quad 80$

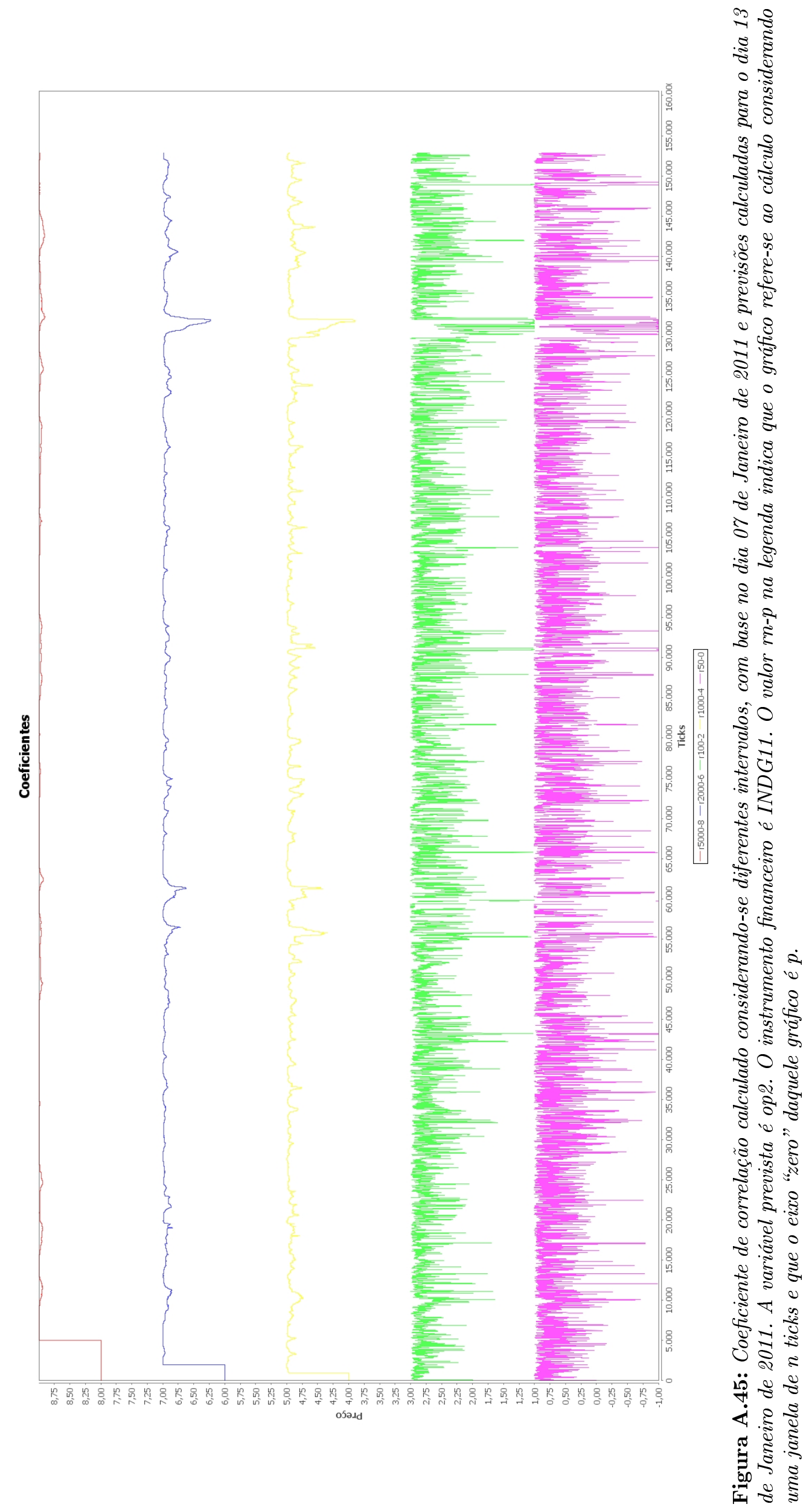




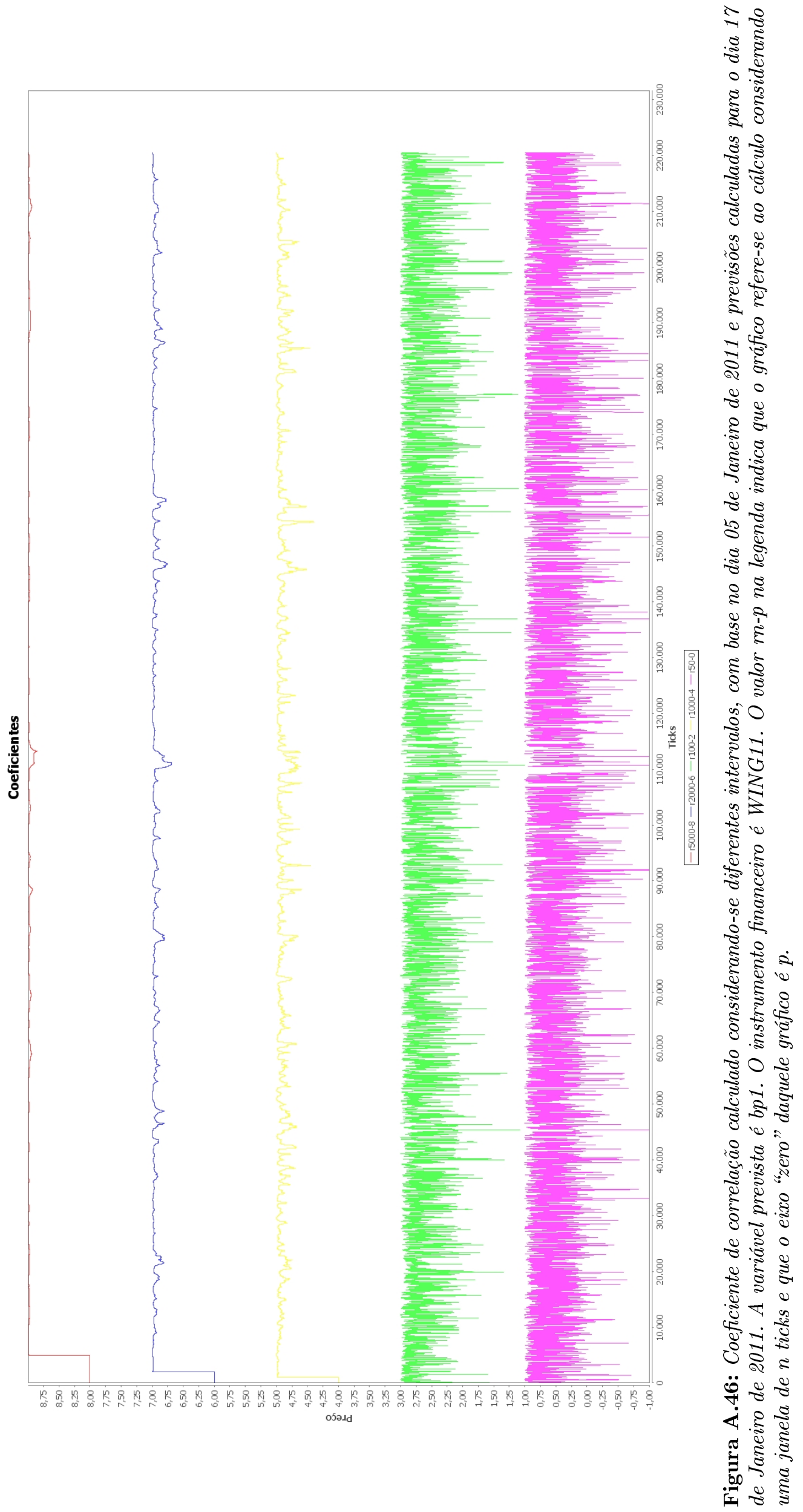




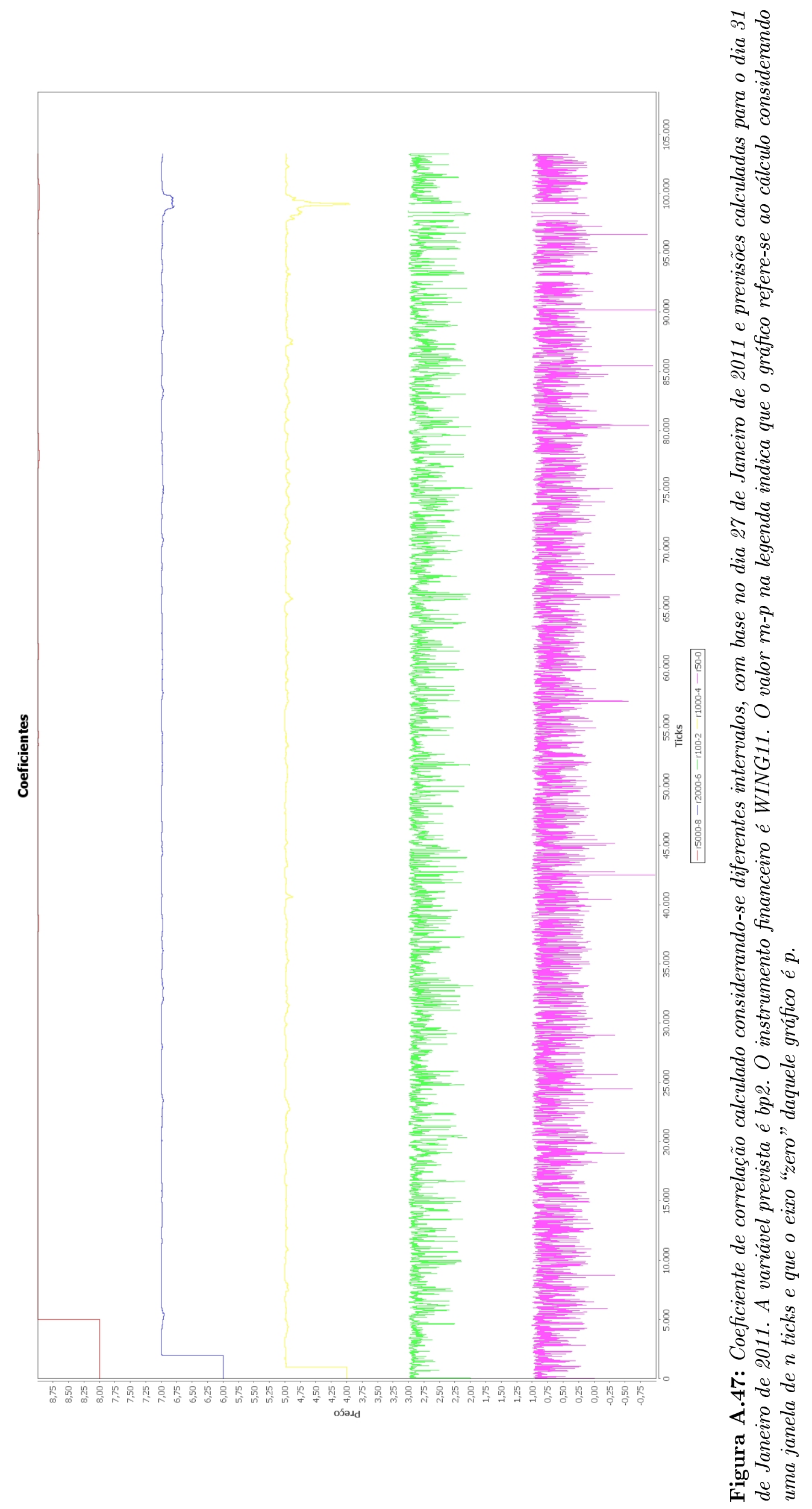




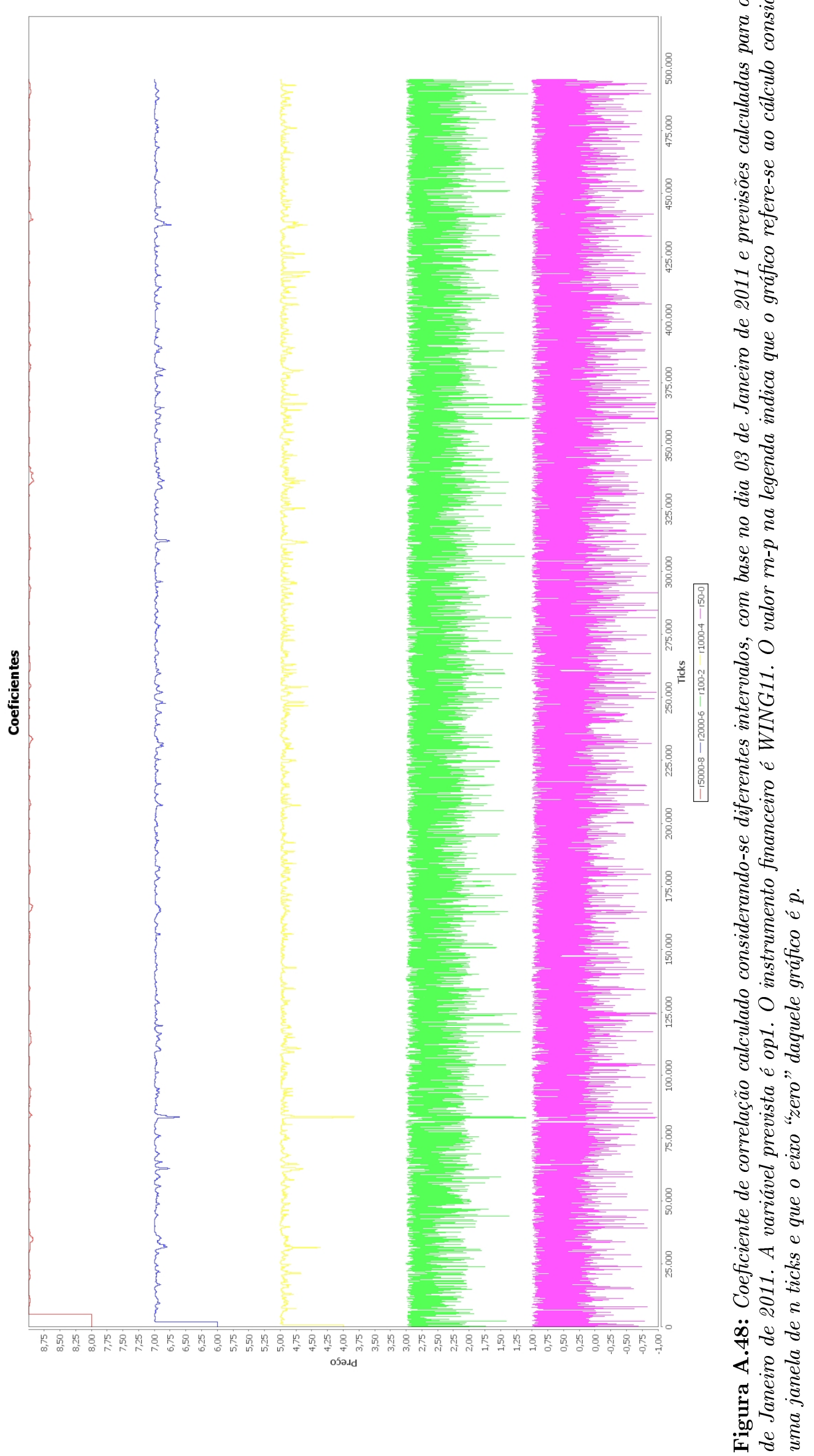


GRÁFICOS

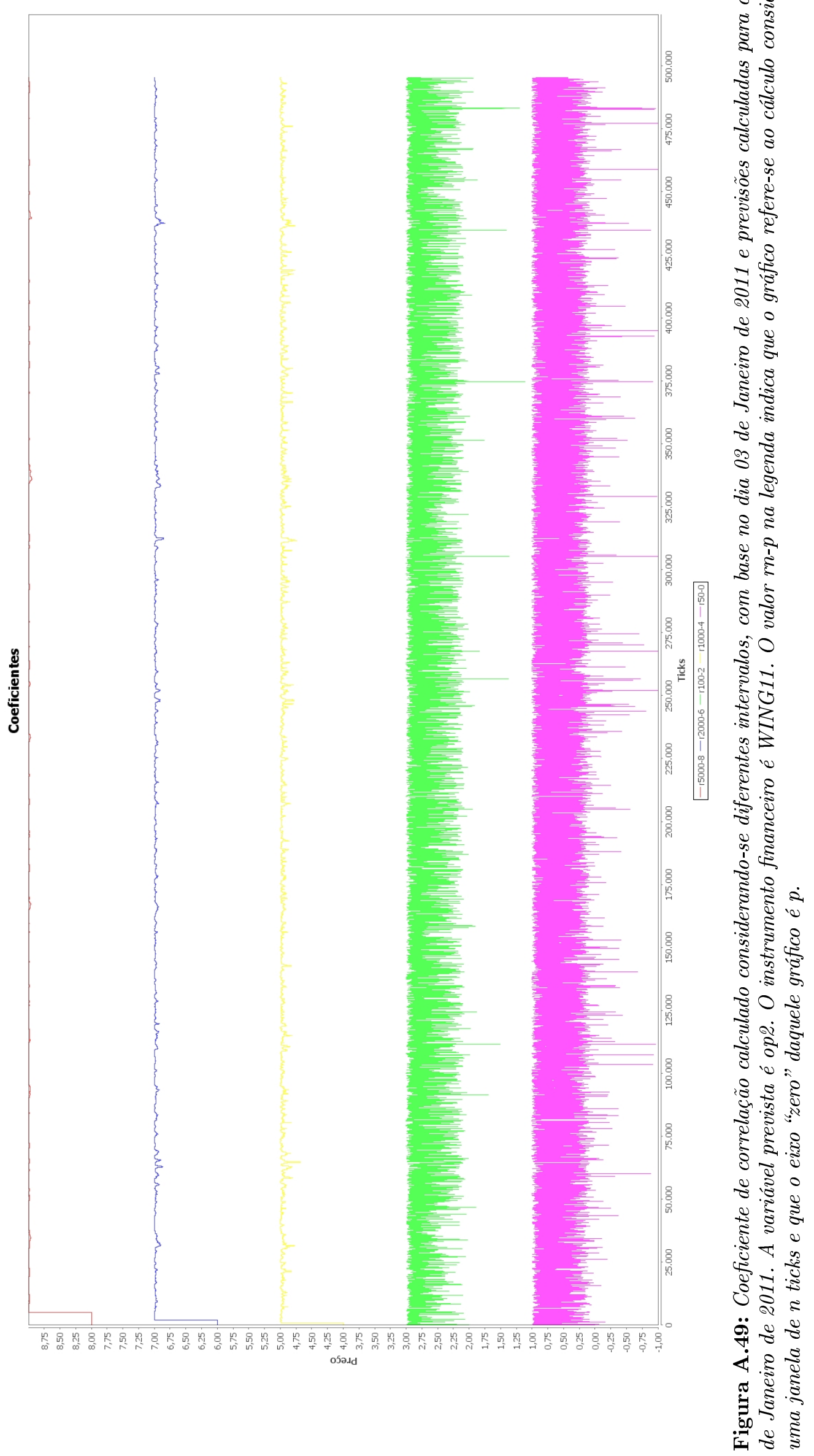

at

$\approx$ है

0

हู ริ

ํำ

\&

कू

(

का

$\approx$

.

ह :

$\approx$ :

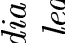

욜

ङ है

हิ

कo

है

o

है

密

क

हैं ㄴ.

हैं 8

कू

\&०

สิ

80

. के

है. त्ष

จ

ป है

$\widetilde{\Xi}$

8 충

จे ह

$\ddot{*} \approx$

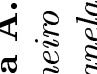

เ्ञ 


\section{Apêndice B}

\section{Tecnologia empregada}

No capítulo 4 são descritas as principais estruturas de dados propostas e utilizadas no trabalho de uma forma que seja possível fazer a implementação dos algoritmos facilmente utilizando-se recursos da linguagem $\mathrm{C}++$ e em particular de recursos presentes na biblioteca conhecida como STL. Neste apêndice são detalhados os principais aspectos referentes a cada componente utilizado.

\section{B.1 C ++ e STL}

Grande parte deste trabalho foi desenvolvida utilizando-se a linguagem de programação $\mathrm{C}++$. A linguagem $\mathrm{C}++$ oferece um conjunto de componentes reutilizáveis, geralmente referido como STL [DD05] cujo desenvolvimento foi voltado para o desempenho em detrimento de boas práticas conhecidas da orientação a objetos [DD05].

A biblioteca padrão do $\mathrm{C}++$ (ou STL) inclui templates de classe [DD05] que representam diversos tipos diferentes de estruturas de dados. Boa parte destes foi utilizada neste trabalho. Um template de classe é uma espécie de modelo de classe independente de tipo. O compilador $\mathrm{C}++$ utiliza um template de classe para gerar código sob demanda, de acordo com a necessidade do programador. Uma vantagem é a reutilização de código. Uma desvantagem é o tempo de compilação que pode aumentar consideravelmente. No capítulo 4, mencionam-se diversos templates de classe utilizados. Quando é importante saber qual o tipo de dado será usado no template, menciona-se isto explicitamente. Por exemplo, std::vector <int>, trata-se de um template de classe std::vector que armazena inteiros. Por outro lado, quando o tipo de dado é omitido, apenas o funcionamento e complexidade do template importam. Por exemplo, se é preciso dizer que a complexidade de um método de inserção de um template é $O(l g n)$, menciona-se o nome do template sem dizer qual o tipo de dado que ele armazena, já que isso é irrelevante para a complexidade do template. Descrevem-se agora os principais templates de classe oferecidos pela biblioteca padrão do $\mathrm{C}++$ junto com a complexidade computacional de suas principais funcionalidades.

- std::vector é um template de classe que encapsula um vetor sequencial simples. É um bom container para inserção no final e acesso por posição. Para inserir no final, sua complexidade é $O(n)$, pois pode acontecer realocação, caso o vetor esteja cheio. Dependendo da política de realocação utilizada, pode-se obter um custo amortizado constante para inserção no final. Utilizando uma política de realocação que dobra a capacidade do vetor quando o mesmo está cheio, o custo amortizado de inserção no final é constante. O mesmo não é válido se utilizar-se uma política de realocação que realoca um novo vetor a cada inserção. Neste caso, o custo, mesmo amortizado, seria $O(n)$, pois uma sequência de $n$ inserções teria custo de $O\left(n^{2}\right)$.

- std::map é um template de classe que representa um container associativo. Armazena pares chave/valor, mantendo os dados ordenados pela chave. Geralmente é implementado utilizando- 
se uma árvore balanceada. Não permite chaves duplicadas. O custo computacional de suas principais funcionalidades é de $O(\lg n)$.

- std::multimap é um template de classe que representa um container associativo. Armazena pares chave/valor, mantendo os dados ordenados pela chave. Geralmente é implementado utilizando-se uma árvore balanceada. Diferentemente de um std::map, permite chaves duplicadas. O custo computacional de suas principais funcionalidades é de $O(\lg n)$.

- std::set é um template de classe que representa um conjunto. Sendo um conjunto, não permite duplicatas. Além disso, garante a ordem dos elementos que armazena, utilizando um critério que o programador pode especificar utilizando a sobrecarga do operador $<$. Assim como std::map, geralmente é implementado utilizando-se uma árvore balanceada. O custo computacional de suas principais funcionalidades é de $O(\lg n)$.

\section{B.2 Boost}

O novo padrão da linguagem $\mathrm{C}++$, conhecido como $\mathrm{C}++11$ introduz novos conceitos à linguagem, incluindo bibliotecas para processamento paralelo. A biblioteca Boost foi incorporada à linguagem e fornece os principais recursos para processamento paralelo. Parte do trabalho desenvolvido envolve processamento paralelo e nesta seção descreve-se a principal funcionalidade desenvolvida.

\section{B.2.1 Processamento paralelo - fila bloqueante}

Em geral, atividades computacionais são classificadas [Tau06] conforme as operações que realizam. Se uma atividade utiliza predominantemente operações relacionadas a leitura e escrita de dados, ela é classificada como IO-Bound. Se uma atividade utiliza predominantemente operações que fazem uso do processador, ela é classificada como $C P U$-Bound.

No tratamento de dados realizado neste trabalho, tem-se atividades IO-Bound e CPU-Bound. O volume de dados oferecidos pela Bovespa referentes a um único dia é grande. Trazê-los da memória secundária para a memória principal é uma atividade IO-Bound. Escrever o arquivo final que contém o livro de ofertas também é uma atividade IO-Bound. No tratamento de dados de futuros, por exemplo, processar cada mensagem e extrair as informações relevantes para o livro de ofertas é uma atividade $C P U$-Bound. Em cenários como esse, onde existem atividades tantoIO-Bound quanto $C P U$-Bound, o processamento paralelo pode ser interessante.

Aplicando-se funcionalidades oferecidas pela biblioteca Boost e pela biblioteca padrão da linguagem $\mathrm{C}++$, é possível implementar-se uma fila bloqueante [Tau06], um mecanismo que permite que os threads responsáveis pela leitura/escrita e pelo tratamento de cada mensagem se comuniquem.

O seguinte código mostra a fila bloqueante implementada neste trabalho, utilizando-se a linguagem $\mathrm{C}++$ juntamente com recursos da biblioteca Boost: 


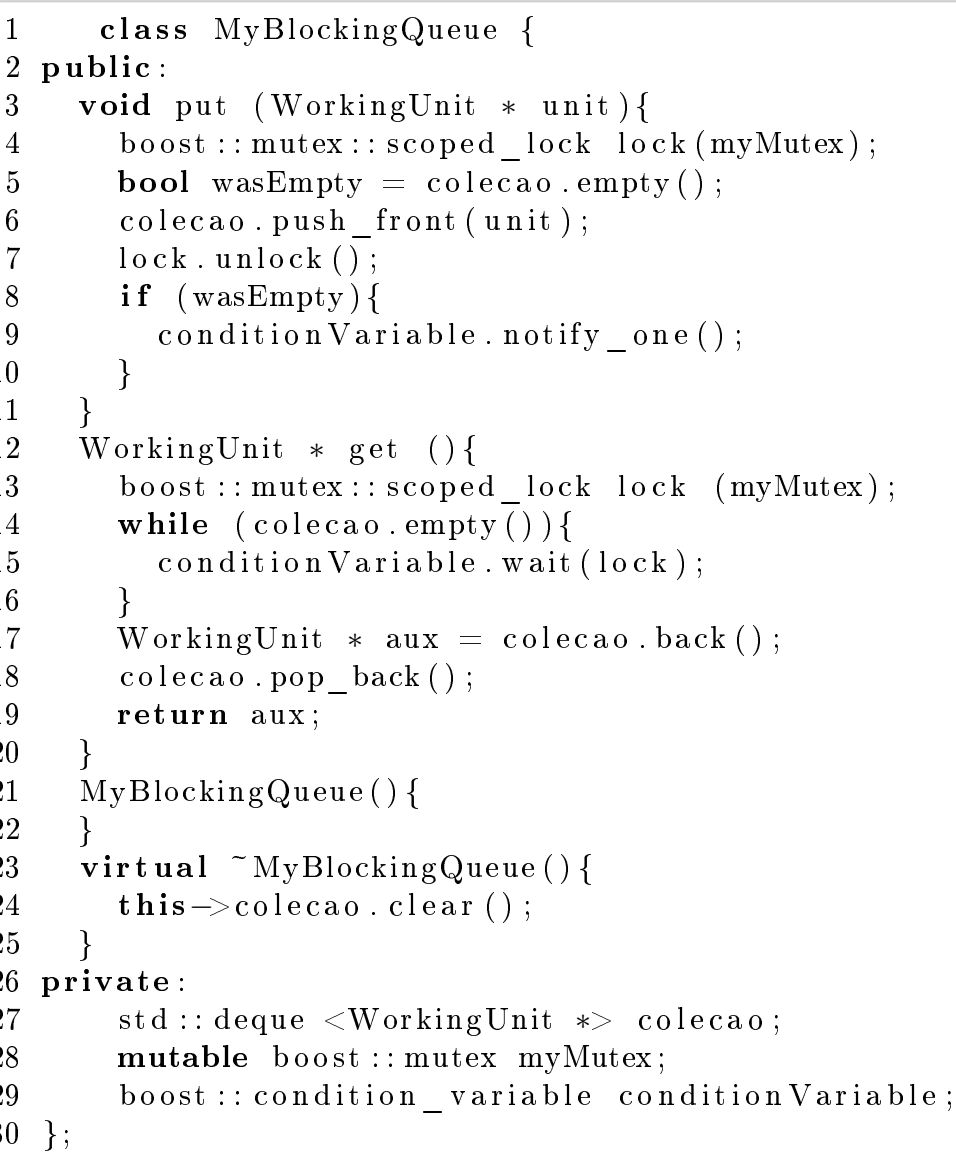

Foi utilizada uma std::deque da biblioteca padrão do $\mathrm{C}++$ para armazenar os valores produzidos que em algum momento serão consumidos. Uma std::deque permite que elementos sejam inseridos e removidos em tempo constante, tanto do seu início quanto do seu final. Assim, uma std::deque é uma boa estrutura de dados para se implementar uma fila "FIFO - (first in, first out)". 


\section{Referências Bibliográficas}

[AV07] David Arthur e Sergei Vassilvitskii. k-means ++ : the advantages of careful seeding. SODA '07 Proceedings of the eighteenth annual ACM-SIAM symposium on Discrete algorithms, 2007. 3, 4

[AV09] David Arthur e Sergei Vassilvitskii. Worst-case and smoothed analysis of the icp algorithm, with an application to the k-means method. SIAM Journal on Computing, 2009. 4

[CLRS09] Thomas H. Cormen, Charles E. Leiserson, Roland L. Rivest e Clifford Stein. Introduction to Algorithms. The MIT Press, $3^{\circ}$ edição, 2009. 16

[DD05] Harvey M. Deitel e Paul J. Deitel. $C++$ How to Program. Prentice Hall, $5^{\circ}$ edição, 2005. 85

[dMGU12] Akira Arice de Moura Galvão Uematsu. Algoritmos de negociação com dados de alta frequência. Dissertação de Mestrado, Universidade de São Paulo, 2012. 30

[Joh10] Barry Johnson. Algorithmic Trading ES DMA. 4Myeloma Press, $1^{\circ}$ edição, 2010. ii, iii, 1

[MdL07] Marcos Nascimento Magalhães e Antonio Carlos Pedroso de Lima. Noções de Probabilidade e Estatística. Editora da Universidade de São Paulo, $6^{\circ}$ edição, 2007. 4

[Tau06] Gadi Taubenfeld. Synchronization Algorithms and Concurrent Programming. Prentice Hall, $5^{\circ}$ edição, 2006. 86

[WFH11] Ian H. Witten, Eibe Frank e Mark A. Hall. Data Mining - Practical Machine Learning Tools and Techniques. Morgan Kaufmann, $3^{\circ}$ edição, 2011. 3, 4 